\title{
Chemistry of massive young stellar objects with a disk-like structure $^{\star}$
}

\author{
K. Isokoski ${ }^{1}$, S. Bottinelli ${ }^{2,3}$, and E. F. van Dishoeck ${ }^{4,5}$ \\ ${ }^{1}$ Raymond and Beverly Sackler Laboratory for Astrophysics, Leiden Observatory, Leiden University, PO Box 9513, 2300 RA Leiden, \\ The Netherlands \\ e-mail: isokoski@strw.leidenuniv.nl \\ 2 Université de Toulouse, UPS-OMP, IRAP, 31400 Toulouse, France \\ 3 CNRS, IRAP, 9 Av. Colonel Roche, BP 44346, 31028 Toulouse Cedex 4, France \\ ${ }^{4}$ Leiden Observatory, Leiden University, PO Box 9513, 2300 RA Leiden, The Netherlands \\ 5 Max-Planck Institut für Extraterrestrische Physik (MPE), Giessenbachstr. 1, 85748 Garching, Germany
}

Received 19 December 2012 / Accepted 21 March 2013

\begin{abstract}
Aims. Our goal is to take an inventory of complex molecules in three well-known high-mass protostars for which disks or toroids have been claimed and to study the similarities and differences with a sample of massive young stellar objects (YSOs) without evidence of such flattened disk-like structures. With a disk-like geometry, UV radiation can escape more readily and potentially affect the ice and gas chemistry on hot-core scales.

Methods. A partial submillimeter line survey, targeting $\mathrm{CH}_{3} \mathrm{OH}, \mathrm{H}_{2} \mathrm{CO}, \mathrm{C}_{2} \mathrm{H}_{5} \mathrm{OH}, \mathrm{HCOOCH}_{3}, \mathrm{CH}_{3} \mathrm{OCH}_{3}, \mathrm{CH}_{3} \mathrm{CN}, \mathrm{HNCO}$, $\mathrm{NH}_{2} \mathrm{CHO}, \mathrm{C}_{2} \mathrm{H}_{5} \mathrm{CN}, \mathrm{CH}_{2} \mathrm{CO}, \mathrm{HCOOH}, \mathrm{CH}_{3} \mathrm{CHO}$, and $\mathrm{CH}_{3} \mathrm{CCH}$, was made toward three massive YSOs with disk-like structures, IRAS 20126+4104, IRAS 18089-1732, and G31.41+0.31. Rotation temperatures and column densities were determined by the rotation diagram method, as well as by independent spectral modeling. The molecular abundances were compared with previous observations of massive YSOs without evidence of any disk structure, targeting the same molecules with the same settings and using the same analysis method.

Results. Consistent with previous studies, different complex organic species have different characteristic rotation temperatures and can be classified either as warm $(>100 \mathrm{~K})$ or cold $(<100 \mathrm{~K})$. The excitation temperatures and abundance ratios are similar from source to source and no significant difference can be established between the two source types. Acetone, $\mathrm{CH}_{3} \mathrm{COCH}_{3}$, is detected for the first time in G31.41+0.31 and IRAS 18089-1732. Temperatures and abundances derived from the two analysis methods generally agree within factors of a few.

Conclusions. The lack of chemical differentiation between massive YSOs with and without observed disks suggest either that the chemical complexity is already fully established in the ices in the cold prestellar phase or that the material experiences similar physical conditions and UV exposure through outflow cavities during the short embedded lifetime.
\end{abstract}

Key words. astrochemistry - line: identification - methods: observational - stars: formation - ISM: abundances - ISM: molecules

\section{Introduction}

Millimeter lines from complex organic molecules are widely associated with high-mass star forming regions and indeed form one of the signposts of the deeply embedded phase of star formation (e.g., Blake et al. 1987; Hatchell et al. 1998; Gibb et al. 2000; Fontani et al. 2007; Requena-Torres et al. 2008; Belloche et al. 2009; Zernickel et al. 2012). Many studies of the chemistry in such regions have been carried out, either through complete spectral surveys of individual sources or by targetting individual molecules in a larger number of sources (see Herbst \& van Dishoeck 2009; Caselli \& Ceccarelli 2012, for reviews). In spite of all this work, only few systematic studies of the abundances of commonly observed complex molecules have been performed across a sample of massive young stellar objects (YSOs), to search for similarities or differences depending on physical structure and evolutionary state of the object. Intercomparison of published data sets is often complicated by the use of different telescopes with different beams, different frequency ranges and different analysis techniques.

\footnotetext{
* Appendices are available in electronic form at http://www . aanda.org
}

Chemical abundances depend on the physical structure of the source such as temperature, density and their evolution with time, as well as the amount of UV radiation impinging on the gas and dust. In contrast with the case of solar-mass stars, the physical structures and mechanisms for forming massive $\left(M>8 M_{\odot}\right)$ stars are still poorly understood. Indeed, theoretically, the powerful UV radiation pressure from a high-mass protostellar object (HMPO) should prevent further accretion and so inhibit the formation of more massive stars (Zinnecker \& Yorke 2007). However, a number of recent studies have claimed the presence of disk- or toroid-like "equatorial" structures surrounding a handful of high-mass protostars (Cesaroni et al. 2007). These data support theories in which high-mass star formation proceeds in a similar way as that of low-mass stars via a disk accretion phase in which high accretion rates and non spherically symmetric structures overcome the problem of radiation pressure. The best evidence so far is that for a $\sim 5000 \mathrm{AU}$ disk in Keplerian rotation around IRAS 20126+4104, claimed by Cesaroni et al. (1999) on the basis of the presence of a velocity gradient in the $\mathrm{CH}_{3} \mathrm{CN}$ emission perpendicular to the direction of the outflow, as predicted by the disk-accretion paradigm. Surprisingly, even in the best case of IRAS 20126+4104, the 

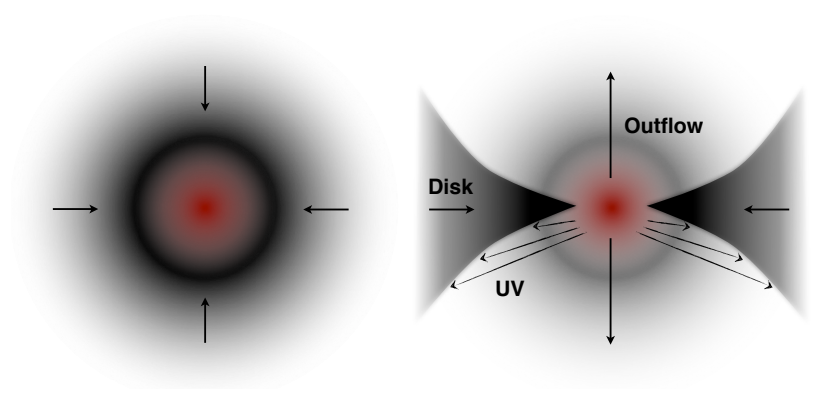

Fig. 1. Illustration of a protostar with a spherical structure (left) and a protostar with a flattened disk-like structure (right) with enhanced UV photons illuminating the walls of the outflow cavity.

detailed chemistry of these (potential) disks has not yet been studied.

Most chemical models invoke grain surface chemistry to create different generations of complex organic molecules (Tielens \& Charnley 1997). Hydrogenation of solid O, C, N and CO during the cold $\left(T_{\mathrm{d}}<20 \mathrm{~K}\right)$ prestellar phase leads to ample production of $\mathrm{CH}_{3} \mathrm{OH}$ and other hydrogenated species like $\mathrm{H}_{2} \mathrm{O}$, $\mathrm{CH}_{4}$ and $\mathrm{NH}_{3}$ (Tielens \& Hagen 1982). Exposure to UV radiation results in photodissociation of these simple ices, with the fragments becoming mobile as the cloud core heats up during the protostellar phase. First generation complex molecules result from the subsequent recombination of the photofragments, and will eventually evaporate once the grain temperature rises above the ice sublimation temperature of $\sim 100 \mathrm{~K}$ (Garrod \& Herbst 2006; Garrod et al. 2008). Good examples are $\mathrm{C}_{2} \mathrm{H}_{5} \mathrm{OH}$, $\mathrm{HCOOCH}_{3}$ and $\mathrm{CH}_{3} \mathrm{OCH}_{3}$ resulting from mild UV processing of $\mathrm{CH}_{3} \mathrm{OH}$ ice (Öberg et al. 2009). Finally, a hot core gas phase chemistry between evaporated molecules can drive further complexity in second generation species (e.g., Millar et al. 1991; Charnley et al. 1992, 1995).

One of the most obvious consequences of an equatorial rather than spherical structure is that UV radiation can more easily escape the central source and illuminate the surface layers of the surrounding disk or toroid as well as the larger scale envelope (Bruderer et al. 2009, 2010) (Fig. 1). This can trigger enhanced formation of complex organic molecules in the ices relative to methanol. Another effect of UV radiation is that it drives increased photodissociation of gaseous $\mathrm{N}_{2}$ and $\mathrm{CO}$. The resulting atomic $\mathrm{N}$ and $\mathrm{C}$ would then be available for grain surface chemistry potentially leading to enhanced abundances of species like $\mathrm{HNCO}$ and $\mathrm{NH}_{2} \mathrm{CHO}$.

To investigate the effects of disk-like structures on the chemistry, we present here a single-dish survey using the James Clerk Maxwell Telescope (JCMT) of three HMPOs for which large equatorial structures (size $>2000 \mathrm{AU}$ ) have been inferred, namely IRAS 20126+4104, IRAS 18089-1732, and $\mathrm{G} 31.41+0.31$. The results are compared with those of a recent survey of a sample of HMPOs by Bisschop et al. (2007, hereafter BIS07), targeting many of the same molecules and settings. The use of the same telescope and analysis method allows a meaningful comparison between the two samples of sources. BIS07 found that the O-rich complex molecules are closely correlated with the grain surface product $\mathrm{CH}_{3} \mathrm{OH}$ supporting the above general chemical scenario. N-rich organic molecules do not appear to be correlated with O-rich ones, but overall, the relative abundances of the various species are found to be remarkably constant within one chemical family. One of the main questions is whether this similarity in abundance ratios also holds for sources with disk-like structures. Although our observations do not spatially resolve these structures, they are sensitive enough and span a large enough energy range to determine abundances on scales of $\sim 1^{\prime \prime}$ and thereby set the scene for future high-angular resolution observations with interferometers like the Atacama Large Millimeter/submillimeter Array (ALMA). Moreover, current interferometers resolve out part of the emission, which is why single-dish observations are still meaningful.

This paper is organized as follows. In Sect. 2, the observed sources and frequency settings are introduced and the details of the observations are presented. Section 3 focuses on the data analysis methods. Specifically, two techniques are used to determine excitation temperatures and column densities: the rotation diagram method employed by BIS07 and spectral modeling tools in which the observed spectra are simulated directly. Section 4 presents the results from both analysis methods and discusses their advantages and disadvantages. Finally, Sect. 5 compares our results with those of BIS07 to draw conclusions on similarities and differences in chemical abundances between sources with and without large equatorial structures.

\section{Observations}

\subsection{Observed sources}

Table 1 gives the coordinates, luminosity $L$, distance $d$, galactocentric radius $R_{\mathrm{GC}}$, velocity of the local standard of rest $V_{\mathrm{LSR}}$ and the typical line width for the observed sources. The selected sources are massive YSOs, for which strong evidence exists for a circumstellar disk structure. All sources are expected to harbor a hot core: a compact, dense $\left(\geq 10^{7} \mathrm{~cm}^{-3}\right)$ and warm $(\geq 100 \mathrm{~K})$ region with complex chemistry triggered by the grain mantle evaporation (Kurtz et al. 2000). $\mathrm{CH}_{3} \mathrm{CN}$ emission from $\geq 100 \mathrm{~K}$ gas is present in all sources. Moreover, $\mathrm{CH}_{3} \mathrm{OH} 7_{\mathrm{K}}-6_{\mathrm{K}}$ transitions (338.5 GHz) with main beam temperatures of $\geq 1 \mathrm{~K}$ have been observed for these sources. Sources also needed to be visible from the $\mathrm{JCMT}^{1}$.

\subsubsection{IRAS $20126+4104$}

IRAS 20126+4104 (hereafter IRAS 20126) is a luminous $\left(\begin{array}{ll}\sim 10^{4} & L_{\odot}\end{array}\right)$ YSO located relatively nearby at a distance of $1.64 \mathrm{kpc}$ (Moscadelli et al. 2011). It was first identified in the IRAS point source catalog by the IR colors typical of ultracompact $\mathrm{HII}$ regions and by $\mathrm{H}_{2} \mathrm{O}$ maser emission characteristic of high-mass star formation (Comoretto et al. 1990). IRAS 20126 features a $\sim 0.25$-pc scale inner jet traced by $\mathrm{H}_{2} \mathrm{O}$ maser spots in the SE-NW direction with decreasing velocity gradient (Tofani et al. 1995). Source and masers are embedded inside a dense, parsec-scale molecular clump (Estalella et al. 1993; Cesaroni et al. 1999). The inner jet feeds into a larger scale bipolar outflow with the two having reversed velocity lobes (Wilking et al. 1990; Cesaroni et al. 1999). The reversal is likely to be due to precession of the inner jet caused by a companion separated by a distance of $\sim 0.5^{\prime \prime}$ (850 AU) (Hofner et al. 1999; Shepherd et al. 2000; Cesaroni et al. 2005; Sridharan et al. 2005). A rotating, flattened, Keplerian disk structure has been detected perpendicular to the inner jet. Observations of $\mathrm{CH}_{3} \mathrm{CN}$ transitions show a

1 The James Clerk Maxwell Telescope is operated by the Joint Astronomy Centre, on behalf of the Particle Physics and Astronomy Research council of the United Kindom, the Netherlands Organization for Scientific Research and the National Research Council of Canada. The project ID is m09bn10. 
Table 1. Coordinates, luminosity, distance, galactocentric radius, velocity of the local standard of rest, ${ }^{12} \mathrm{C} /{ }^{13} \mathrm{C}$ isotope ratio and the typical line width for the observed sources.

\begin{tabular}{|c|c|c|c|c|c|c|c|c|}
\hline Sources & $\alpha(2000)$ & $\bar{c} \delta(2000)$ & $\begin{array}{c}L \\
{\left[10^{5} L_{\odot}\right]}\end{array}$ & $\begin{array}{c}d \\
{[\mathrm{kpc}]}\end{array}$ & $\begin{array}{l}R_{\mathrm{GC}}{ }^{*} \\
{[\mathrm{kpc}]}\end{array}$ & $\begin{array}{c}V_{\mathrm{LSR}} \\
{\left[\mathrm{km} \mathrm{s}^{-1}\right]}\end{array}$ & ${ }^{12} \mathrm{C} /{ }^{13} \mathrm{C}$ & $\begin{array}{c}\Delta V \\
{\left[\mathrm{~km} \mathrm{~s}^{-1}\right]}\end{array}$ \\
\hline IRAS 20126+4104 & $20: 14: 26.04$ & $+41: 13: 32.5$ & $0.13^{a}$ & $1.64^{b}$ & 8.3 & -3.5 & 70 & $6^{c}$ \\
\hline IRAS 18089-1732 & $18: 11: 51.40$ & $-17: 31: 28.5$ & $0.32^{d}$ & $2.34^{e}$ & 6.2 & 33.8 & 54 & $5^{c}$ \\
\hline $\mathrm{G} 31.41+0.31$ & $18: 47: 34.33$ & $-01: 12: 46.5$ & $2.6^{f}$ & $7.9^{g}$ & 4.5 & 97.0 & 41 & $6-10^{h}$ \\
\hline
\end{tabular}

Notes. ${ }^{(*)}$ The galactocentric radii were calculated using distances $d$ in this table and a IAU recommended distance from the galactic center $R_{0}=$ $8.5 \mathrm{kpc}$. The ${ }^{12} \mathrm{C} /{ }^{13} \mathrm{C}$ isotope ratios are calculated from Eq. (11).

References. ${ }^{(a)}$ Cesaroni et al. (1997), ${ }^{(b)}$ Moscadelli et al. (2011), ${ }^{(c)}$ Leurini et al. (2007), ${ }^{(d)}$ Sridharan et al. (2002), ${ }^{(e)}$ Xu et al. $(2011),{ }^{(f)}$ Cesaroni et al. (1994b), ${ }^{(g)}$ Churchwell et al. (1990), ${ }^{(h)}$ Fontani et al. (2007).

Keplerian circumstellar disk (radius $\sim 1000 \mathrm{AU}$ ) with a velocity gradient perpendicular to the jet and a hot core with a diameter of $\sim 0.0082 \mathrm{pc}$ and a temperature of $\sim 200 \mathrm{~K}$ at a geometric center of the outflow (Cesaroni et al. 1997, 1999; Zhang et al. 1998). Direct near-infrared (NIR) observations show a disk structure as a dark line (Sridharan et al. 2005). The disk shows a temperature and density gradient and is going through infall of material with a rate of $\sim 2 \times 10^{-3} M_{\odot} \mathrm{yr}^{-1}$ as expected for a protostar of this mass and luminosity (Cesaroni et al. 2005). Recent modeling of the Spectral Energy Distribution (SED) of IRAS 20126 shows indeed a better fit when a disk is included (Johnston et al. 2011).

\subsubsection{IRAS $18089-1732$}

IRAS 18089-1732 (hereafter IRAS 18089) is a luminous $\left(\sim 10^{4.5} L_{\odot}\right.$, Sridharan et al. 2002) YSO located at a distance of $2.34 \mathrm{kpc}$ (Xu et al. 2011). It was identified based on CS detections of bright IRAS point sources with colors similar to ultracompact HII regions and the absence of significant free-free emission (Sridharan et al. 2002), and with $\mathrm{H}_{2} \mathrm{O}$ and $\mathrm{CH}_{3} \mathrm{OH}$ maser emission (Beuther et al. 2002). The $\mathrm{CO}$ line profile shows a wing structure characteristic of an outflow, although no clear outflow structure could be resolved from the $\mathrm{CO}$ maps (Beuther et al. 2002). A collimated outflow in the Northern direction is however seen in $\mathrm{SiO}$ emission on scales of 5" (Beuther et al. 2004). IRAS 18089 has a highly non-circular dust core of $\sim 3000$ AU diameter $\left(\sim 1^{\prime \prime}\right)$, with optically thick $\mathrm{CH}_{3} \mathrm{CN}$ at $\sim 350 \mathrm{~K}$ (Beuther et al. 2005). $\mathrm{HCOOCH}_{3}$ was found to be optically thin, with emission confined to the core, and showing a velocity gradient perpendicular to the outflow indicative of a rotating disk (Beuther et al. 2004). Also hot $\mathrm{NH}_{3}$ shows a velocity gradient perpendicular to the outflow, although no Keplerian rotation was found, possibly due to infall and/or self gravitation (Beuther \& Walsh 2008). Several hot-core molecules $\left(\mathrm{HCOOCH}{ }_{3}, \mathrm{CH}_{3} \mathrm{CN}, \mathrm{CH}_{3} \mathrm{OCH}_{3}, \mathrm{HNCO}, \mathrm{NH}_{2} \mathrm{CHO}, \mathrm{CH}_{3} \mathrm{OH}\right.$, $\mathrm{C}_{2} \mathrm{H}_{5} \mathrm{OH}$ ) were mapped by Beuther et al. (2005) but no column densities or abundances were reported.

\subsubsection{G31.41+0.31}

G31.41+0.31 (hereafter G31) is a luminous $\left(2.6 \times 10^{5} L_{\odot}\right.$, Cesaroni et al. 1994b) YSO at a distance of $7.9 \mathrm{kpc}$ (Churchwell et al. 1990). Preliminary evidence for a rotating disk with a perpendicular bipolar outflow was reported by Cesaroni et al. (1994a,b) and Olmi et al. (1996) showing a velocity gradient across the core in the NE-SW direction, similar to previously detected OH masers (Gaume \& Mutel 1987). High-angular resolution $\mathrm{CH}_{3} \mathrm{CN}$ observations by Beltrán et al. (2005) could not detect Keplerian rotation typical for less luminous stars, nevertheless a toroidal structure undergoing gravitational collapse and fast accretion $\left(\sim 3 \times 10^{-2} M_{\odot} \mathrm{yr}^{-1}\right)$ onto the central object was found. The G31 hot molecular core (HMC) is part of a complex region in which multiple stellar sources are detected (Benjamin et al. 2003); indeed, it is separated from an ultracompact (UC) HII region by only $\sim 5^{\prime \prime}$ and overlaps with a diffuse halo of freefree emission, possibly associated with the UC HII region itself (Cesaroni et al. 1998). More recent interferometric observations confirm the velocity gradient in the $\mathrm{NH}_{3}(4,4)$ inversion transition and in $\mathrm{CH}_{3} \mathrm{CN}$ data (Cesaroni et al. 2010, 2011). Line profiles look like a rotating toroid with infall motion. Several complex hot-core molecules have been observed in G31, including glycolaldehyde $\mathrm{CH}_{2} \mathrm{OHCHO}$ (Beltrán et al. 2009), but again no abundance ratios have been presented.

\subsection{Observational details}

The observations were performed at the JCMT on Mauna Kea, Hawaii, between August 2007 and September 2009. The observations of the $338 \mathrm{GHz}$ region covering $\mathrm{CH}_{3} \mathrm{OH}\left(7_{\mathrm{K}} \rightarrow 6_{\mathrm{K}}\right)$ transitions were taken from JCMT archive. The front ends consisted of the facility receivers A3 (230 GHz region) and HARP-B ( $340 \mathrm{GHz}$ region). The back-end was the digital autocorrelation spectrometer (ACSIS), covering 400 and $250 \mathrm{MHz}$ of instantaneous bandwidth for A3 and HARP-B, respectively, with a channel width of $50 \mathrm{kHz}$. The noise level for both receivers was $T_{\mathrm{rms}} \sim 20 \mathrm{mK}$ on a $T_{\mathrm{A}}^{*}$ scale when binned to $0.5 \mathrm{~km} \mathrm{~s}^{-1}$. The integration time was $\sim 1 \mathrm{~h}$ and $1.8 \mathrm{~h}$ for A3 and HARP-B, respectively. The spectra were scaled from the observed antenna temperature, $T_{\mathrm{A}}^{*}$, to main-beam temperature, $T_{\mathrm{MB}}$, using main beam efficiencies $\eta_{\mathrm{MB}}$ of 0.69 and 0.63 at $230 \mathrm{GHz}$ and $345 \mathrm{GHz}$, respectively. We adopt a $T_{\mathrm{A}}^{*}$ calibration error of $20 \%$.

The HPBW (half-power beam width, $\theta_{\mathrm{B}}$ ) for the 230 and $345 \mathrm{GHz}$ band observations are 20-21" and $14^{\prime \prime}$, respectively. Emission from a volume with a source diameter $\theta_{\mathrm{S}} \leq \theta_{\mathrm{B}}$ undergoes beam dilution described by the beam-filling factor, $\eta_{\mathrm{BF}}$ :

$\eta_{\mathrm{BF}}=\frac{\theta_{\mathrm{S}}^{2}}{\theta_{\mathrm{S}}^{2}+\theta_{\mathrm{B}}^{2}}$.

Table 2 gives the observed frequency settings and the targeted molecular lines. The settings were taken from BIS07 and were chosen to cover at least one strong line for the target molecules as well as lines of other interesting species. Strong lines of target molecules were chosen due to their high main-beam temperatures and minimum line-confusion in line surveys of Orion-KL by Sutton et al. (1985) and Schilke et al. (1997) at $230 \mathrm{GHz}$ and 
Table 2. Observed frequency settings and molecular lines.

\begin{tabular}{llllll}
\hline \hline Molecule & $\begin{array}{l}\text { Freq. } \\
{[\mathrm{GHz}]}\end{array}$ & $\begin{array}{l}E_{\text {up }} \\
{[\mathrm{K}]}\end{array}$ & $\begin{array}{l}\mu^{2} S \\
{\left[\mathrm{D}^{2}\right]}\end{array}$ & Transition & Additional molecules \\
& 239.1195 & 144.77 & 811.86 & $13_{K}-12_{K}$ & $\mathrm{CH}_{3}{ }^{13} \mathrm{CN}, \mathrm{HCOOCH}_{3}, \mathrm{CH}_{3} \mathrm{OCH}_{3}$ \\
$\mathrm{CH}_{3} \mathrm{CN}$ & 219.7983 & 58.02 & 28.112 & $10_{0,10,11}-9_{0,9,10}$ & $\mathrm{H}_{2}{ }^{13} \mathrm{CO}, \mathrm{C}_{2} \mathrm{H}_{5} \mathrm{CN}$ \\
$\mathrm{HNCO}$ & 240.8809 & 112.53 & 30.431 & $11_{1,11,12}-10_{1,10,11}$ & $\mathrm{CH}_{3} \mathrm{OCH}_{3}, \mathrm{CH}_{3} \mathrm{OH}, \mathrm{HN}^{13} \mathrm{CO}$ \\
& 222.3453 & 37.89 & 42.100 & $8_{5,4}-7_{4,3}$ & $\mathrm{CH}_{3} \mathrm{OCH}_{3}, \mathrm{NH}_{2} \mathrm{CHO}$ \\
$\mathrm{HCOOCH}_{3}$ & 225.2568 & 125.50 & 33.070 & $18_{6,12}-17_{6,12}$ & $\mathrm{H}_{2} \mathrm{CO}, \mathrm{CH}_{3} \mathrm{OCH}_{3},{ }^{13} \mathrm{CH}_{3} \mathrm{OH}$ \\
& 364.2752 & 158.42 & 52.165 & $5_{3,3}-4_{3,2}$ & $\mathrm{C}_{2} \mathrm{H}_{5} \mathrm{OH}$ \\
$\mathrm{H}_{2} \mathrm{CO}$ & 331.0716 & 151.11 & 513.924 & $18_{K}-17_{K}$ & $\mathrm{HCOOCH}_{3}, \mathrm{HNCO}, \mathrm{CH}_{3}{ }^{13} \mathrm{CN}$ \\
$\mathrm{CH}_{3} \mathrm{CN}$ & 352.8979 & 187.25 & 43.387 & $16_{1,15,17}-15_{1,14,16}$ & $\mathrm{C}_{2} \mathrm{H}_{5} \mathrm{CN}, \mathrm{C}_{2} \mathrm{H}_{5} \mathrm{OH}, \mathrm{HCOOCH}_{3}$ \\
$\mathrm{HNCO}$ & 345.1826 & 151.59 & 664.219 & $17_{0,17}-16_{0,16}$ & $\mathrm{HCOOCH}_{3}, \mathrm{C}_{2} \mathrm{H} \mathrm{H}_{5} \mathrm{OH},{ }^{13} \mathrm{CH}_{3} \mathrm{OH}$ \\
$\mathrm{NH}_{2} \mathrm{CHO}$ & 354.6084 & 293.39 & 87.321 & $33_{2,32}-32_{2,31}$ & $\mathrm{NH}_{2} \mathrm{CHO}, \mathrm{C}_{2} \mathrm{H}_{5} \mathrm{CN}$ \\
$\mathrm{HCOOCH}_{3}$ & 354 & & \\
\hline
\end{tabular}

$345 \mathrm{GHz}$, respectively. In order to determine rotation temperatures, we covered at least two transitions for a given species with $E_{\text {up }}<100 \mathrm{~K}$ and $E_{\text {up }}>100 \mathrm{~K}$ each. BIS07 used the single pixel receiver B3, the predecessor of HARP-B, together with DAS (Digital Autocorrelation Spectrometer) as the back-end, covering a larger instantaneous bandwidth of $500 \mathrm{MHz}$. Only the central receptor of HARP-B array is analyzed here as no significant off source emission was detected in the complex molecules.

Data reduction and line fitting were done using the CLASS software package ${ }^{2}$. Line assignments were done by comparison of observed frequencies corrected for source velocity with the $\mathrm{JPL}^{3}, \mathrm{CDMS}^{4}$ and NIST ${ }^{5}$ catalogs (Pickett et al. 1998; Müller et al. 2005). The line assignment/detection was based on Gaussian fitting with the following criteria: (i) the fitted line position had to be within $\pm 1 \mathrm{MHz}$ of the catalog frequency; (ii) the FWHM had to be consistent with those given in Table 1; and (iii) a $S / N>3$ is required on the peak intensity. Section A.1 in the Appendix describes in more detail the error analysis. In general, our errors on the integrated intensities are conservative and suggest a lower $\mathrm{S} / \mathrm{N}$ than that on the peak intensity or obtained using more traditional error estimates.

\section{Data analysis}

\subsection{Rotation diagrams}

Rotation temperatures and column densities were obtained through the rotation diagram (RTD) method (Goldsmith \& Langer 1999), when 3 or more lines are detected over a sufficiently large energy range. Integrated main-beam temperatures, $\int T_{\mathrm{MB}} \mathrm{d} V$, can be related to the column density in the upper energy level by:

$\frac{N_{\text {up }}}{g_{\text {up }}}=\frac{3 k \int T_{\mathrm{MB}} \mathrm{d} V}{8 \pi^{3} v \mu^{2} S}$,

where $N_{\text {up }}$ is the column density in the upper level, $g_{\text {up }}$ is the degeneracy of the upper level, $k$ is Boltzmann's constant, $v$ is the transition frequency, $\mu$ is the dipole moment and $S$ is the line

\footnotetext{
2 CLASS is part of the GILDAS software package developed by IRAM.

3 http://spec.jpl.nasa.gov/ftp/pub/catalog/catform. html

4 http://www.ph1.uni-koeln.de/vorhersagen

5 http://physics.nist.gov/PhysRefData/Micro/Html/ contents.html
}

strength. The total beam-averaged column density $N_{\mathrm{T}}$ in $\mathrm{cm}^{-2}$ can then be computed from:

$\frac{N_{\text {up }}}{g_{\text {up }}}=\frac{N_{\mathrm{T}}}{Q\left(T_{\text {rot }}\right)} \mathrm{e}^{-E_{\text {up }} / T_{\text {rot }}}$,

where $Q\left(T_{\text {rot }}\right)$ is the rotational partition function, and $E_{\text {up }}$ is the upper level energy in $\mathrm{K}$.

Blended transitions of a given species with similar $E_{\text {up }}\left(\Delta E_{\text {up }}<30 \mathrm{~K}\right)$ were assigned intensities according to their Einstein coefficients $(A)$ and upper level degeneracies $\left(g_{\text {up }}\right)$ :

$\int T_{\mathrm{MB}} \mathrm{d} V(i)=\int T_{\mathrm{MB}} \mathrm{d} V \times \frac{A^{i} g_{\text {up }}^{i}}{\sum_{i} A^{i} g_{\text {up }}^{i}}$,

where the summation is over all the contributing transitions. Blended transitions with different $E_{\text {up }}$, or with contamination from transitions belonging to other species, were excluded from the RTD fit.

The beam averaged column density, $N_{\mathrm{T}}$, is converted to the source-averaged column density $N_{\mathrm{S}}$ using the beam-filling factor $\eta_{\mathrm{BF}}$ :

$N_{\mathrm{S}}=\frac{N_{\mathrm{T}}}{\eta_{\mathrm{BF}}}$.

The standard RTD method assumes that the lines are optically thin. Lines with strong optical depth, determined from the arguments in Sect. 4.1 as well as the models discussed in Sect. 3.2, were excluded from the fit. For $\mathrm{CH}_{3} \mathrm{OH}$, also low- $E_{\text {up }}$ lines arising from a cold extended component (see Sect. 4.4.1) were excluded.

Differential beam dilution is taken into account by multiplying the line intensities in the $230 \mathrm{GHz}$ range by $\eta_{\mathrm{BF}}$ $(340 \mathrm{GHz}) / \eta_{\mathrm{BF}}(230 \mathrm{GHz})$. For warm and cold molecules, beam dilution is derived assuming source diameters $\theta_{T=100 \mathrm{~K}}$ (see Eq. (10) below) and 14", respectively (see Eq. (1)). All emission is thus assumed to be contained within the smallest beam size. Same approach was used in BIS07.

The vibrational partition function was ignored assuming that all emission arises from the ground vibrational state so that the vibrational partition function can be set to unity. This approximation can cause an underestimation of the derived column densities for larger molecules, even at temperatures of 100-200 K. Indeed, Widicus Weaver et al. (2005) show that the error can be up to a factor of 2 for temperatures up to $300 \mathrm{~K}$. Since this approximation affects all complex molecules (albeit at different levels), the overall error in abundance ratios will be less than a factor of 2 and well within the other uncertainties. 


\subsection{Spectral modeling}

The alternative method for analysing the emission is to model the observed spectra directly. For this purpose, we used the socalled "Weeds" extension of the CLASS software package ${ }^{6}$, developed to facilitate the analysis of large millimeter and submillimeter spectral surveys (Maret et al. 2011). In this model, the excitation of a species is assumed to be in LTE (Local Thermodynamic Equilibrium) at a temperature $T_{\mathrm{ex}}$. The brightness temperature, $T_{\mathrm{B}}$, of a given species as a function of the rest frequency $v$ is then given by:

$T_{\mathrm{B}}(v)=\eta_{\mathrm{BF}}\left[J_{v}\left(T_{\mathrm{ex}}\right)-J_{v}\left(T_{\mathrm{bg}}\right)\right]\left(1-\mathrm{e}^{-\tau(v)}\right)$,

where $\eta_{\mathrm{BF}}$ is the beam filling factor (see Eq. (1)), $J_{v}$ is the radiation field such that:

$J_{v}(T)=\frac{h v / k}{\mathrm{e}^{h v / k T}-1}$

and $T_{\mathrm{bg}}$ is the temperature of the background emission. The HPBW $\theta_{\mathrm{B}}$ is calculated within the Weeds model as $\theta_{\mathrm{B}}=$ $1.22 c / v D$, where $c$ is the speed of light and $D$ is the diameter of the telescope ${ }^{7}$. The opacity $\tau(v)$ is:

$\tau(v)=\frac{c^{2}}{8 \pi v^{2}} \frac{N_{\mathrm{T}}}{Q\left(T_{\mathrm{ex}}\right)} \sum_{i} A^{i} g_{\text {up }}^{i} \mathrm{e}^{-E_{\text {up }}^{i} / k T_{\text {ex }}}\left(\mathrm{e}^{h v_{0}^{i} / k T_{\mathrm{ex}}}-1\right) \phi^{i}$

where the summation is over each line $i$ of the considered species. $v_{0}^{i}$ is the rest frequency of the line and $\phi^{i}$ is the profile function of the line, given by:

$\phi^{i}=\frac{1}{\Delta v \sqrt{2 \pi}} \mathrm{e}^{-\left(v-v_{0}^{i}\right)^{2} / 2 \Delta v^{2}}$,

where $\Delta v$ is the line width in frequency units at $1 / e$ height. $\Delta v$ can be expressed as a function of the line FWHM in velocity units $\Delta V$ by:

$\Delta v=\frac{v_{0}^{i}}{c \sqrt{8 \ln 2}} \Delta V$

The input parameters in the model are the column density $N_{\mathrm{S}}$ in $\mathrm{cm}^{-2}$, excitation temperature $T_{\mathrm{ex}}$ in $\mathrm{K}$, the source diameter $\theta_{\mathrm{S}}$ in arcseconds, offset velocity from the source LSR (Local Standard of Rest) in $\mathrm{km} \mathrm{s}^{-1}$ and the line FWHM in $\mathrm{km} \mathrm{s}^{-1}$. All parameters excluding the source diameter are optimized manually to obtain the best agreement with the observed spectra. The source diameter for emission from cold species is allowed to vary over a larger area; generally $14^{\prime \prime}$ is used. The emission from hot-core molecules targeted in our work is assumed to originate from the central region with $T_{\text {dust }} \geq 100 \mathrm{~K}$. The source diameter for the warm emission is calculated using a relation derived from dust modeling of a large range of sources (BIS07):

$R_{T=100 \mathrm{~K}} \approx 2.3 \times 10^{14}\left(\sqrt{\frac{L}{L_{\odot}}}\right) \mathrm{cm}$,

where $L / L_{\odot}$ is the luminosity of the source relative to the solar luminosity. Table 3 gives the calculated $R_{T=100 \mathrm{~K}}$ radii and diameters for the observed sources.

6 CLASS is part of the GILDAS software package developed by
IRAM.
7 For JCMT with $15-\mathrm{m}$ antenna diameter, the equation gives a $\theta_{\mathrm{B}}$ of
$21.9^{\prime \prime}$ and $14.8^{\prime \prime}$ for the $230 \mathrm{GHz}$ band and $345 \mathrm{GHz}$ bands, respectively.
Table 3. Source radii and angular diameters for $T=100 \mathrm{~K}$.

\begin{tabular}{l|cc}
\hline \hline Sources & $\begin{array}{c}R_{T=100 \mathrm{~K}} \\
{[\mathrm{AU}]}\end{array}$ & $\begin{array}{c}\theta_{\mathrm{S}, T=100 \mathrm{~K}} \\
{\left[{ }^{\prime \prime}\right]}\end{array}$ \\
\hline IRAS 20126+4104 & 1753 & 2.2 \\
IRAS 18089-1732 & 2750 & 2.4 \\
G31.41+0.31 & 7840 & 2.0 \\
\hline
\end{tabular}

In the analysis for individual molecules, the initial values for $T_{\text {ex }}$ were based on the $T_{\text {rot }}$ from the RTD analysis in case of optically thin species. For optically thick species the value of $T_{\text {ex }}$ from the ${ }^{13} \mathrm{C}$-isotope was used. If $T_{\mathrm{ex}}$ for the isotopologue could not be obtained, the initial temperature was guessed. The $T_{\text {ex }}$ value was then optimized visually based on the relative intensity of the emission lines. The simulated emission was not allowed to exceed the emission of optically thin lines in the spectrum in any of the observed spectral ranges. Coinciding and blended transitions, which together contribute to an optically thick line, are excluded in the analysis.

Due to the visual optimization and the possibility of overlapping lines (particularly in the line-rich source G31), the resulting $T_{\text {ex }}$ values are only a rough estimate $( \pm 50-100 \mathrm{~K})$ and do not differ significantly from those from the RTD method. The column density for each species was constrained by optically thin, unblended lines, where available.

For the specific case of $\mathrm{CH}_{3} \mathrm{OH}$, which requires two temperature components for a proper fit, the analysis was also done with the CASSIS analysis package ${ }^{8}$. CASSIS has the advantage that it can properly model the emission from overlapping optically thick lines, as well as from nested regions of emission. For $\mathrm{CH}_{3} \mathrm{OH}$, warm emission from the compact inner region may be absorbed by the surrounding colder gas, which can influence the derived hot core abundances.

\section{Results}

\subsection{General results and comparison between sources}

The observed sources, IRAS 20126, IRAS 18089 and G31, differ from each other significantly in the observed chemical richness in the JCMT single-dish data. Figure 2 presents two frequency ranges with lines from several observed species. For G31, strong lines of all complex organic species are detected, whereas for IRAS 20126 many targeted lines are below the detection limit. Many complex molecules are also found in IRAS 18089 but with weaker lines than for G31. Among the serendipitous discoveries acetone, $\mathrm{CH}_{3} \mathrm{COCH}_{3}$, is possibly seen in G31 and IRAS 18089 for the first time (see Sect. 4.5). Integrated line intensities for all detected lines and selected upper limits are given in Tables A.1A.14. The rotation diagrams for the detected species are shown in Figs. B.1-B.13 whereas the optimized parameters in the Weeds model for each molecule and source are available online in Tables C.1-C.3.

\subsection{Optical depth determinations}

To assess the importance of optical depths effects, the ratio of lines of different isotopologues are compared. The expected

8 CASSIS has been developed by IRAP-UPS/CNRS (http:// cassis.irap.omp.eu). 


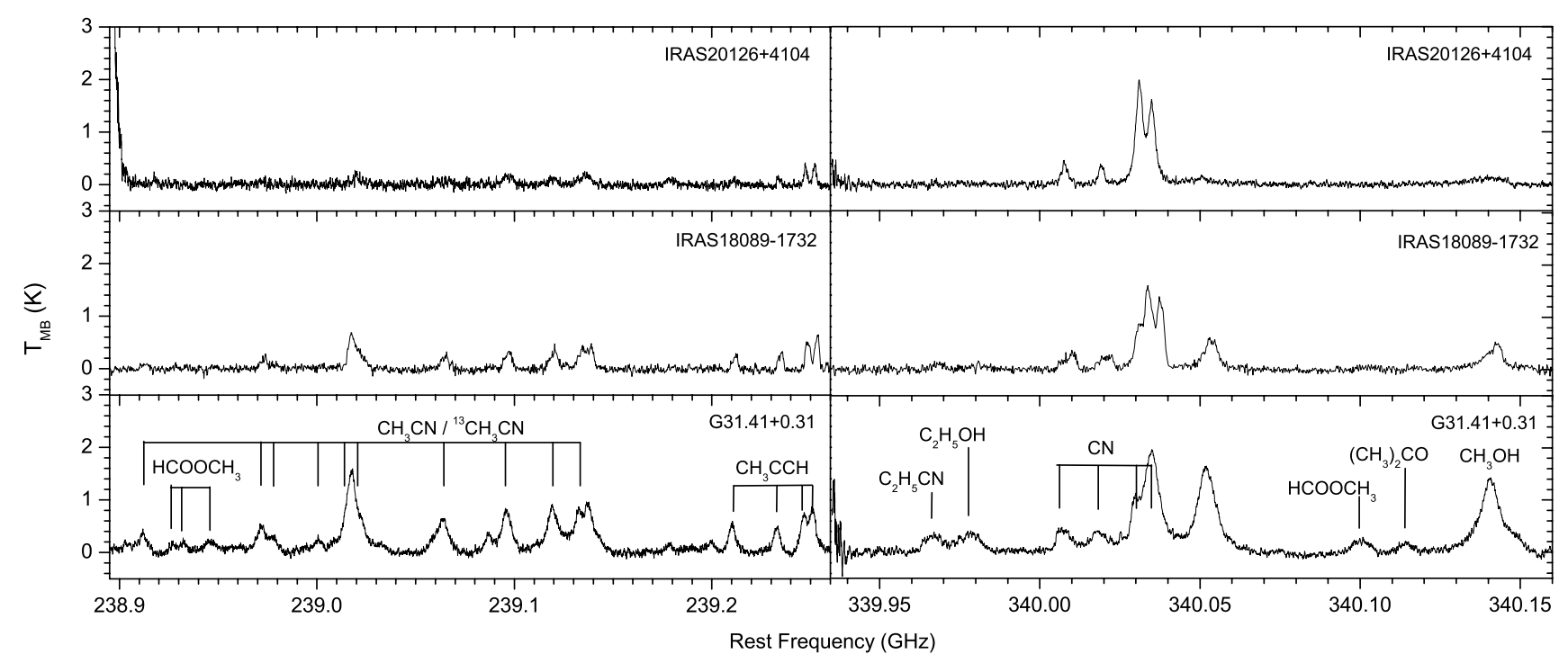

Fig. 2. Spectral ranges $238.83-239.26 \mathrm{GHz}$ and $339.94-340.18 \mathrm{GHz}$ with lines from several targeted species for the three sources.

Table 4. Isotopologue line intensity ratios in the observed sources.

\begin{tabular}{l|ccc}
\hline \hline Species & IRAS 20126+4104 & IRAS 18089-1732 & G31.41+0.31 \\
\hline $\mathrm{CH}_{3} \mathrm{OH} /{ }^{13} \mathrm{CH}_{3} \mathrm{OH}$ & $>6$ & $>18$ & 6 \\
$\mathrm{CH}_{3} \mathrm{CN} / \mathrm{CH}_{3}{ }^{13} \mathrm{CN}$ & $>65$ & 4.7 & 4.5 \\
\hline
\end{tabular}

Notes. Lower limits are those for which the ${ }^{13} \mathrm{C}$-isotopologue was not detected.

${ }^{12} \mathrm{C} /{ }^{13} \mathrm{C}$ isotope ratio depends on the galactocentric radius, $R_{\mathrm{GC}}$, according to Eq. (11) (Wilson \& Rood 1994).

${ }^{12} \mathrm{C} /{ }^{13} \mathrm{C}=(7.5 \pm 1.9) R_{\mathrm{GC}}[\mathrm{kpc}]+(7.6 \pm 12.9)$.

The isotope ratios derived for our sources using Eq. (11) are given in Table 1 . The galactocentric radii were calculated trigonometrically from the galactic coordinates, using the IAU value for the distance to the Galactic center $R_{0}=8.5 \mathrm{kpc}$ (Kerr \& Lynden-Bell 1986).

Table 4 lists the observed isotopologue intensity ratios for the most abundant species in our sources. The $\mathrm{CH}_{3} \mathrm{OH} /{ }^{13} \mathrm{CH}_{3} \mathrm{OH}$ ratios are derived from a low-energy transition $22,0,+0-3,3,+0$ with $E_{\text {up }}=44.6 \mathrm{~K}$. No high $E_{\text {up }}$ transitions were reliably detected for ${ }^{13} \mathrm{CH}_{3} \mathrm{OH}$ in our sources in our standard settings and the low $E_{\text {up }}$ ratios are therefore taken to apply to cold methanol. For $\mathrm{G} 31.41+0.31$, one additional observation was carried out to cover a transition with $E_{\text {up }}>100 \mathrm{~K}$. A C $\mathrm{CH}_{3} \mathrm{OH} /{ }^{13} \mathrm{CH}_{3} \mathrm{OH}$ intensity ratio of 4.0 is derived for a transition with $E_{\mathrm{up}} \approx 210 \mathrm{~K}$ $\left(13_{1,12,-0}-13_{0,13,+0}\right)$. This indicates that also warm methanol is optically thick in this source.

The $\mathrm{CH}_{3} \mathrm{CN} / \mathrm{CH}_{3}{ }^{13} \mathrm{CN}$ ratios are derived from the $13_{3}-12_{3}$ line intensities for G31 and IRAS 18089 and indicate that $\mathrm{CH}_{3} \mathrm{CN}$ is optically thick in these two sources, but not in IRAS 20126. For $\mathrm{H}_{2} \mathrm{CO}$ and $\mathrm{HNCO}$, isotopologue lines are detected but for different transitions than the main isotopologues. Thus, a model is needed to infer the optical depths. Fits to each of the isotopologues independently at a fixed temperature of $150 \mathrm{~K}$ using the $R_{T=100 \mathrm{~K}}$ source size gives column density ratios that are significantly smaller than the overall isotope ratios, suggesting that these species are also optically thick for G31 and IRAS 18089 . In practice, we have excluded the optically thick lines (as indicated by the Weeds model) from the RTD fits for all species.

\subsection{Temperatures}

Table 5 summarizes the derived temperatures from the RTD fit for the various species. As also found by BIS07, molecules can be classified into cold $(<100 \mathrm{~K})$ and warm $(>100 \mathrm{~K})$, and our categorization is similar to theirs. The Weeds analysis is consistent with this grouping. There is however variation in temperatures within the groups, with warm species having rotation temperatures from 70 to $300 \mathrm{~K}$, and cold species from 40 to $100 \mathrm{~K}$. Some variation is seen in rotation temperatures of individual species between different sources; the rotation temperatures are generally higher in G31 than in IRAS 18089, while IRAS 20126 has the lowest of the three.

The $T_{\text {rot }}$ value for $\mathrm{CH}_{3} \mathrm{OH}$ is $\sim 300 \mathrm{~K}$ for $\mathrm{G} 31$ and IRAS 18089 and $\sim 100 \mathrm{~K}$ for IRAS 20126. For G31, several lines with $E_{\text {up }}>400 \mathrm{~K}$ are detected, which makes the RTD fit more robust. For IRAS 18089 and IRAS 20126 the accuracy of the RTD fits suffers from the small range of $E_{\text {up }}$ in the detected transitions. In addition to optically thick lines, low- $E_{\text {up }}$ lines have been excluded from the fit. These lines are underestimated by the RTD fit and probably originate from a colder extended region also seen in the ${ }^{13} \mathrm{C}$ lines (Fig. 3). The $T_{\text {rot }}$ from the RTD analysis therefore represents the warm $\mathrm{CH}_{3} \mathrm{OH}$ alone. See Sect. 4.4.1 for a more detailed discussion on the $\mathrm{CH}_{3} \mathrm{OH}$ emission.

For $\mathrm{CH}_{3} \mathrm{CN}$, the $T_{\text {rot }}$ values range from $\sim 200$ and $\sim 350 \mathrm{~K}$ for the three sources. The $\mathrm{CH}_{3}{ }^{13} \mathrm{CN}$ rotation diagram gives a value of $T_{\text {rot }}$ of only $53 \mathrm{~K}$, however (Fig. 3). This illustrates the large uncertainties at high temperatures for optically thick species and the possibility of a cold component in addition to the warm one.

Contrary to the general trend, the $T_{\text {rot }}$ value for $\mathrm{H}_{2} \mathrm{CO}$ is somewhat higher $(204 \mathrm{~K})$ in IRAS 18089 than in G31 (157 K). The discrepancy could be influenced by the small number of lines used for the analysis. All fitted lines are those belonging to the para- $\mathrm{H}_{2} \mathrm{CO}$, and the $T_{\text {rot }}$ fits are thus not affected by fluxes from different spin states. A single transition of 
K. Isokoski et al.: Chemistry of massive young stellar objects with a disk-like structure

Table 5. Temperatures $(\mathrm{K})$ derived from the RTD analysis and the Weeds or CASSIS $\left(\mathrm{CH}_{3} \mathrm{OH}\right)$ model.

\begin{tabular}{l|cc|cc|cc}
\hline \hline & \multicolumn{2}{|c}{ IRAS 20126+4104 } & \multicolumn{2}{c}{ IRAS 18089-1732 } & \multicolumn{2}{c}{ G31.41+0.31 } \\
\hline & RTD & Model & \multicolumn{7}{c}{ RTD } & Model & RTD & Model \\
\hline & \multicolumn{7}{c}{ warm species } \\
\hline $\mathrm{H}_{2} \mathrm{CO}$ & $123 \pm 21$ & 150 & $204 \pm 82$ & $(150)$ & $157 \pm 44$ & $(150)$ \\
$\mathrm{CH}_{3} \mathrm{OH}$ & $122 \pm 17$ & $300,14 \pm 1$ & $291 \pm 37$ & $300,15 \pm 2$ & $323 \pm 34$ & $200,14 \pm 2$ \\
$\mathrm{C}_{2} \mathrm{H}_{5} \mathrm{OH}$ & - & $(100)$ & $85 \pm 18$ & 150 & $120 \pm 15$ & 100 \\
$\mathrm{HNCO}$ & - & $(200)$ & $92 \pm 25$ & 200 & $111 \pm 32$ & 200 \\
$\mathrm{NH}_{2} \mathrm{CHO}$ & - & 300 & $72 \pm 28$ & 100 & $94 \pm 50$ & 300 \\
$\mathrm{CH}_{3} \mathrm{CN}$ & $217 \pm 352$ & $(200)$ & {$[346 \pm 106]$} & $(200)$ & {$[311 \pm 68]$} & $(300)$ \\
$\mathrm{C}_{2} \mathrm{H}_{5} \mathrm{CN}$ & - & $(80)$ & $84 \pm 33$ & 80 & $105 \pm 23$ & 80 \\
$\mathrm{HCOOCH}_{3}$ & - & $(200)$ & $118 \pm 20$ & 200 & $174 \pm 11$ & 300 \\
$\mathrm{CH}_{3} \mathrm{OCH}$ & - & $(100)$ & $66 \pm 11$ & 100 & $90 \pm 6$ & 100 \\
\hline & - & \multicolumn{7}{c}{ cold species } & $97 \pm 101$ & 50 \\
$\mathrm{CH}_{2} \mathrm{CO}$ & - & $(50)$ & $71 \pm 11$ & 50 & - & 50 \\
$\mathrm{CH}_{3} \mathrm{CHO}$ & - & $(50)$ & - & $(50)$ & - & 40 \\
$\mathrm{HCOOH}$ & - & $(40)$ & - & $(40)$ & - & 80 \\
$\mathrm{CH}_{3} \mathrm{CCH}$ & $40 \pm 10$ & 35 & $46 \pm 12$ & 40 & $67 \pm 14$ & \\
\hline
\end{tabular}

Notes. The species are classified warm and cold according to BIS07. Square bracketed values are $T_{\text {rot }}$ values for optically thick species and round bracketed values are $T_{\mathrm{ex}}$ values assumed based on temperatures derived from the other sources in this study. - Means not enough lines were detected for a rotation diagram. Typical uncertainties in the Weeds excitation temperatures are $\pm 50 \mathrm{~K}$.

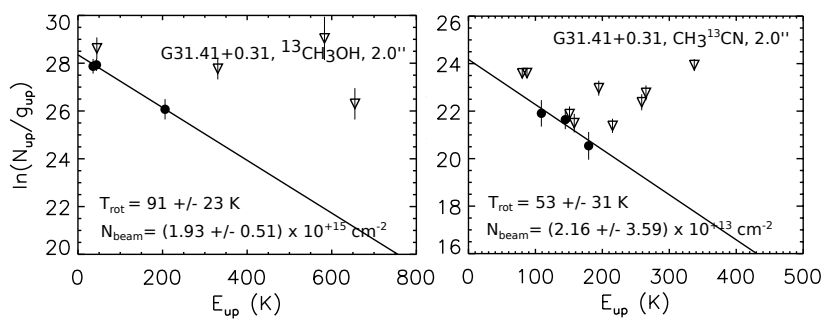

Fig. 3. Rotation diagrams for ${ }^{13} \mathrm{CH}_{3} \mathrm{OH}$ (left panel) and $\mathrm{CH}_{3}{ }^{13} \mathrm{CN}$ (right panel) in G31. Triangles represent blended lines and are not included from the fit.

$\mathrm{H}_{2}{ }^{13} \mathrm{CO}\left(3_{1,2}-2_{1,1}\right)$ was covered, and no information on the excitation temperature can therefore be obtained from the minor isotopologue.

The $T_{\text {rot }}$ values of the other complex species, HNCO, $\mathrm{C}_{2} \mathrm{H}_{5} \mathrm{OH}, \mathrm{C}_{2} \mathrm{H}_{5} \mathrm{CN}, \mathrm{NH}_{2} \mathrm{CHO}$ and $\mathrm{CH}_{3} \mathrm{OCH}_{3}$ are around $100 \mathrm{~K}$ and are slightly higher in G31 than in IRAS 18089. The $T_{\text {rot }}$ of $\mathrm{HCOOCH}_{3}$ stands out in both sources, in G31 being closer to $200 \mathrm{~K}$. No lines belonging to these species were detected in IRAS 20126.

The species classified as cold by BIS07, $\mathrm{CH}_{2} \mathrm{CO}$ and $\mathrm{CH}_{3} \mathrm{CCH}$, indeed show cold rotation temperatures in all sources. Not enough lines of $\mathrm{CH}_{3} \mathrm{CHO}$ or $\mathrm{HCOOH}$, which are also classified as cold in BIS07, are observed in our sources for making rotation diagrams.

\subsection{Column densities}

Table 7 presents the column densities derived from the RTD analysis, Weeds or CASSIS model, and from the ${ }^{13} \mathrm{C}$-isotopologues for the optically thick species. Following BIS07, the column densities for warm molecules are given as source-averaged values (see Eq. (5)). The emission from cold molecules extends over a larger volume and the values are given as beam-averaged column densities. Typical uncertainty of the column densities derived from the RTD analysis is $\sim 40 \%$.

\subsection{1. $\mathrm{CH}_{3} \mathrm{OH}$}

An accurate determination of the $\mathrm{CH}_{3} \mathrm{OH}$ column density is essential for comparing the abundance ratios of complex organic species. For hot-core molecules, it is particularly important to quantify the warm $\mathrm{CH}_{3} \mathrm{OH}$ emission. The column densities of $\mathrm{CH}_{3} \mathrm{OH}$ in BIS07 were determined by the RTD method excluding the optically thick lines. The same is done in our analysis. Our rotation diagrams however also show emission from low- $E_{\text {up }}$ transitions, which are strongly underestimated by the RTD fit on the warm lines, providing further evidence for the presence of a colder component. We have therefore also excluded these transitions. The fit to the higher $E_{\text {up }}$, optically thin lines should give the warm $\mathrm{CH}_{3} \mathrm{OH}$ column density obtained in a similar way as BIS07.

$\mathrm{CH}_{3} \mathrm{OH}$ emission was also simulated using a two-component CASSIS model. A single-component model is not able to simultaneously reproduce the warm and cold lines without overestimating the lines from intermediate energy levels. Indeed, a better agreement is obtained using a two-component model, consisting of a warm compact component and a cold extended component. Table 6 shows the best model parameters obtained from the fitting. The warm components are fixed to $\theta_{T=100 \mathrm{~K}}$ while the cold component is allowed to extend beyond the beam diameter. The warm $\mathrm{CH}_{3} \mathrm{OH}$ column densities derived from the CASSIS fit are in agreement with the values derived from the RTD analysis. The best fits plotted onto the $\mathrm{CH}_{3} \mathrm{OH} 7_{\mathrm{K}}-6_{\mathrm{K}}$ transitions $(338.5 \mathrm{GHz})$ are shown in Fig. 4.

Several ${ }^{13} \mathrm{CH}_{3} \mathrm{OH}$ lines are detected in G31. However, only low- $E_{\text {up }}$ lines are reliably detected since the high$E_{\text {up }}$ lines are very weak or blended. Assigning these lines to the cold component and assuming $T_{\text {rot }}=20 \mathrm{~K}$ (Öberg et al. 2011; Requena-Torres et al. 2008), the beam-averaged 
Table 6. CASSIS model parameters for $\mathrm{CH}_{3} \mathrm{OH}$ in the observed sources.

\begin{tabular}{l|c|cccccc}
\hline \hline Source & Component $^{a}$ & $\begin{array}{c}N_{\mathrm{S}} \\
{\left[\mathrm{cm}^{-2}\right]}\end{array}$ & $\begin{array}{c}T_{\text {ex }} \\
{[\mathrm{K}]}\end{array}$ & $\begin{array}{c}F W H M \\
{\left[\mathrm{~km} \mathrm{~s}^{-1}\right]}\end{array}$ & $\begin{array}{c}\theta_{\mathrm{S}} \\
{\left[{ }^{\prime \prime}\right]}\end{array}$ & $\begin{array}{c}V_{\text {LSR }} \\
{\left[\mathrm{km} \mathrm{s}^{-1}\right]}\end{array}$ & $\chi^{2}$ \\
\hline IRAS 20126+4104 & comp. & $(1.1 \pm 0.1) \mathrm{E}+17$ & $300^{c}$ & $8.15 \pm 0.60$ & $2.2^{b}$ & $-4.05 \pm 0.70$ & 1.9 \\
& ext. & $\left(2.2_{-0.7}^{+0.9} \mathrm{E}+15\right.$ & $14 \pm 1$ & $7.00_{-0.75}^{+0.60}$ & $\gg 14.0$ & $-4.25_{-0.25}^{+0.80}$ & 1.0 \\
\hline IRAS 18089-1732 & comp. & $\left(2.0_{-0.2}^{+0.1}\right) \mathrm{E}+17$ & $300^{c}$ & $5.45_{-0.5}^{+0.40}$ & $2.4^{b}$ & $33.4 \pm 0.2$ & 4.4 \\
& ext. & $\left(2.4_{-0.5}^{+1.4}\right) \mathrm{E}+15$ & $15 \pm 2$ & $3.50_{-0.55}^{+0.50}$ & $\gg 14.0$ & $32.3_{-0.2}^{+0.4}$ & \\
\hline G31.41+0.31 & comp. & $(1.0 \pm 0.2) \mathrm{E}+18$ & $200^{c}$ & $6.35 \pm 0.35$ & $2.0^{b}$ & $97.2 \pm 0.2$ & 7.4 \\
& ext. & $(1.2 \pm 0.6) \mathrm{E}+16$ & $14 \pm 2$ & $3.95 \pm 0.40$ & $\gg 14.0$ & $97.2_{-0.3}^{+0.2}$ & \\
\hline
\end{tabular}

Notes. ${ }^{(a)}$ “comp." for warm, compact component; “ext.” for colder, more extended component. ${ }^{(b)}$ Fixed to $\theta_{\mathrm{s}, T=100 \mathrm{~K} .}{ }^{(c)}$ Fixed.

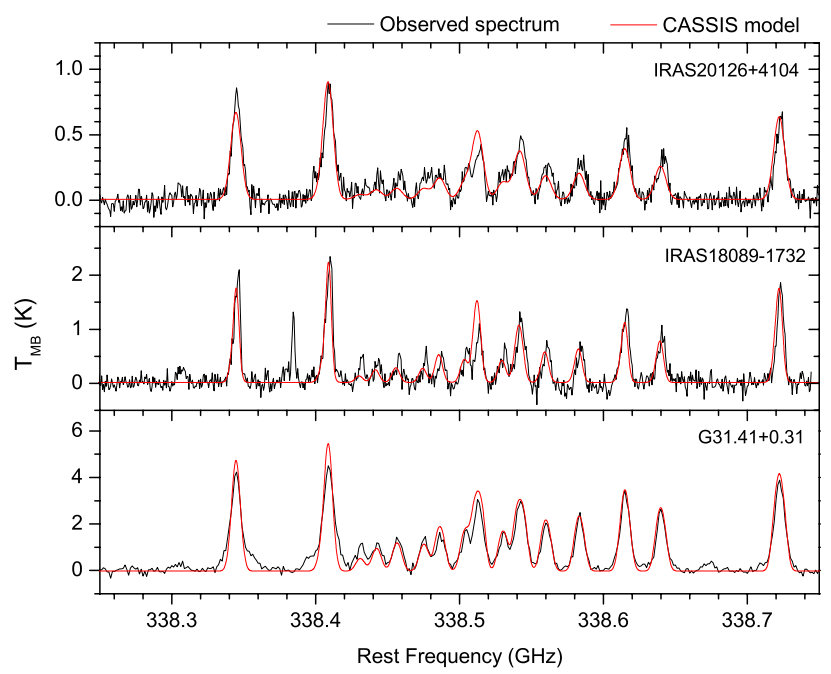

Fig. 4. CASSIS two-component models for $\mathrm{CH}_{3} \mathrm{OH}$ emission in the $338 \mathrm{GHz}$ region covering the $7_{\mathrm{K}}-6_{\mathrm{K}}$ transitions with $K=0-6$.

${ }^{13} \mathrm{CH}_{3} \mathrm{OH}$ column density is $2.1 \times 10^{15} \mathrm{~cm}^{-2}$, corresponding to a $\mathrm{CH}_{3} \mathrm{OH}$ column density of $1.7 \times 10^{17} \mathrm{~cm}^{-2}$ for the $14^{\prime \prime}$ volume. This is more than an order of magnitude higher than found in the Weeds model for the cold component, supporting the optically thick interpretation of the cold component. Similarly, for the case of IRAS 18089, the detected ${ }^{13} \mathrm{CH}_{3} \mathrm{OH}$ lines may indicate a high optical depth.

As mentioned before, the ${ }^{13} \mathrm{CH}_{3} \mathrm{OH}$ line with $E_{\text {up }}=211 \mathrm{~K}$, covered in additional observations for $\mathrm{G} 31$, reveals optical thickness in the warm component as well. The $\mathrm{CH}_{3} \mathrm{OH}$ column density derived from this line assuming temperature of $300 \mathrm{~K}$ is $2.7 \times 10^{18} \mathrm{~cm}^{-2}$ and the CASSIS fit as well as the RTD analysis underestimate the warm column density by a factor of $\sim 2.5$. In principle, the CASSIS analysis could be made consistent with the ${ }^{13} \mathrm{CH}_{3} \mathrm{OH}$ value by letting the warm source size vary as well. However, since such information is not known for other molecules, as well as for consistency with BIS07, we have chosen to keep the warm source size fixed at the $100 \mathrm{~K}$ radius.

In summary, it seems plausible that at least in our sources, methanol emission arises from two temperature components, a warm $\left(T_{\mathrm{ex}} \approx 300 \mathrm{~K}\right)$ compact component and a cold $\left(T_{\mathrm{ex}} \approx 20 \mathrm{~K}\right)$ significantly more extended component. At least for G31, the $\mathrm{CH}_{3} \mathrm{OH}$ emission is optically thick in both components.

\subsubsection{Other molecules}

Overall, the column densities of the various species follow the same pattern in all sources, and hence seem to be well correlated relative to each other. $\mathrm{CH}_{3} \mathrm{OH}$ is the most abundant complex molecule in all sources. The other species have in general half to one order of magnitude lower column densities.

The $\mathrm{CH}_{3} \mathrm{CN}$ emission is optically thick for $\mathrm{G} 31$ and IRAS 18089. Column densities from the RTD analysis are therefore underestimated. Due to a lack of sufficient optically thin lines, also the Weeds analysis underestimates the column densities. Values derived from the ${ }^{13} \mathrm{C}$-isotopologues are thus more reliable, even though some fraction may arise from a colder component. Indeed, the column density for $\mathrm{CH}_{3} \mathrm{CN}$ derived from the 13-isotopologue is an order of magnitude larger than that from the RTD of the main isotopologue alone. The same procedure was used by BIS07.

For $\mathrm{H}_{2} \mathrm{CO}$, the best estimates come from the RTD analysis on the optically thin para- $\mathrm{H}_{2} \mathrm{CO}$ lines. The derived $\mathrm{H}_{2} \mathrm{CO}$ column densities assuming $T_{\text {rot }}$ from Table 5 and a statistical orthoto-para ratio of 3 are given in Table 7 . The column densities derived from the ${ }^{13} \mathrm{C}$-isotopologue of ortho- $\mathrm{H}_{2} \mathrm{CO}$ are still larger than from RTD analysis using optically thin lines, which indicates either larger ortho-to-para ratio in these sources (ratio of $\sim 3$ to 5 has been predicted for cold clouds by Kahane et al. 1984) or non LTE excitation. BIS07 derived the $\mathrm{H}_{2} \mathrm{CO}$ column densities from the ${ }^{13} \mathrm{C}$-isotopologue.

The column density derived for $\mathrm{HCOOCH}_{3}$ from the RTD diagram is significantly smaller than that derived from the Weeds model. The $\mathrm{HCOOCH}_{3}$ emission is stronger in the $230 \mathrm{GHz}$ beam (20-21") than in the $345 \mathrm{GHz}$ beam (14") probably indicating significant extended emission. The RTD analysis was performed on the entire dataset, while only lines in the $230 \mathrm{GHz}$ band was used in the Weeds modeling.

\section{Discussion}

\subsection{Comparison to massive YSOs without a disk structure}

In order to see the effect of a flattened circumstellar structure on the chemistry around the YSO, we compare the temperatures and abundances of the complex organic molecules in sources studied in this work and those studied in BIS07. In addition to our sources (IRAS 20126, IRAS 18089 and G31), AFGL 2591, NGC 7538 IRS1 and G24.78 from the BIS07 sample are now known to have disk structures as well (van der Tak et al. 2006; Wang et al. 2012; Pestalozzi et al. 2004, 2009; Knez et al. 2009; Beltrán et al. 2005). A disk-like structure may be present also for other sources but current evidence is not as strong as for the above sources. For the comparison with the BIS07 sample, we use the results primarily from the RTD method to exclude method based differences. 
Table 7. Column densities for the targeted species from the RTD analysis, Weeds or CASSIS $\left(\mathrm{CH}_{3} \mathrm{OH}\right)$ models and those derived from ${ }^{13}$ C-isotopologues.

\begin{tabular}{l|ccc|ccc|ccc}
\hline \hline & \multicolumn{3}{|c}{ IRAS 20126+4104 } & \multicolumn{3}{c}{ IRAS 18089-1732 } & \multicolumn{3}{c}{ G31.41+0.31 } \\
\hline Species & RTD & Model & $N\left({ }^{12} \mathrm{C}\right)^{a}$ & RTD & Model & $N\left({ }^{12} \mathrm{C}\right)^{a}$ & RTD & Model & $N\left({ }^{12} \mathrm{C}\right)^{a}$ \\
\hline $\mathrm{H}_{2} \mathrm{CO}^{b}$ & $8.4 \mathrm{E}+15$ & $6.0 \mathrm{E}+15$ & $<4.7 \mathrm{E}+16$ & $1.9 \mathrm{E}+16$ & $1.5 \mathrm{E}+16$ & $6.3 \mathrm{E}+16$ & $6.5 \mathrm{E}+16$ & $6.0 \mathrm{E}+16$ & $9.6 \mathrm{E}+16$ \\
$\mathrm{CH}_{3} \mathrm{OH}$ & $2.9 \mathrm{E}+16$ & $1.1 \mathrm{E}+17$ & $<4.0 \mathrm{E}+17^{c}$ & $2.2 \mathrm{E}+17$ & $2.0 \mathrm{E}+17$ & $2.0 \mathrm{E}+18^{c}$ & $1.2 \mathrm{E}+18$ & $1.0 \mathrm{E}+18$ & $2.7 \mathrm{E}+18^{d}$ \\
$\mathrm{C}_{2} \mathrm{H}_{5} \mathrm{OH}$ & - & $<0.3 \mathrm{E}+16$ & - & $3.9 \mathrm{E}+16$ & $2.5 \mathrm{E}+16$ & - & $1.5 \mathrm{E}+17$ & $1.0 \mathrm{E}+17$ & - \\
$\mathrm{HNCO}$ & - & $1.0 \mathrm{E}+15$ & $<7.0 \mathrm{E}+15$ & $2.5 \mathrm{E}+15$ & $0.4 \mathrm{E}+16$ & $<3.8 \mathrm{E}+16$ & $3.6 \mathrm{E}+15$ & $0.6 \mathrm{E}+16$ & $<8.2 \mathrm{E}+16$ \\
$\mathrm{NH}_{2} \mathrm{CHO}$ & - & $0.3 \mathrm{E}+15$ & - & $8.4 \mathrm{E}+14$ & $0.5 \mathrm{E}+15$ & - & $2.1 \mathrm{E}+15$ & $0.4 \mathrm{E}+16$ & - \\
$\mathrm{CH}_{3} \mathrm{CN}$ & $1.5 \mathrm{E}+15$ & $1.3 \mathrm{E}+15$ & $<1.4 \mathrm{E}+15$ & $>4.7 \mathrm{E}+15$ & $>3.5 \mathrm{E}+15$ & $2.2 \mathrm{E}+16$ & $>1.6 \mathrm{E}+16$ & $>2.0 \mathrm{E}+16$ & $1.6 \mathrm{E}+17$ \\
$\mathrm{C}_{2} \mathrm{H}_{5} \mathrm{CN}$ & - & $<0.5 \mathrm{E}+15$ & - & $3.1 \mathrm{E}+15$ & $0.4 \mathrm{E}+16$ & - & $2.0 \mathrm{E}+16$ & $2.0 \mathrm{E}+16$ & - \\
$\mathrm{HCOOCH}_{3}$ & - & $<0.2 \mathrm{E}+16$ & - & $2.8 \mathrm{E}+16$ & $3.0 \mathrm{E}+16$ & - & $1.7 \mathrm{E}+17^{*}$ & $1.0 \mathrm{E}+18$ & - \\
$\mathrm{CH}_{3} \mathrm{OCH}$ & - & $<0.1 \mathrm{E}+17$ & - & $1.3 \mathrm{E}+17$ & $1.0 \mathrm{E}+17$ & - & $5.4 \mathrm{E}+17$ & $5.0 \mathrm{E}+17$ & - \\
\hline $\mathrm{CH}_{2} \mathrm{CO}$ & - & $<2.5 \mathrm{E}+13$ & - & $7.9 \mathrm{E}+13$ & $7.5 \mathrm{E}+13$ & - & - & $3.3 \mathrm{E}+14$ & - \\
$\mathrm{CH}_{3} \mathrm{CHO}$ & - & $<0.5 \mathrm{E}+14$ & - & - & $<0.5 \mathrm{E}+14$ & - & - & $5.0 \mathrm{E}+14$ & - \\
$\mathrm{HCOOH}$ & - & $<2.5 \mathrm{E}+13$ & - & - & $<2.5 \mathrm{E}+13$ & - & $3.2 \mathrm{E}+15$ & $1.0 \mathrm{E}+15$ & - \\
$\mathrm{CH}_{3} \mathrm{CCH}$ & $2.7 \mathrm{E}+14$ & $3.5 \mathrm{E}+14$ & - & $5.2 \mathrm{E}+14$ & $0.9 \mathrm{E}+15$ & - & $1.0 \mathrm{E}+15$ & $1.4 \mathrm{E}+15$ & - \\
\hline
\end{tabular}

Notes. Column densities for the warm molecules are source-averaged, while those for cold molecules are beam-averaged. Column densities where optical depth has a significant effect are labeled as lower limits. ${ }^{(*)}$ Rotation diagram fit on $\mathrm{HCOOCH}_{3}$ on all lines, while Weeds model on the 230 GHz lines only. ${ }^{(a)} N\left({ }^{12} \mathrm{C}\right)$ obtained from the $N\left({ }^{13} \mathrm{C}\right)$ adopting a ${ }^{12} \mathrm{C} /{ }^{13} \mathrm{C}$ ratio equal to 70,54 and 41 for IRAS 20126, IRAS 18089 and G31.41, respectively. ${ }^{(b)}$ Column density from ${ }^{13} \mathrm{C}$-isotopologue from ortho- $\mathrm{H}_{2}{ }^{13} \mathrm{CO}$, corrected using the statistical ortho to para ratio of 3:1. ${ }^{(c)} \mathrm{Calculated}$ from the line intensity of transition $2_{2,0,+0}-3_{1,3,+0}$ at $345.084 \mathrm{GHz}$ with $E_{\text {up }}=44.6 \mathrm{~K}$, assuming a $T_{\text {rot }}$ of $300 \mathrm{~K}$. ${ }^{(d)}$ Calculated from the line intensity of transition $13_{1,12,-0}-13_{0,13,+0}$ at $341.132 \mathrm{GHz}$ with $E_{\text {up }}=206 \mathrm{~K}$, assuming a $T_{\text {rot }}$ of $300 \mathrm{~K}$.

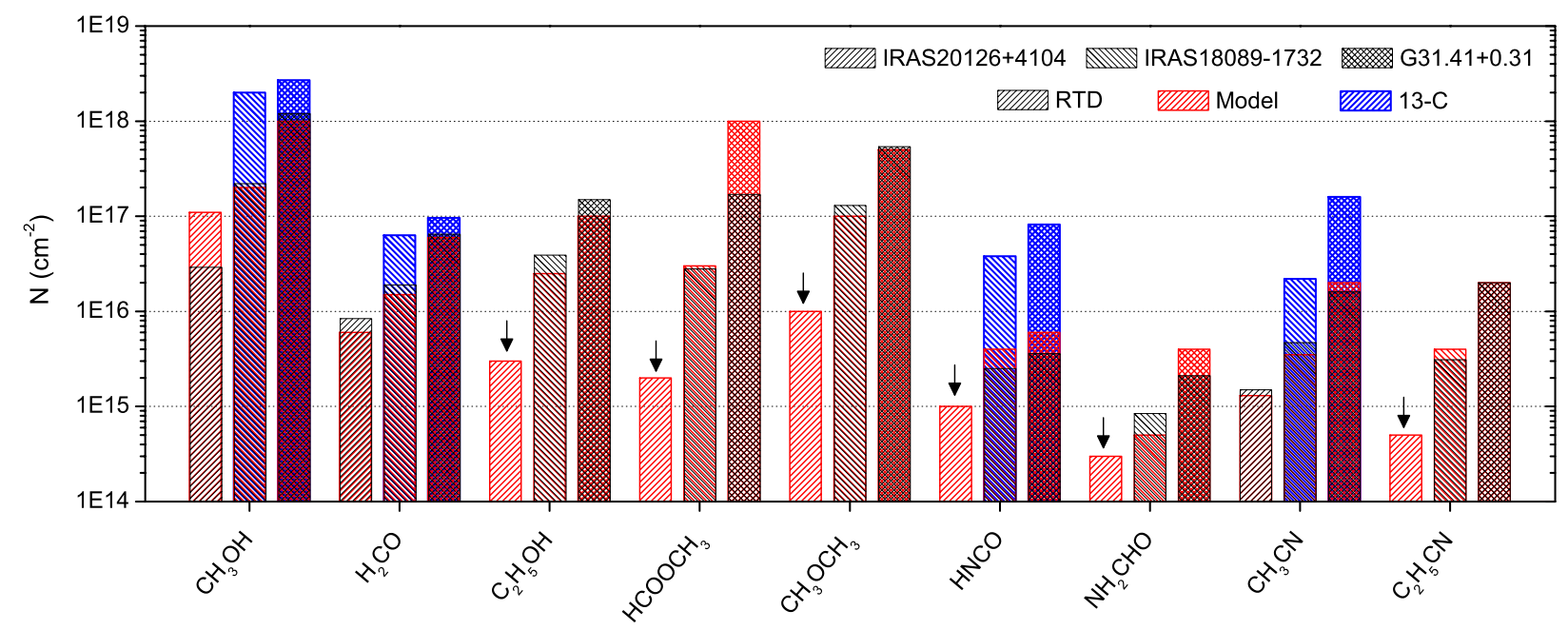

Fig. 5. Source-averaged column densities for the targeted warm species in $\theta_{T=100 \mathrm{~K}}$ volume. Column densities from the RTD analysis are marked in black bars. The red and blue bars show column densities from the Weeds or CASSIS $\left(\mathrm{CH}_{3} \mathrm{OH}\right)$ models and from ${ }^{13} \mathrm{C}$-isotopologue, respectively. Arrows indicate upper limits.

\subsubsection{Rotation temperatures}

Figure 7 shows the rotation temperatures of the complex species for the observed sources together with those from BIS07. As in BIS07, we find that the complex molecules can be divided into warm and cold species based on their rotation temperatures. The rotation temperatures obtained for the molecules in our sources agree with the division; $\mathrm{CH}_{3} \mathrm{OH}, \mathrm{H}_{2} \mathrm{CO}, \mathrm{C}_{2} \mathrm{H}_{5} \mathrm{OH}, \mathrm{HCOOCH}_{3}$, $\mathrm{CH}_{3} \mathrm{OCH}_{3}, \mathrm{HNCO}, \mathrm{NH}_{2} \mathrm{CHO}, \mathrm{CH}_{3} \mathrm{CN}$ and $\mathrm{C}_{2} \mathrm{H}_{5} \mathrm{CN}$ show rotation temperatures generally $\geq 100 \mathrm{~K}$ while $\mathrm{CH}_{2} \mathrm{CO}, \mathrm{CH}_{3} \mathrm{CHO}$, $\mathrm{HCOOH}$ and $\mathrm{CH}_{3} \mathrm{CCH}$ have rotation temperatures $<100 \mathrm{~K}$.

The rotation temperatures of the cold molecules show a very small scatter $( \pm 25 \mathrm{~K})$ from source to source, with or without a disk structure, ignoring the one outlier for $\mathrm{HCOOH}$. Of the warm species, $\mathrm{C}_{2} \mathrm{H}_{5} \mathrm{OH}$ has a consistent rotation temperature of 100-150 K from source to source. The RTD analysis for these species is reliable due to low optical depths and lack of anomalous excitation.

The other warm species show more scatter in the derived rotation temperatures. This is particularly the case for $\mathrm{CH}_{3} \mathrm{OH}$ and $\mathrm{CH}_{3} \mathrm{CN}$, which have rotation temperatures ranging from 100 to $350 \mathrm{~K}$. No systematic difference is seen between the two source types. Moreover, the $\mathrm{HCOOCH}_{3}$ rotation temperatures for AFGL 2591 and NGC 7538 IRS1 are similar to the diskless sources, disproving any difference between the two source types. The scatter in the rotation temperatures could indicate that they exist in environments with different 


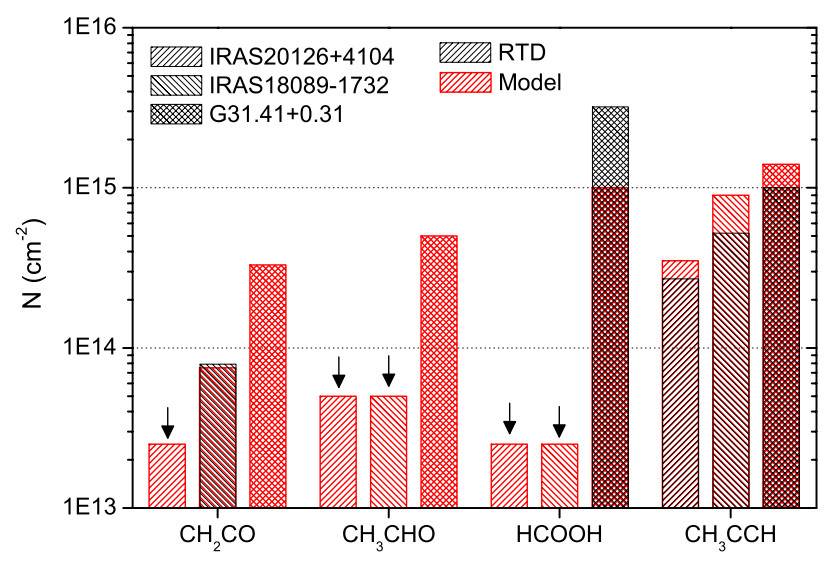

Fig. 6. Beam-averaged column densities for the targeted cold species. Column densities from the RTD analysis are marked in black bars while the red bars show column densities from the Weeds model. Arrows indicate upper limits.

temperatures, but it may also be caused by optical depth effects $\left(\mathrm{H}_{2} \mathrm{CO}, \mathrm{HNCO}, \mathrm{CH}_{3} \mathrm{OH}\right.$ and $\left.\mathrm{CH}_{3} \mathrm{CN}\right)$ and (anomalous) radiative excitation. The latter has been previously seen for, e.g., $\mathrm{NH}_{2} \mathrm{CHO}$ and $\mathrm{HCOOCH}_{3}$ (Nummelin et al. 2000) as well as HNCO (Churchwell et al. 1986). For species with significant radiative excitation, e.g., $\mathrm{HCOOCH}_{3}$, the scatter of the data points in the RTD plots is higher and results in additional uncertainty since the linear fits do not properly capture this scatter.

\subsubsection{Column densities}

Figures 8 and 9 show the column densities for the targeted species in our sources and those from BIS07 for warm and cold molecules, respectively. For the warm species the column densities within the sources vary by 1-2 orders of magnitude. There is also a significant variation between sources. G31 is chemically richest of the sources, with highest column densities of all the targeted species, compared to other sources. IRAS 20126 is among the chemically poorest sources. The pattern of column densities is remarkably similar, however, and the disk sources do not stand out.

\subsubsection{Abundance ratios}

Table 8 gives the abundance ratios for the targeted species with respect to $\mathrm{CH}_{3} \mathrm{OH}$ for oxygen-bearing species and $\mathrm{HNCO}$ for nitrogen-bearing species. Column densities from the RTD analysis are primarily used. In cases where column densities are not available from the RTD analysis (mainly for IRAS 20126) the values are taken from the Weeds analysis.

The resulting abundance ratios are presented in Fig. 10. Values from the RTD method are shown in black bars and can thus be directly compared to BIS07, whereas those from the Weeds model and ${ }^{13} \mathrm{C}$-isotopologue are in red and blue bars. In general, the abundance ratios in different sources have larger variations within the source types than between them. For example, $\mathrm{H}_{2} \mathrm{CO}$ has both lowest and highest abundance ratio for two disk candidates, G31 and IRAS 20126, respectively. The $\mathrm{H}_{2} \mathrm{CO}$ results depend somewhat on the analysis method used.

$\mathrm{C}_{2} \mathrm{H}_{5} \mathrm{OH}, \mathrm{HCOOCH}_{3}$ and $\mathrm{CH}_{3} \mathrm{OCH}_{3}$ abundances peak for G31 and IRAS 18089, and are generally lower for other sources. $\mathrm{CH}_{3} \mathrm{OCH}_{3}$ also peaks for some diskless sources. The N-bearing species $\mathrm{NH}_{2} \mathrm{CHO}$ has a large variation in the abundance ratio with respect to $\mathrm{HNCO}$. Among our sources, $\mathrm{NH}_{2} \mathrm{CHO}$ peaks for G31, the source with largest abundance of O-bearing species, and the least clear disk structure.

Figure 11 shows the abundance ratios of $\mathrm{N}$-bearing species with respect to $\mathrm{CH}_{3} \mathrm{OH}$. Again, a lot of variation is seen within each source type, with no specific trend found for sources with a disk-like structure.

We stress that the absolute inferred column densities and abundance ratios are uncertain by a factor of a few up to an order of magnitude, as already indicated by the different analysis techniques. An independent assessment of the accuracy of the results can be made by comparison with the inferred column densities and abundances of Zernickel et al. (2012) for NGC 6334 I (=NGC 6334 IRS), who observed a completely different set of lines of the same molecules with Herschel-HIFI and the SMA in beams ranging from 2-40". Comparison with the results of BIS07 shows good agreement within a factor of a few for the abundances of several species $\left(\mathrm{CH}_{3} \mathrm{OH}, \mathrm{CH}_{3} \mathrm{OCH}_{3}, \mathrm{CH}_{3} \mathrm{OCHO}\right.$, $\mathrm{C}_{2} \mathrm{H}_{5} \mathrm{OH}, \mathrm{C}_{2} \mathrm{H}_{5} \mathrm{CN}$ ) whereas others differ by an order of magnitude $\left(\mathrm{H}_{2} \mathrm{CO}, \mathrm{CH}_{3} \mathrm{CN}\right)$. The species that show the largest discrepancy are those with highly optically thick lines and without a large set of isotopologue lines. Thus, a combination of differences in adopted source sizes and optical depth effects can account for the discrepancies. Because our approach is the same for all sources, the relative values from source to source should be more reliable.

\subsection{Chemical and physical implications}

The main goal of this study is to investigate similarities and differences between sources with and without a disk-like structures. The presence of a flattened accretion disk should allow the UV radiation from the central object to escape more readily and then impinge on the gas and dust in the outer walls of a flared disk or outflow cavity (Bruderer et al. 2010). Increased UV radiation could manifest itself as enhancement in the complex organic species produced through UV photodissociation from $\mathrm{CH}_{3} \mathrm{OH}$ in the solid state, such as $\mathrm{CH}_{3} \mathrm{OCH}_{3}, \mathrm{C}_{2} \mathrm{H}_{5} \mathrm{OH}$ and $\mathrm{CH}_{3} \mathrm{OCHO}$ (Öberg et al. 2009). In this scenario, $\mathrm{CH}_{3} \mathrm{OH}$ is photodissociated into various radicals such as $\mathrm{CH}_{3}, \mathrm{CH}_{3} \mathrm{O}$ and $\mathrm{CH}_{2} \mathrm{OH}$ which can become mobile at higher ice temperatures $(20-40 \mathrm{~K})$ and form the observed complex organic molecules (Garrod \& Herbst 2006). Higher temperatures favor diffusion of larger radicals resulting in the formation of larger complex organic molecules compared with small molecules like $\mathrm{H}_{2} \mathrm{CO}$. Another related parameter that plays a role is the $\mathrm{CO}$ content of ices, with $\mathrm{H}_{2} \mathrm{CO}, \mathrm{CHO}$ - and $\mathrm{COOH}$-containing species enriched in cold, $\mathrm{CO}$-rich $\mathrm{CH}_{3} \mathrm{OH}$ ices in which $\mathrm{CO}$ has not evaporated. Indeed Öberg et al. (2011) show that the increased abundance of $\mathrm{HCOOCH}_{3}$ in low-mass YSOs compared with the high-mass sample of BIS07 may be due to this effect. Although only limited laboratory experiments exist on $\mathrm{N}$-containing molecules, the abundance of $\mathrm{N}$-bearing complex organic molecules could be enhanced due to photodissociation of $\mathrm{N}_{2}$ or $\mathrm{NH}_{3}$.

Our results show that there is no consistent enhancement of complex organic species produced through $\mathrm{CH}_{3} \mathrm{OH}$ photochemistry, nor of $\mathrm{N}$-bearing species, that can be attributed to the presence of a flattened disk structure on the scales probed by our data. The variations within source types are larger than between the source types. One explanation for this lack of differentation could be that all high-mass sources have a source structure through which UV radiation can impact the larger surroundings. In particular, just like low-mass sources, all highmass YSOs are expected to have outflows and cavities through 
K. Isokoski et al.: Chemistry of massive young stellar objects with a disk-like structure

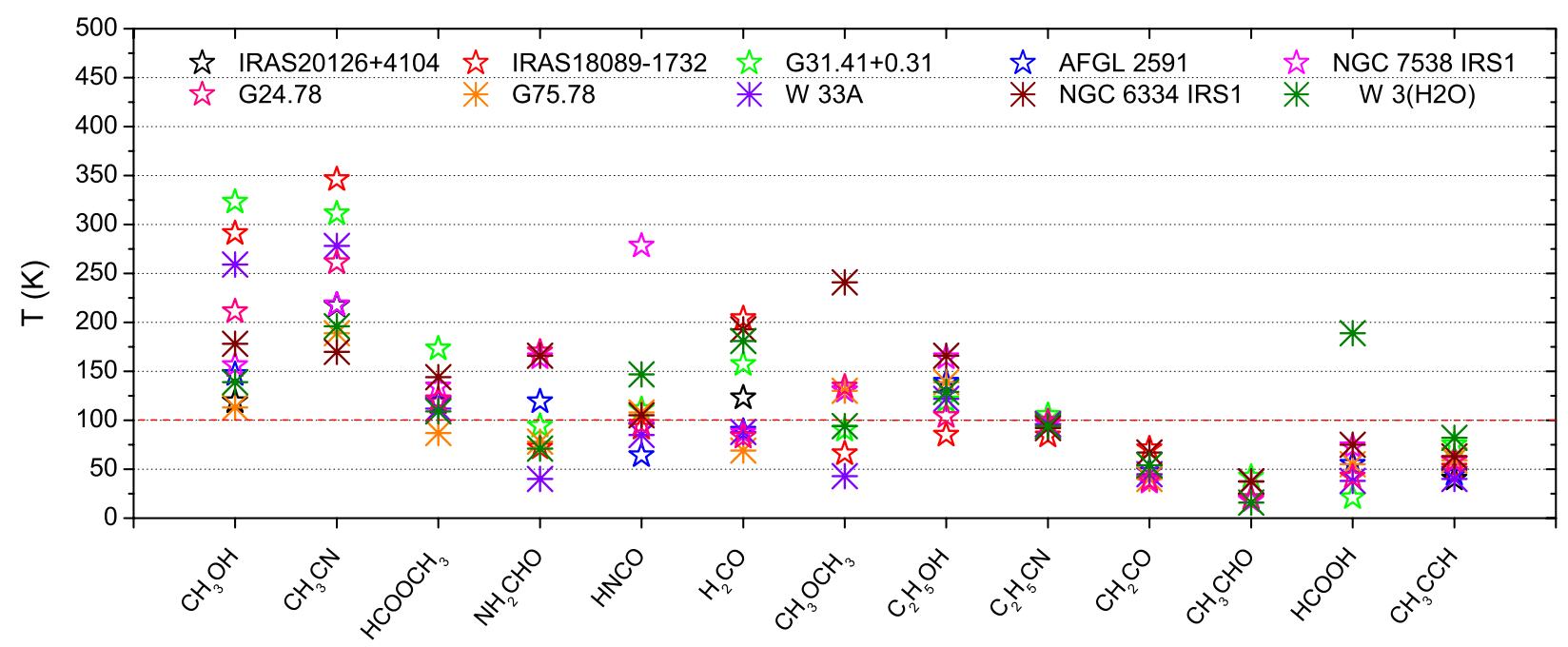

Fig. 7. Rotation temperatures for selected species in massive YSOs with (open stars) and without (asterisks) observed disk structure.

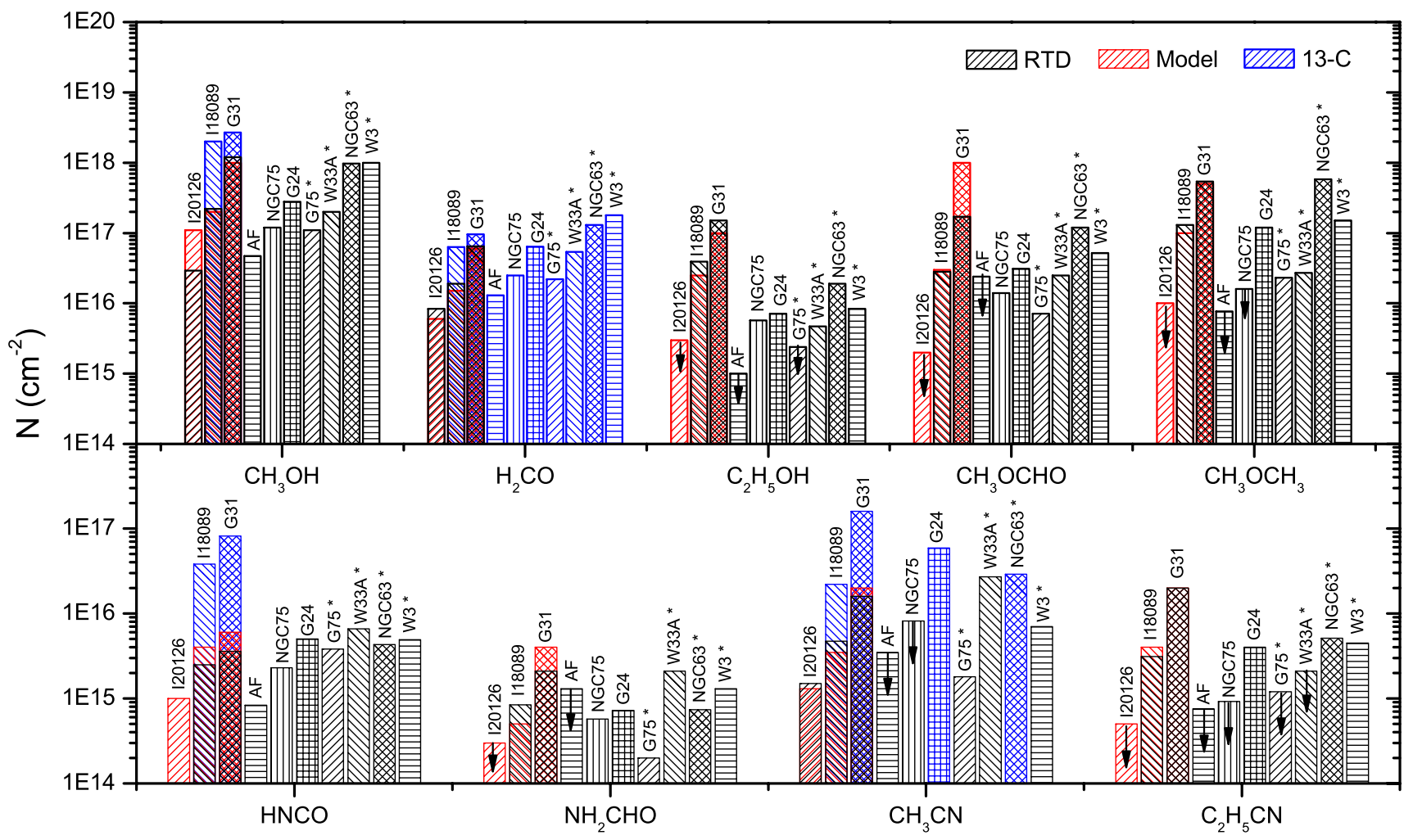

Fig. 8. Source-averaged column densities for warm molecules. Column densities from the RTD analysis are marked in black bars. Sources without disk structure are marked with an asterisk. The red and blue bars show column densities from the Weeds or CASSIS $\left(\mathrm{CH}_{3} \mathrm{OH}\right)$ models and from ${ }^{13} \mathrm{C}$-isotopologue, respectively. Upper limits are indicated with arrows.

which UV radiation can escape and affect the chemistry, whether or not they have a large disk-like structure. This scenario can be tested with future high angular resolution data on $<1^{\prime \prime}$ scale with ALMA which should then reveal the emission from complex molecules coating the walls of the outflow cavities.

An alternative explanation is that enhanced temperature in the YSO environment is not needed for the production of complex organic molecules and that they are already formed in the prestellar stage through UV- and cosmic-ray processing of cold ices, using just the internal UV field produced by interaction of cosmic rays with $\mathrm{H}_{2}$ (Prasad \& Tarafdar 1983) rather than that of the star. This scenario has gained support over the last few years with the detection of $\mathrm{HCOOCH}_{3}$ and $\mathrm{CH}_{3} \mathrm{OCH}_{3}$ in cold lowmass cores away from the YSO where the molecules are either released by shocks (Arce et al. 2008; Öberg et al. 2010) or by photodesorption (Bacmann et al. 2012) although the precise formation mechanisms are still unclear. Gas-phase processes may also contribute in some cases. Again, high spatial resolution and sensitivity such as ALMA will be key to testing this scenario.

\section{Summary and conclusions}

We have carried out a partial submillimeter line survey, targeting several complex organic species toward selected massive 


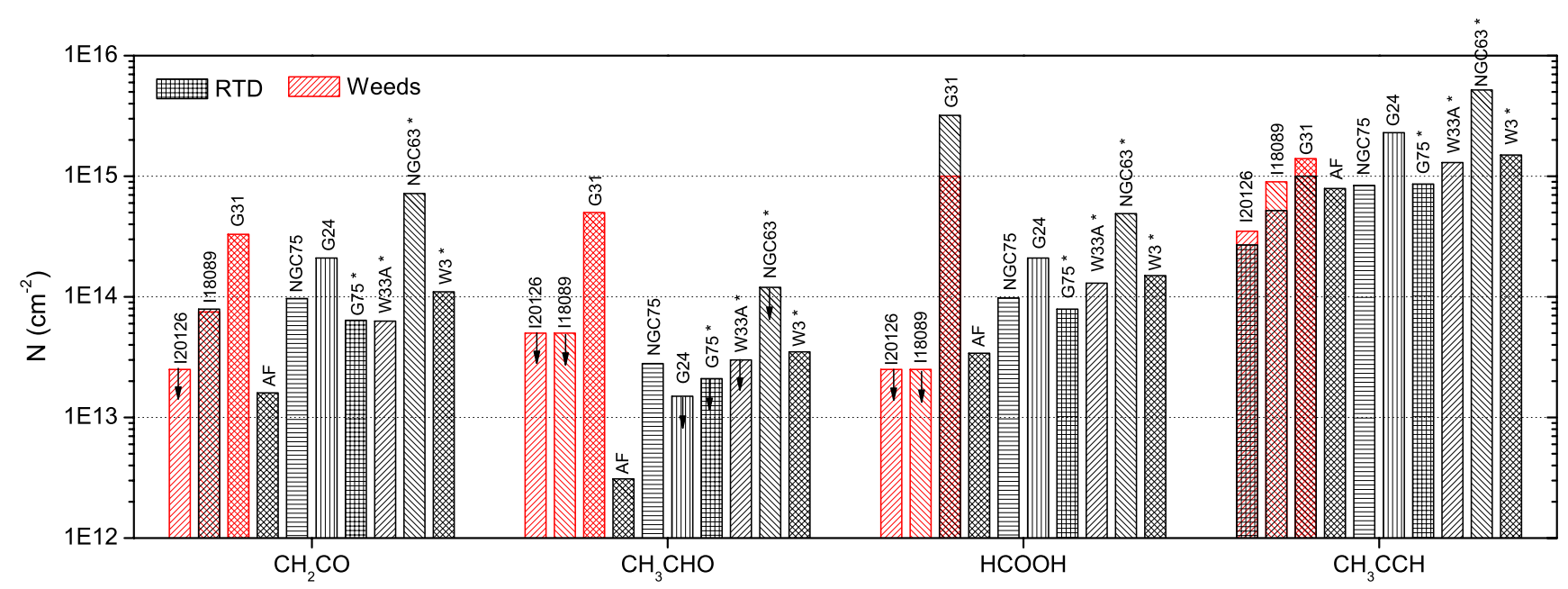

Fig. 9. Beam-averaged column densities for cold molecules in sources observed in this study and those from BIS07. Sources without disk structure are marked with an asterisk. Column densities from the RTD analysis are marked in black bars while the red bars show column densities from the Weeds model. Upper limits are indicated with arrows.

Table 8. Abundance ratios of complex species in the observed sources and those in other chemically rich environments.

\begin{tabular}{|c|c|c|c|c|c|c|}
\hline Source & $\mathrm{H}_{2} \mathrm{CO}$ & $\mathrm{C}_{2} \mathrm{H}_{5} \mathrm{OH}$ & $\mathrm{NH}_{2} \mathrm{CHO}$ & $\mathrm{HCOOCH}_{3}$ & $\mathrm{CH}_{3} \mathrm{OCH}_{3}$ & Refs. \\
\hline \multicolumn{7}{|c|}{ Massive protostellar objects with a disk structure } \\
\hline IRAS $20126+4104$ & $0.29^{p}$ & $<0.10$ & $<0.30$ & $<0.34$ & $<0.34$ & this work \\
\hline IRAS 18089-1732 & $0.09^{p}$ & 0.18 & 0.34 & 0.13 & 0.60 & this work \\
\hline $\mathrm{G} 31.41+0.31$ & $0.06^{p}$ & 0.12 & 0.59 & 0.14 & 0.46 & this work \\
\hline AFGL 2591 & $0.28^{\circ}$ & $<0.02$ & $<1.00$ & 0.51 & $<0.16$ & 1 \\
\hline NGC 7538 IRS1 & $0.21^{o}$ & 0.05 & 0.25 & 0.12 & $<0.13$ & 1 \\
\hline G24.78 & $0.23^{\circ}$ & 0.03 & 0.14 & 0.11 & 0.43 & 1 \\
\hline \multicolumn{7}{|c|}{ Massive protostellar objects with no detected disk structure } \\
\hline G75.78 & $0.20^{\circ}$ & $<0.02$ & 0.05 & 0.06 & 0.21 & 1 \\
\hline W 33A & $0.27^{\circ}$ & 0.02 & 0.32 & 0.13 & 0.14 & 1 \\
\hline NGC 6334 IRS1 & $0.13^{\circ}$ & 0.02 & 0.17 & 0.12 & 0.60 & 1 \\
\hline W 3(H2O) & $0.18^{\circ}$ & 0.01 & 0.27 & 0.05 & 0.15 & 1 \\
\hline \multicolumn{7}{|l|}{ Low-mass outflows } \\
\hline B1-b core & 1.2 & $<1.0$ & - & 2.3 & $<0.8$ & 2 \\
\hline SMM4-W & 0.6 & $<0.4$ & - & 3.5 & 1.1 & 3 \\
\hline L1157 outflow & - & 0.7 & - & 1.8 & - & 4,5 \\
\hline \multicolumn{7}{|l|}{ Low-mass protostars } \\
\hline SMM1 & 6.6 & $<3.4$ & - & 10 & 5.3 & 3 \\
\hline SMM4 & 2.2 & $<0.6$ & - & $<1.0$ & 0.8 & 3 \\
\hline NGC1333 IRAS 4A env. & - & - & - & 56 & $<22$ & $6,7,8$ \\
\hline NGC1333 IRAS 4B env. & - & - & - & 26 & $<19$ & $6,7,8$ \\
\hline IRAS 16293 env. & 4 & - & - & 30 & 20 & $8,9,10$ \\
\hline \multicolumn{7}{|l|}{ Low-mass hot corinos } \\
\hline IRAS $16293 \mathrm{~A}$ & $<0.02$ & 1.4 & - & 0.6 & 0.6 & 11,12 \\
\hline IRAS 16293 B & 0.6 & - & - & 0.8 & 1.6 & 11,12 \\
\hline NGC 1333 IRAS 2A & - & - & - & - & 2 & 13,14 \\
\hline
\end{tabular}

Notes. The abundances are column densities with respect to $\mathrm{CH}_{3} \mathrm{OH}$ for oxygen-bearing species and with respect to $\mathrm{HNCO}$ for nitrogen-bearing species. The $\mathrm{CH}_{3} \mathrm{OH}$ and $\mathrm{HNCO}$ column densities are taken from the RTD analysis when available. ${ }^{(p)}$ Para- $\mathrm{H}_{2} \mathrm{CO} .{ }^{(o)}$ Ortho- $\mathrm{H}_{2} \mathrm{CO}$.

References. (1) Bisschop et al. (2007); (2) Öberg et al. (2010); (3) Öberg et al. (2011); (4) Bachiller \& Perez Gutierrez (1997); (5) Arce et al. (2008); (6) Maret et al. (2005); (7) Bottinelli et al. (2007); (8) Herbst \& van Dishoeck (2009); (9) van Dishoeck et al. (1995); (10) Cazaux et al. (2003); (11) Kuan et al. (2004); (12) Bisschop et al. (2008); (13) Huang et al. (2005); (14) Jørgensen et al. (2005). 
K. Isokoski et al.: Chemistry of massive young stellar objects with a disk-like structure
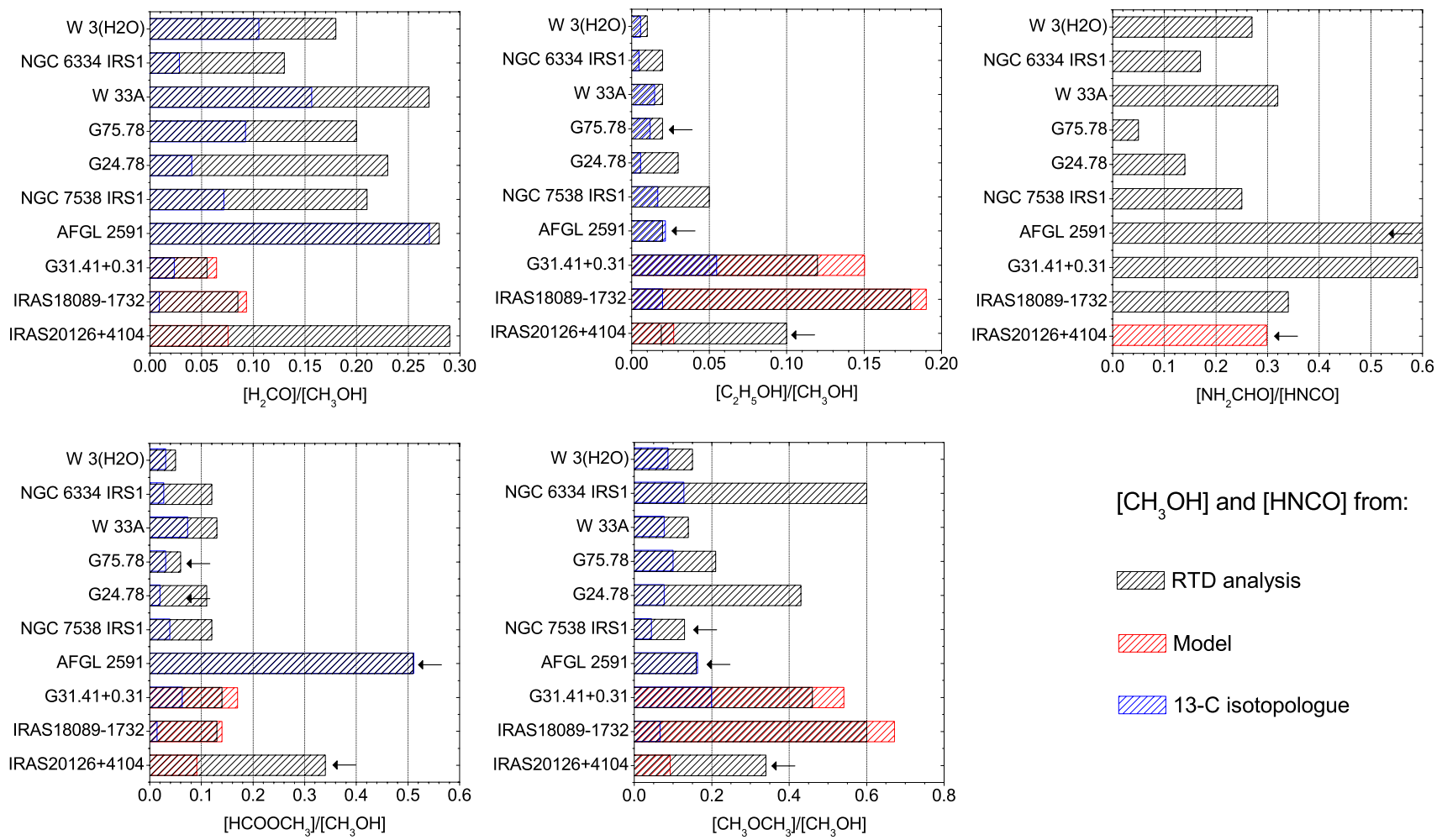

$\left[\mathrm{CH}_{3} \mathrm{OH}\right]$ and $[\mathrm{HNCO}]$ from:

VIIIA RTD analysis

VIIIS Model

VIIIS 13-C isotopologue

Fig. 10. Abundance ratios of complex species with respect to $\mathrm{CH}_{3} \mathrm{OH}$ for oxygen-bearing species and $\mathrm{HNCO}$ for nitrogen-bearing species. The black bars indicate abundance ratios calculated with the $\mathrm{CH}_{3} \mathrm{OH}$ and $\mathrm{HNCO}$ column density derived from the RTD analysis similar to BIS07. The red and blue bars indicate abundance ratios where $\mathrm{CH}_{3} \mathrm{OH}$ and $\mathrm{HNCO}$ column densities are derived from CASSIS or Weeds (HNCO) model, respectively. Upper limits are marked with arrows.

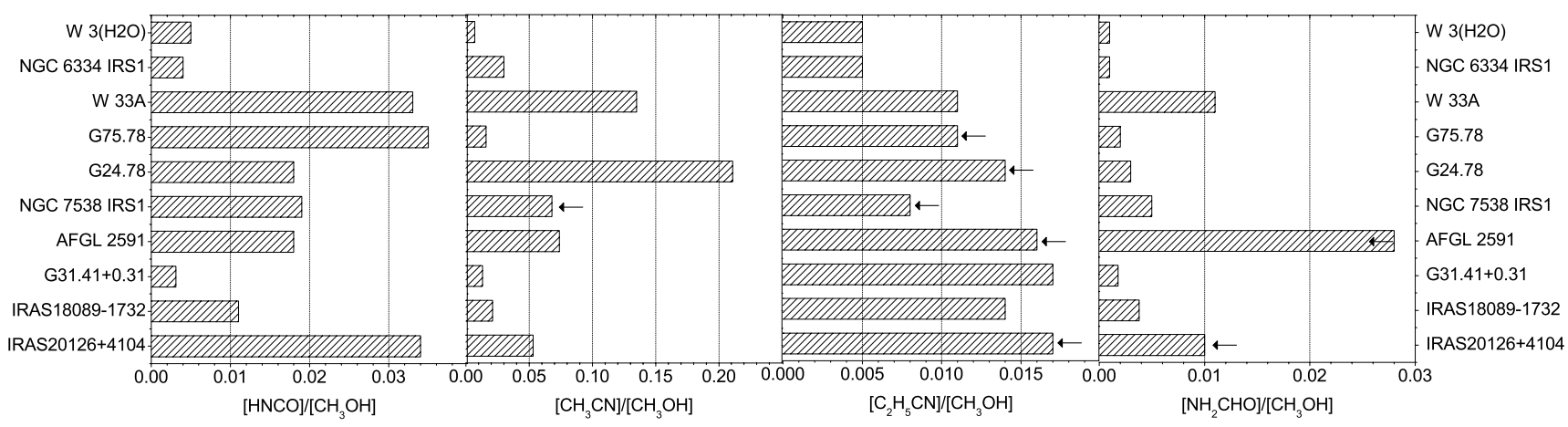

Fig. 11. Abundance ratios of $\mathrm{N}$-bearing species $\mathrm{HNCO}, \mathrm{CH}_{3} \mathrm{CN}, \mathrm{C}_{2} \mathrm{H}_{5} \mathrm{CN}$ and $\mathrm{NH}_{2} \mathrm{CHO}$ with respect to $\mathrm{CH}_{3} \mathrm{OH}$ (from $\mathrm{RTD}$ analysis). Arrows indicate upper limits.

YSOs with strong evidence of circumstellar accretion disks, IRAS 20126+4104, IRAS 18089-1732 and G31.41+0.31. This is the first time that molecular abundances are reported for these well-known sources. The analysis is performed using both the rotation diagram method and spectral modeling. The inferred rotation temperatures and molecular abundances are compared to sources without reported disk structures analyzed using the same techniques. The molecules can be divided into two different groups based on their rotation temperatures, independent of source type. In particular, the cold $(<100 \mathrm{~K})$ species have remarkably constant rotation temperatures from source to source. The warm $(>100 \mathrm{~K})$ species exhibit more scatter possibly due to optical depth effects, non-LTE conditions and radiative excitation. The column densities peak for the same sources, with G31.41+0.31 being chemically the richest of the studied sources.
The relative abundances of species follow the same pattern, and no chemical differentiation could be established between the two source types within the (considerable) uncertainties. The lack of chemical differentiation between massive YSOs with and without observed disk-like structure suggests similarity in the physical conditions and level of UV exposure for all sources, for example through outflow cavities. Alternatively, the complex molecules may already be formed in the cold prestellar stage under similar conditions. Ultimately and indirectly, these results imply that the mechanism of the formation of massive stars does not differ significantly from source to source. Future high angular and high sensitivity observations of optically thin lines will be key to distinguishing the different scenarios and derive accurate abundance ratios that can be directly compared with chemical models. 
Acknowledgements. Astrochemistry in Leiden is supported by the Netherlands Research School for Astronomy (NOVA), by a Spinoza grant from the Netherlands Organisation for Scientific Research (NWO), and by the European Community's Seventh Framework Programme FP7/2007-2013 under grant agreement 238258 (LASSIE) and 291141 (CHEMPLAN).

\section{References}

Arce, H. G., Santiago-García, J., Jørgensen, J. K., Tafalla, M., \& Bachiller, R. 2008, ApJ, 681, L21

Bachiller, R., \& Perez Gutierrez, M. 1997, ApJ, 487, L93

Bacmann, A., Taquet, V., Faure, A., Kahane, C., \& Ceccarelli, C. 2012, A\&A, 541, L12

Belloche, A., Garrod, R. T., Müller, H. S. P., et al. 2009, A\&A, 499, 215

Beltrán, M. T., Cesaroni, R., Neri, R., et al. 2005, A\&A, 435, 901

Beltrán, M. T., Codella, C., Viti, S., Neri, R., \& Cesaroni, R. 2009, ApJ, 690, L93

Benjamin, R. A., Churchwell, E., Babler, B. L., et al. 2003, PASP, 115, 953

Beuther, H., \& Walsh, A. J. 2008, ApJ, 673, L55

Beuther, H., Schilke, P., Sridharan, T. K., et al. 2002, A\&A, 383, 892

Beuther, H., Hunter, T. R., Zhang, Q., et al. 2004, ApJ, 616, L23

Beuther, H., Zhang, Q., Sridharan, T. K., \& Chen, Y. 2005, ApJ, 628, 800

Bisschop, S. E., Jørgensen, J. K., van Dishoeck, E. F., \& de Wachter, E. B. M. 2007, A\&A, 465, 913 (BIS07)

Bisschop, S. E., Jørgensen, J. K., Bourke, T. L., Bottinelli, S., \& van Dishoeck, E. F. 2008, A\&A, 488, 959

Blake, G. A., Sutton, E. C., Masson, C. R., \& Phillips, T. G. 1987, ApJ, 315, 621 Bottinelli, S., Ceccarelli, C., Williams, J. P., \& Lefloch, B. 2007, A\&A, 463, 601

Bruderer, S., Benz, A. O., Doty, S. D., van Dishoeck, E. F., \& Bourke, T. L. 2009, ApJ, 700, 872

Bruderer, S., Benz, A. O., Stäuber, P., \& Doty, S. D. 2010, ApJ, 720, 1432

Caselli, P., \& Ceccarelli, C. 2012, A\&ARv, 20, 56

Cazaux, S., Tielens, A. G. G. M., Ceccarelli, C., et al. 2003, ApJ, 593, L51

Cesaroni, R., Churchwell, E., Hofner, P., Walmsley, C. M., \& Kurtz, S. 1994a, A\&A, 288, 903

Cesaroni, R., Olmi, L., Walmsley, C. M., Churchwell, E., \& Hofner, P. 1994b, ApJ, 435, L137

Cesaroni, R., Felli, M., Testi, L., Walmsley, C. M., \& Olmi, L. 1997, A\&A, 325, 725

Cesaroni, R., Hofner, P., Walmsley, C. M., \& Churchwell, E. 1998, A\&A, 331, 709

Cesaroni, R., Felli, M., Jenness, T., et al. 1999, A\&A, 345, 949

Cesaroni, R., Neri, R., Olmi, L., et al. 2005, A\&A, 434, 1039

Cesaroni, R., Galli, D., Lodato, G., Walmsley, C. M., \& Zhang, Q. 2007, Protostars and Planets V, 197

Cesaroni, R., Hofner, P., Araya, E., \& Kurtz, S. 2010, A\&A, 509, A50

Cesaroni, R., Beltrán, M. T., Zhang, Q., Beuther, H., \& Fallscheer, C. 2011, A\&A, 533, A73

Charnley, S. B., Tielens, A. G. G. M., \& Millar, T. J. 1992, ApJ, 399, L71

Charnley, S. B., Kress, M. E., Tielens, A. G. G. M., \& Millar, T. J. 1995, ApJ, 448,232

Churchwell, E., Wood, D., Myers, P. C., \& Myers, R. V. 1986, ApJ, 305, 405

Churchwell, E., Walmsley, C. M., \& Cesaroni, R. 1990, A\&AS, 83, 119

Comoretto, G., Palagi, F., Cesaroni, R., et al. 1990, A\&AS, 84, 179

Estalella, R., Mauersberger, R., Torrelles, J. M., et al. 1993, ApJ, 419, 698

Fontani, F., Pascucci, I., Caselli, P., et al. 2007, A\&A, 470, 639

Garrod, R. T., \& Herbst, E. 2006, A\&A, 457, 927

Garrod, R. T., Weaver, S. L. W., \& Herbst, E. 2008, ApJ, 682, 283

Gaume, R. A., \& Mutel, R. L. 1987, ApJS, 65, 193

Gibb, E., Nummelin, A., Irvine, W. M., Whittet, D. C. B., \& Bergman, P. 2000, ApJ, 545, 309

Goldsmith, P. F., \& Langer, W. D. 1999, ApJ, 517, 209
Hatchell, J., Thompson, M. A., Millar, T. J., \& MacDonald, G. H. 1998, A\&AS, 133,29

Herbst, E., \& van Dishoeck, E. F. 2009, ARA\&A, 47, 427

Hofner, P., Cesaroni, R., Rodríguez, L. F., \& Martí, J. 1999, A\&A, 345, L43

Huang, H.-C., Kuan, Y.-J., Charnley, S. B., et al. 2005, Adv. Space Res., 36, 146

Johnston, K. G., Keto, E., Robitaille, T. P., \& Wood, K. 2011, MNRAS, 415, 2953

Jørgensen, J. K., Bourke, T. L., Myers, P. C., et al. 2005, ApJ, 632, 973

Kahane, C., Lucas, R., Frerking, M. A., Langer, W. D., \& Encrenaz, P. 1984, A\&A, 137, 211

Kerr, F. J., \& Lynden-Bell, D. 1986, MNRAS, 221, 1023

Knez, C., Lacy, J. H., Evans, II, N. J., van Dishoeck, E. F., \& Richter, M. J. 2009, ApJ, 696, 471

Kuan, Y.-J., Huang, H.-C., Charnley, S. B., et al. 2004, ApJ, 616, L27

Kurtz, S., Cesaroni, R., Churchwell, E., Hofner, P., \& Walmsley, C. M. 2000, Protostars and Planets IV, 299

Leurini, S., Schilke, P., Wyrowski, F., \& Menten, K. M. 2007, A\&A, 466, 215

Maret, S., Ceccarelli, C., Tielens, A. G. G. M., et al. 2005, A\&A, 442, 527

Maret, S., Hily-Blant, P., Pety, J., Bardeau, S., \& Reynier, E. 2011, A\&A, 526, A47

Millar, T. J., Herbst, E., \& Charnley, S. B. 1991, ApJ, 369, 147

Moscadelli, L., Cesaroni, R., Rioja, M. J., Dodson, R., \& Reid, M. J. 2011, A\&A, 526, A66

Müller, H. S. P., Schlöder, F., Stutzki, J., \& Winnewisser, G. 2005, J. Mol. Struct., 742,215

Nummelin, A., Bergman, P., Hjalmarson, Å., et al. 2000, ApJS, 128, 213

Öberg, K. I., Garrod, R. T., van Dishoeck, E. F., \& Linnartz, H. 2009, A\&A, 504, 891

Öberg, K. I., Bottinelli, S., Jørgensen, J. K., \& van Dishoeck, E. F. 2010, ApJ, 716,825

Öberg, K. I., van der Marel, N., Kristensen, L. E., \& van Dishoeck, E. F. 2011, ApJ, 740, 14

Olmi, L., Cesaroni, R., \& Walmsley, C. M. 1996, A\&A, 307, 599

Pestalozzi, M. R., Elitzur, M., Conway, J. E., \& Booth, R. S. 2004, ApJ, 603, L113

Pestalozzi, M. R., Elitzur, M., \& Conway, J. E. 2009, A\&A, 501, 999

Pickett, H. M., Poynter, R. L., Cohen, E. A., et al. 1998 J. Quant. Spec. Radiat. Transf., 60, 883

Prasad, S. S., \& Tarafdar, S. P. 1983, ApJ, 267, 603

Requena-Torres, M. A., Martín-Pintado, J., Martín, S., \& Morris, M. R. 2008, ApJ, 672, 352

Schilke, P., Groesbeck, T. D., Blake, G. A., \& Phillips, T. G. 1997, ApJS, 108, 301

Shepherd, D. S., Yu, K. C., Bally, J., \& Testi, L. 2000, ApJ, 535, 833

Sridharan, T. K., Beuther, H., Schilke, P., Menten, K. M., \& Wyrowski, F. 2002, ApJ, 566, 931

Sridharan, T. K., Williams, S. J., \& Fuller, G. A. 2005, ApJ, 631, L73

Sutton, E. C., Blake, G. A., Masson, C. R., \& Phillips, T. G. 1985, ApJS, 58, 341

Tielens, A. G. G. M., \& Charnley, S. B. 1997, Origins of Life and Evolution of the Biosphere, 27, 23

Tielens, A. G. G. M., \& Hagen, W. 1982, A\&A, 114, 245

Tofani, G., Felli, M., Taylor, G. B., \& Hunter, T. R. 1995, A\&AS, 112, 299

van der Tak, F. F. S., Walmsley, C. M., Herpin, F., \& Ceccarelli, C. 2006, A\&A, 447, 1011

van Dishoeck, E. F., Blake, G. A., Jansen, D. J., \& Groesbeck, T. D. 1995, ApJ, 447,760

Wang, K.-S., van der Tak, F. F. S., \& Hogerheijde, M. R. 2012, A\&A, 543, A22

Widicus Weaver, S. L., Butler, R. A. H., Drouin, B. J., et al. 2005, ApJS, 158, 188

Wilking, B. A., Blackwell, J. H., \& Mundy, L. G. 1990, AJ, 100, 758

Xu, Y., Moscadelli, L., Reid, M. J., et al. 2011, ApJ, 733, 25

Zernickel, A., Schilke, P., Schmiedeke, A., et al. 2012, A\&A, 546, A87

Zhang, Q., Hunter, T. R., \& Sridharan, T. K. 1998, ApJ, 505, L151

Zinnecker, H., \& Yorke, H. W. 2007, ARA\&A, 45, 481 


\section{Appendix A: Detected lines per species for all sources}

The line assignment and detection is based on Gaussian fitting with the following criteria: (i) the fitted line position has to be within $\pm 1 \mathrm{MHz}$ of the catalog frequency; (ii) the FWHM is consistent with the those given in Table 1; and (iii) the peak intensity has at least a $S / N=3$. The errors on the integrated intensities are computed as follows.

The integrated main beam temperatures, $\int T_{\mathrm{MB}} \mathrm{d} V$, were obtained by Gaussian fits to the lines (Eq. (A.1)).

$\int T_{\mathrm{MB}} \mathrm{d} V=c^{s t} T_{0} \Delta V$

with

$c^{s t}=\frac{\sqrt{\pi / \ln 2}}{2}$

where $T_{0}$ is the peak intensity and $\Delta V$ is the FWHM of the line. The error, $d \int T_{\mathrm{MB}} \mathrm{d} V$, is calculated from Eq. (A.2).

$d \int T_{\mathrm{MB}} \mathrm{d} V=c^{s t}\left[\Delta V d\left(T_{0}\right)+T_{0} d(\Delta V)\right]$

with

$d\left(T_{0}\right)=\sqrt{\mathrm{rms}^{2}+\left(\mathrm{cal} \times T_{0}\right)^{2}+\sigma_{T 0}^{2}}$

and

$d(\Delta V)=\sigma_{\Delta V}$ where rms is the root mean square amplitude of the noise in the spectral bin $\delta \mathrm{v}$, cal is the calibration uncertainty of the telescope, and $\sigma$ 's are the statistical errors on $T_{0}$ and $\Delta V$ from the Gaussian fits.

The errors on the integrated intensities derived from Eq. (A.2) include all statistical errors from the Gaussian fit.

$\mathrm{d} \int T_{\mathrm{MB}} \mathrm{d} V=\mathrm{c}^{s t} \Delta V \sqrt{\mathrm{rms}^{2}+\left(\mathrm{cal} \times T_{0}\right)^{2}}$.

For undetected transitions the upper limits were determined as $3 \sigma$ limits (Eq. (A.4)) using:

$\sigma=1.2 \sqrt{\delta v \Delta V} \mathrm{rms}$

where 1.2 is the coefficient related to the calibration uncertainty of $20 \%$.

CLASS was used to determine the Gaussian fits and the uncertainties in the individual parameters. The formal errors on the integrated intensities derived from Eq. (A.3) in some cases yield a $S / N<2.5$. This is caused by: (i) a conservative estimate of the statistical error on the FWHM parameter in the Gaussian fitter of CLASS; (ii) all statistical errors are included into our error calculation. Considering the higher $\mathrm{S} / \mathrm{N}$ on the peak intensity, a more traditional error estimate without the statistical errors from the Gaussian fit (Eq. (A.3)) would result in a $S / N>3$ for the integrated intensity as well. All weak line fits were confirmed by visual inspection.

Table A.1. Observed line fluxes $\int T_{\mathrm{MB}} \mathrm{d} V\left(\mathrm{~K} \mathrm{~km} \mathrm{~s}^{-1}\right)$ for $\mathrm{H}_{2} \mathrm{CO}$ and its isotopic species.

\begin{tabular}{llrcccc}
\hline $\begin{array}{l}\text { Frequency } \\
{[\mathrm{GHz}]}\end{array}$ & Transition & $\begin{array}{c}E_{\text {up }} \\
{[\mathrm{K}]}\end{array}$ & $\begin{array}{c}A \\
{\left[\mathrm{~s}^{-1}\right]}\end{array}$ & $\begin{array}{l}\text { Sources } \\
\text { IRAS 20126+4104 }\end{array}$ & IRAS 18089-1732 & G31.41+0.31 \\
\hline $\mathrm{H}_{2} \mathrm{CO}$ & & & & & & \\
\hline $218.222^{p}$ & $3_{0,3}-2_{0,2}$ & 21 & $2.8(-4)$ & $2.82(0.65)$ & - & $>7.14(1.71)$ \\
$218.476^{p}$ & $3_{2,2}-2_{2,1}$ & 68 & $1.6(-4)$ & - & - & $4.15(1.03)$ \\
$363.946^{p}$ & $5_{2,4}-4_{2,3}$ & 100 & $1.2(-3)$ & $4.65(1.08)$ & $9.92(2.15)$ & $>20.29(3.31)$ \\
$364.103^{p}$ & $5_{4,1 / 2}-4_{4,0 / 1}$ & 241 & $5.0(-4)$ & $1.90(0.58)$ & $4.25(1.07)$ & $10.97(2.88)$ \\
$364.275^{\circ}$ & $5_{3,3}-4_{3,2}$ & $143 / 158$ & $8.9(-4)$ & $>5.08(1.50)$ & $>12.62(3.34)$ & $>21.56(5.08)$ \\
$364.289^{\circ}$ & $5_{3,2}-4_{3,1}$ & $143 / 158$ & $8.9(-4)$ & $>5.78(1.71)$ & $>10.68(2.83)$ & $>20.46(4.85)$ \\
\hline $\mathrm{H}_{2}{ }^{13} \mathrm{CO}$ & & & & & \\
\hline $219.909^{\circ}$ & $3_{1,2}-2_{1,1}$ & 33 & $2.6(-4)$ & $<0.34$ & $1.08(0.60)$ & $1.60(0.55)$ \\
\hline
\end{tabular}

Notes. The notation $a(-b)$ stands for $a \times 10^{-b}$. > Means lower limit (optically thick line). - Means frequency not observed. ${ }^{(p)}$ Para- $\mathrm{H}_{2} \mathrm{CO}$. (o) Ortho- $\mathrm{H}_{2} \mathrm{CO}$. 
A\&A 554, A100 (2013)

Table A.2. Observed line fluxes $\int T_{\mathrm{MB}} \mathrm{d} V\left(\mathrm{~K} \mathrm{~km} \mathrm{~s}^{-1}\right)$ for $\mathrm{CH}_{3} \mathrm{OH}$ and its isotopic species.

\begin{tabular}{|c|c|c|c|c|c|c|}
\hline $\begin{array}{l}\text { Frequency } \\
{[\mathrm{GHz}]}\end{array}$ & Transition & $\begin{array}{l}E_{\text {up }} \\
{[\mathrm{K}]}\end{array}$ & $\begin{array}{c}A \\
{\left[\mathrm{~s}^{-1}\right]}\end{array}$ & $\begin{array}{l}\text { Sources } \\
\text { IRAS 20126+4104 }\end{array}$ & IRAS 18089-1732 & $\mathrm{G} 31.41+0.31$ \\
\hline \multicolumn{7}{|l|}{$\mathrm{CH}_{3} \mathrm{OH}$} \\
\hline 218.440 & $4_{2,0}-3_{1,0}$ & 45 & $6.9(-5)$ & - & - & $10.10(2.22)::$ \\
\hline 219.984 & $25_{3,0}-24_{4,0}$ & 802 & $3.0(-5)$ & $<1.33$ & $<0.24$ & $<0.45(0.24)^{:}$ \\
\hline 219.994 & $23_{5,0}-22_{6,0}$ & 776 & $2.6(-5)$ & $<1.33$ & $<0.24$ & $<1.74(0.56)$ \\
\hline 240.739 & $26_{3,-0}-26_{2,+0}$ & 864 & $1.1(-4)$ & $<0.20$ & $<0.40(0.32)$ & $<0.78(0.47)$ \\
\hline 240.818 & $5_{1,2}-4_{1,2}$ & 834 & $8.5(-5)$ & $<0.20$ & $<0.23$ & $<3.58(0.88)^{:}$ \\
\hline 240.861 & $5_{-4,2}-4_{-4,2}$ & 779 & $3.2(-5)$ & $<0.20$ & $<0.27$ & $<0.81(0.37)^{:}$ \\
\hline 240.870 & $5_{0,2}-4_{0,2}$ & 769 & $8.9(-5)$ & $<0.20$ & $<0.90(0.71)^{:}$ & $<3.26(1.06)^{:}$ \\
\hline 240.916 & $5_{3,-2 /+2}-4_{3,-2 /+2}$ & 693 & $5.7(-5)$ & $<0.20$ & $<1.17(0.46)$ & $1.43(0.45)$ \\
\hline 240.932 & $5_{4,-2 /+2}-4_{4,-2 /+2}$ & 649 & $3.2(-5)$ & $<0.20$ & $<0.57(0.20)$ & $\sim 0.42(0.21)$ \\
\hline 240.937 & $5_{-2,2}-4_{-2,2}$ & 680 & $7.4(-5)$ & $<0.20$ & $<1.03(0.69)$ & $\sim 0.49(0.24)$ \\
\hline 240.939 & $5_{0,+2}-4_{0,+2}$ & 543 & $1.2(-4)$ & $<0.20$ & $<1.03(0.69)^{:}$ & $2.54(0.86)$ \\
\hline 240.948 & $5_{3,2}-4_{3,2}$ & 656 & $5.6(-5)$ & $<0.20$ & $\sim 0.24(0.12)^{*}$ & $\sim 0.74(0.30)^{*}$ \\
\hline 240.952 & $5_{2,2}-4_{2,2}$ & 621 & $7.5(-5)$ & $<0.20$ & $\sim 0.24(0.12)^{*}$ & $\sim 0.74(0.30)^{*}$ \\
\hline 240.959 & $5_{-1,2}-4_{-1,2}$ & 567 & $8.5(-5)$ & $<0.20$ & $1.18(0.42)^{:}$ & $1.74(0.61)^{:}$ \\
\hline 240.961 & $5_{1,+1}-4_{1,+1}$ & 360 & $8.5(-5)$ & $<0.20$ & $1.18(0.42)^{:}$ & $1.74(0.61)^{:}$ \\
\hline 241.043 & $22_{-6,0}-23_{-5,0}$ & 776 & $3.4(-5)$ & - & $\sim 0.35(0.48)$ & $<0.38(0.54)^{:}$ \\
\hline 330.794 & $8_{-3,0}-9_{-2,0}$ & 146 & $8.0(-5)$ & $\sim 0.28(0.57)$ & $3.23(1.12)$ & $8.06(2.43)$ \\
\hline 331.220 & $16_{-1,0}-15_{-2,0}$ & 321 & $7.8(-5)$ & $<0.39^{c}$ & $2.66(0.79)$ & $>3.19(0.91)^{b}$ \\
\hline 338.124 & $7_{0,0}-6_{0,0}$ & 78 & $2.5(-4)$ & - & - & $30.57(11.11)^{::}$ \\
\hline 338.345 & $7_{-1,0}-6_{-1,0}$ & 70 & $2.5(-4)$ & $7.29(2.05)::$ & $10.34(2.58)::$ & $38.03(9.06)^{::}$ \\
\hline 338.405 & $7_{6,0}-6_{6,0}$ & 244 & $6.7(-5)$ & $<8.90(2.54)^{:}$ & $<12.95(3.14)$ & $<44.10(10.87)$ \\
\hline 338.409 & $7_{0,+0}-6_{0,+0}$ & 65 & $2.5(-4)$ & $8.90(2.54)::$ & $12.95(3.14)::$ & $44.10(10.87)::$ \\
\hline 338.431 & $7_{-6,0}-6_{-6,0}$ & 254 & $6.7(-5)$ & $\sim 0.72(0.14)$ & $\sim 2.23(1.06)$ & $8.49(2.90)$ \\
\hline 338.442 & $7_{6,-0 /+0}-6_{6,-0 /+0}$ & 259 & $6.7(-5)$ & $\sim 1.20(0.79)^{:}$ & $\sim 2.29$ (1.27) & $8.80(3.44)$ \\
\hline 338.457 & $7_{-5,0}-6_{-5,0}$ & 189 & $1.2(-4)$ & $1.80(0.66)^{:}$ & $\sim 2.55$ (1.44) & $10.12(3.74)$ \\
\hline 338.475 & $7_{5,0}-6_{5,0}$ & 201 & $1.2(-4)$ & $\sim 1.43(0.94)$ & $\sim 1.89(1.21)$ & $9.22(3.46)$ \\
\hline 338.486 & $7_{5,-0 /+0}-6_{5,-0 /+0}$ & 203 & $1.2(-4)$ & $\sim 2.86(0.94)$ & $>3.40(3.00)$ & $>13.31(5.28)$ \\
\hline 338.504 & $7_{-4,0}-6_{-4,0}$ & 153 & $1.7(-4)$ & $\sim 1.78(0.85)$ & $\sim 3.39(1.88)$ & $>12.14$ (4.99) \\
\hline 338.5126 & $7_{4 / 4,-0 /+0}-6_{4 / 4,-0 /+0}$ & 145 & $1.7(-4)$ & $>2.61(0.94)^{:}$ & $>5.87(1.81)^{:}$ & $>26.88$ (9.59): \\
\hline 338.5129 & $7_{2,-0}-6_{2,-0}$ & 103 & $2.3(-4)$ & $>2.61(0.94)^{:}$ & $>5.87(1.81)^{:}$ & $>26.88(9.59)^{:}$ \\
\hline 338.530 & $7_{4,0}-6_{4,0}$ & 161 & $1.7(-4)$ & $\sim 1.34(0.59)$ & $\sim 3.69(2.22)$ & $11.33(4.40)$ \\
\hline 338.541 & $7_{3,+0 /-0}-6_{3,+0 /-0}$ & 115 & $2.1(-4)$ & $>3.75(1.24)$ & $>8.71(2.71)$ & $>29.00(8.01)$ \\
\hline 338.560 & $7_{-3,0}-6_{-3,0}$ & 128 & $2.1(-4)$ & $\sim 2.14(0.95)$ & $>4.50(1.87)$ & $14.94(4.70)$ \\
\hline 338.583 & $7_{3,0}-6_{3,0}$ & 113 & $2.1(-4)$ & $2.74(1.17)$ & $>4.02(1.61)$ & $18.35(5.14)$ \\
\hline 338.615 & $7_{1,0}-6_{1,0}$ & 86 & $2.5(-4)$ & $4.48(1.33)^{::}$ & $9.01(2.57)::$ & $28.49(6.87)::$ \\
\hline 338.640 & $7_{2,+0}-6_{2,+0}$ & 103 & $2.3(-4)$ & $>2.99(1.07)$ & $>6.46(2.36)$ & $21.12(5.79)$ \\
\hline 338.722 & $7_{2,0}-6_{2,0}$ & 87 & $2.3(-4)$ & $2.60(0.70)::$ & $5.24(1.36)::$ & $17.99(8.33)::$ \\
\hline 338.723 & $7_{-2,0}-6_{-2,0}$ & 91 & $2.3(-4)$ & $2.60(0.70)::$ & $5.24(1.36)::$ & $17.99(8.33)::$ \\
\hline 340.141 & $22_{2,+0}-3_{1,+0}$ & 45 & $4.1(-5)$ & $1.56(0.71)::$ & $3.31(1.04)::$ & $12.35(2.83)::$ \\
\hline $342.730^{a}$ & $13_{1,12,-0}-13_{0,13,+0}$ & 147 & $2.4(-5)$ & - & - & $14.19(3.54)$ \\
\hline 344.971 & $12_{7,1}-11_{6,1}$ & 762 & $1.3(-4)$ & $<0.12$ & - & 2.27 (1.07) \\
\hline 364.159 & $9_{3,1}-9_{2,1}$ & 522 & $6.5(-5)$ & $\sim 0.20(0.41)$ & $2.97(1.10)^{:}$ & $2.66(0.77)$ \\
\hline \multicolumn{7}{|l|}{${ }^{13} \mathrm{CH}_{3} \mathrm{OH}$} \\
\hline 222.468 & $21_{1,20,0}-21_{0,21,0}$ & 544 & $3.6(-5)$ & $<0.23$ & $<0.32$ & $<0.59$ \\
\hline 225.404 & $16_{2,14,0}-15_{3,12,0}$ & 331 & $2.0(-5)$ & $<0.19$ & $<0.45(0.35)^{:}$ & $<3.49(1.55)^{:}$ \\
\hline 338.760 & $13_{0,13,+0}-12_{1,12,+0}$ & 206 & $2.2(-4)$ & $<0.20$ & $<0.39$ & $\sim 5.55(2.36)$ \\
\hline $341.132^{a}$ & $13_{1,12,-0}-13_{0,13,+0}$ & 211 & $2.4(-5)$ & - & - & $3.55(2.22)$ \\
\hline 345.084 & $2_{2,0,+0}-3_{1,3,+0}$ & 45 & $2.9(-5)$ & $<0.29$ & $<0.24$ & $<1.69(0.77)^{:}$ \\
\hline 345.133 & $4_{0,4,0}-3_{-1,3,0}$ & 36 & $8.2(-5)$ & $<0.29$ & $1.81(0.70)$ & $4.06(1.25)$ \\
\hline 354.446 & $4_{1,3,0}-3_{0,3,0}$ & 44 & $1.3(-4)$ & $<0.18$ & $1.68(0.65)$ & $6.32(1.59)$ \\
\hline 363.924 & $14_{3,12,1}-14_{2,13,1}$ & 655 & $4.7(-5)$ & $<0.24$ & $<2.06(0.94)^{:}$ & $<1.40(0.92)$ \\
\hline
\end{tabular}

Notes. The notation $a(-b)$ stands for $a \times 10^{-b} .{ }^{(a)}$ From additional observations on G31 only. ${ }^{(b)}$ Line close to the edge of the frequency band. ${ }^{(c)}$ Used to constrain the RTD fit. $>$ Means lower limit (optically thick line). $<$ Means upper limit. $\sim$ Means uncertain detection, $S / N \lesssim 2 .-$ Means frequency not observed. : Means blended frequency. :: Cold $\left(E_{\text {up }}<100 \mathrm{~K}\right) \mathrm{CH}_{3} \mathrm{OH}$ line (treated as a blend with cold component). $\left.{ }^{*}\right)$ Calculated flux (see Eq. (4)). 
K. Isokoski et al.: Chemistry of massive young stellar objects with a disk-like structure

Table A.3. Observed line fluxes $\int T_{\mathrm{MB}} \mathrm{d} V\left(\mathrm{~K} \mathrm{~km} \mathrm{~s}^{-1}\right)$ for $\mathrm{C}_{2} \mathrm{H}_{5} \mathrm{OH}$.

\begin{tabular}{|c|c|c|c|c|c|c|}
\hline $\begin{array}{l}\text { Frequency } \\
{[\mathrm{GHz}]}\end{array}$ & Transition & $\begin{array}{l}E_{\text {up }} \\
{[\mathrm{K}]}\end{array}$ & $\begin{array}{c}A \\
{\left[\mathrm{~s}^{-1}\right]}\end{array}$ & $\begin{array}{l}\text { Sources } \\
\text { IRAS 20126+4104 }\end{array}$ & IRAS 18089-1732 & $\mathrm{G} 31.41+0.31$ \\
\hline \multicolumn{7}{|l|}{$\mathrm{C}_{2} \mathrm{H}_{5} \mathrm{OH}$} \\
\hline 218.461 & $5_{3,2,2}-4_{2,3,2}$ & 24 & $6.6(-5)$ & - & - & $<2.60(0.52)$ \\
\hline 218.554 & $21_{5,16,2}-21_{4,17,2}$ & 226 & $6.2(-5)$ & - & - & $\sim 0.77(0.65)$ \\
\hline 222.217 & $20_{5,15,2}-20_{4,16,2}$ & 208 & $6.5(-5)$ & $<0.22$ & $\sim 0.56(0.59)$ & $<1.29$ (0.26): \\
\hline 222.419 & $20_{4,17,1}-19_{5,15,0}$ & 256 & $1.1(-5)$ & $<0.22$ & $<0.34(0.30)$ : & $<1.18(0.24)$ : \\
\hline 222.519 & $26_{4,23,2}-26_{3,24,2}$ & 316 & $6.7(-5)$ & $<0.22$ & $<0.27$ & $\sim 0.26(0.24)$ \\
\hline 225.105 & $13_{10,3 / 4,0}-12_{10,2 / 3,0}$ & 255 & $4.2(-5)$ & $<0.19$ & $<0.25$ & $\sim 0.66(0.42)$ \\
\hline 225.108 & $13_{11,2 / 3,0}-12_{11,1 / 2,0}$ & 280 & $2.9(-5)$ & $<0.19$ & $<0.25$ & $\sim 0.40(0.42)$ \\
\hline 225.110 & $13_{6,8 / 7,1}-12_{6,7 / 6,1}$ & 181 & $8.0(-5)$ & $<0.19$ & $<0.25$ & $1.12(0.42)$ \\
\hline 225.112 & $13_{9,5 / 4,0}-12_{9,4 / 3,0}$ & 231 & $5.3(-5)$ & $<0.19$ & $<0.25$ & $\sim 0.74(0.42)$ \\
\hline 225.116 & $13_{12,1 / 2,0}-12_{12,0 / 1,0}$ & 308 & $1.5(-5)$ & $<0.25$ & $<0.25$ & $<0.55(0.43)$ \\
\hline 225.131 & $13_{8,5 / 6,0}-12_{8,4 / 5,0}$ & 211 & $6.4(-5)$ & $<0.19$ & $<0.25$ & $\sim 1.16(1.12)$ \\
\hline 225.171 & $13_{7,6 / 7,0}-12_{7,5 / 6,0}$ & 192 & $7.3(-5)$ & $<0.19$ & $<0.25$ & $\sim 1.86(0.84)$ \\
\hline 225.210 & $19_{5,14,2}-19_{4,15,2}$ & 191 & $6.7(-5)$ & $<0.19$ & $<0.25$ & $\sim 1.98(1.05)$ \\
\hline 225.229 & $17_{2,15,2}-16_{3,14,2}$ & 137 & $2.5(-5)$ & $<0.19$ & $\sim 0.37(0.24)$ & $<2.76(0.55)$ \\
\hline 225.249 & $13_{6,8 / 7,0}-12_{6,7 / 8,0}$ & 176 & $8.1(-5)$ & $<0.19$ & $\sim 0.40(0.30)$ & ح2.34 (0.93) \\
\hline 225.279 & $13_{5,9,1}-12_{5,8,1}$ & 168 & $8.7(-5)$ & $<0.19$ & $<0.25$ & $\sim 1.61(0.77)^{*}$ \\
\hline 225.283 & $13_{5,8,1}-12_{5,7,1}$ & 168 & $8.7(-5)$ & $<0.19$ & $<0.25$ & $\sim 1.61(0.77)^{*}$ \\
\hline 225.400 & $13_{5,9,0}-12_{5,8,0}$ & 163 & $8.7(-5)$ & $<0.19$ & $\sim 0.13(0.15)$ & $0.74(0.32)^{*}$ \\
\hline 225.404 & $13_{5,8,0}-12_{5,7,0}$ & 163 & $8.7(-5)$ & $<0.19$ & $\sim 0.13(0.15)$ & $0.74(0.32)^{*}$ \\
\hline 225.457 & $13_{3,11,1}-12_{3,10,1}$ & 148 & $9.7(-5)$ & $<0.19$ & $<0.25$ & $\sim 0.95(0.48)$ \\
\hline 238.841 & $21_{2,19,0}-21_{1,21,1}$ & 258 & $4.8(-5)$ & - & $<0.22$ & $<2.28(0.46)$ \\
\hline 239.020 & $28_{4,25,2}-27_{5,22,2}$ & 362 & $2.9(-5)$ & $<0.21$ & $<0.22$ & $<4.79$ (0.96): \\
\hline 239.186 & $16_{0,16,1}-15_{1,14,0}$ & 171 & $4.4(-5)$ & $<0.21$ & $<0.22$ & $<0.92(0.18)$ \\
\hline 240.654 & $4_{2,2,1}-3_{1,2,0}$ & 75 & $4.1(-5)$ & - & $<0.22$ & - \\
\hline 240.782 & $15_{2,13,0}-14_{1,13,1}$ & 163 & $2.9(-5)$ & $<0.2$ & $<0.23$ & $<3.38(0.68)$ \\
\hline 240.839 & $14_{1,13,0}-13_{0,13,1}$ & 147 & $5.1(-5)$ & $<0.20$ & $\sim 0.20(0.33)$ & $\sim 0.85(0.52)$ \\
\hline 330.985 & $6_{3,4,1}-5_{2,4,0}$ & 90 & $1.2(-4)$ & $<0.31$ & - & $\sim 1.46(0.84)$ \\
\hline 331.027 & $13_{5,8,1}-13_{4,10,0}$ & 168 & $1.1(-4)$ & $<0.29$ & $<0.29$ & $<1.84$ (0.37): \\
\hline 331.079 & $43_{7,37,2}-43_{6,38,2}$ & 860 & $2.2(-4)$ & $<0.29$ & $\sim 0.36(0.39)$ & $\sim 0.15(0.22)$ \\
\hline 331.095 & $27_{7,20,2}-27_{6,21,2}$ & 380 & $2.1(-4)$ & $<0.29$ & $<0.29$ & $\sim 0.33(0.55)$ \\
\hline 338.088 & $25_{1,24,1}-24_{2,22,0}$ & 332 & $5.9(-5)$ & - & - & 〜3.64 (1.99) \\
\hline 338.099 & $18_{7,11,2}-18_{6,12,2}$ & 205 & $2.1(-4)$ & - & - & $\sim 2.05(1.54)^{*}$ \\
\hline 338.110 & $18_{7,12,2}-18_{6,13,2}$ & 205 & $2.1(-4)$ & - & - & $\sim 2.05(1.54)^{*}$ \\
\hline 338.163 & $10_{2,8,1}-9_{1,8,0}$ & 113 & $8.6(-5)$ & - & - & $2.05(0.98)$ \\
\hline 338.412 & $17_{7,10,2}-17_{6,11,2}$ & 190 & $2.1(-4)$ & $<4.41(1.31)$ & $<13.78$ (3.29): & $<21.70(5.13)$ \\
\hline 338.417 & $17_{7,11,2}-17_{6,12,2}$ & 190 & $2.1(-4)$ & $<4.41(1.31)$ & $<0.71$ & $<21.70(5.13)$ \\
\hline 338.672 & $16_{7,9,2}-16_{6,10,2}$ & 176 & $2.0(-4)$ & $<0.32$ & $<0.83$ & $1.63(0.85)^{*}$ \\
\hline 338.674 & $16_{7,10,2}-16_{6,11,2}$ & 176 & $2.0(-4)$ & $<0.32$ & $<0.83$ & $1.63(0.85)^{*}$ \\
\hline 339.979 & $9_{4,6,2}-8_{3,5,2}$ & 58 & $2.2(-4)$ & $<0.15$ & $\sim 0.55(0.47)$ & $3.23(0.93)$ \\
\hline 345.174 & $7_{7,0 / 1,0}-6_{6,0 / 1,1}$ & 140 & $2.5(-4)$ & $<0.26$ & $\sim 1.16(0.70)$ & $\sim 2.28$ (1.56) \\
\hline 345.229 & $21_{1,21,0}-20_{1,20,0}$ & 242 & $3.7(-4)$ & $<0.29$ & $\sim 0.58(0.37)$ & $<5.52$ (1.10): \\
\hline 345.295 & $21_{1,21,1}-20_{1,20,1}$ & 246 & $3.7(-4)$ & $<0.29$ & $\sim 1.03(1.00)$ & $\sim 2.91(1.31)$ \\
\hline 345.312 & $22_{3,19,1}-21_{4,17,0}$ & 286 & $5.0(-5)$ & $<0.29$ & $<0.19$ & $<0.39$ \\
\hline 345.333 & $21_{0,21,0}-20_{0,20,0}$ & 242 & $3.7(-4)$ & $<0.29$ & $<6.54$ (1.31): & $<17.35$ (3.47): \\
\hline 345.408 & $21_{0,21,1}-20_{0,20,1}$ & 246 & $3.7(-4)$ & $<0.29$ & $\sim 0.75(0.47)$ & $\sim 2.47$ (1.13) \\
\hline 352.858 & $21_{1,20,2}-20_{2,19,2}$ & 196 & $1.2(-4)$ & $<0.18$ & $\sim 0.51(0.43)$ & $\sim 1.56(0.78)$ \\
\hline 353.034 & $12_{3,9,2}-11_{2,10,2}$ & 77 & $1.9(-4)$ & $<0.16$ & $\sim 0.61(0.59)$ & $3.12(1.00)$ \\
\hline 354.758 & $20_{3,17,1}-19_{3,16,1}$ & 249 & $4.0(-4)$ & $<0.18$ & $\sim 0.59(0.52)$ & $3.96(1.05)$ \\
\hline 363.968 & $21_{7,15 / 14,1}-20_{7,14 / 13,1}$ & 314 & $3.9(-4)$ & $<0.22$ & $\sim 0.64(0.44)$ & $2.66(1.02)$ \\
\hline 364.001 & $21_{8,14 / 13,0}-20_{8,13 / 12,0}$ & 327 & $3.7(-4)$ & $<0.22$ & $\sim 0.70(0.48)$ & $2.28(0.80)$ \\
\hline 364.233 & $21_{7,15 / 14,0}-20_{7,14 / 13,0}$ & 309 & $3.9(-4)$ & $<0.24$ & $\sim 0.64(0.56)$ & $\sim 1.94(1.48)$ \\
\hline
\end{tabular}

Notes. The notation $a(-b)$ stands for $a \times 10^{-b}$. $<$ Means upper limit. $\sim$ Means uncertain detection, $S / N \lesssim 2 .-$ Means frequency not observed. : Means blended line. ${ }^{*}$ Calculated flux (see Eq. (4)). 
A\&A 554, A100 (2013)

Table A.4. Observed line fluxes $\int T_{\mathrm{MB}} \mathrm{d} V\left(\mathrm{~K} \mathrm{~km} \mathrm{~s}^{-1}\right)$ for $\mathrm{HNCO}$ and its isotopic species.

\begin{tabular}{|c|c|c|c|c|c|c|}
\hline $\begin{array}{l}\text { Frequency } \\
{[\mathrm{GHz}]}\end{array}$ & Transition & $\begin{array}{l}E_{\text {up }} \\
{[\mathrm{K}]}\end{array}$ & $\begin{array}{c}A \\
{\left[\mathrm{~s}^{-1}\right]}\end{array}$ & $\begin{array}{l}\text { Sources } \\
\text { IRAS 20126+4104 }\end{array}$ & IRAS 18089-1732 & $\mathrm{G} 31.41+0.31$ \\
\hline \multicolumn{7}{|l|}{$\mathrm{HNCO}$} \\
\hline 219.657 & $10_{3,8 / 7,9 / 11 / 10}-9_{3,7 / 6,9 / 10 / 8}$ & 447 & $1.4(-4)$ & $<1.33$ & $<0.73(0.70):$ & $<1.52(0.63):$ \\
\hline 219.736 & $10_{2,9 / 8,9 / 11 / 10}-9_{2,8 / 7,9 / 10 / 8}$ & 231 & $1.4(-4)$ & $<0.28$ & $<0.84(0.75)$ & $\sim 0.64(0.91)$ \\
\hline 219.798 & $10_{0,10,9 / 11 / 10}-9_{0,9,9 / 10 / 8}$ & 58 & $1.5(-4)$ & $<0.28$ & $1.31(0.50)$ & $1.22(0.55)$ \\
\hline 240.876 & $11_{1,11,10 / 12 / 11}-10_{1,10,10 / 11 / 9}$ & 113 & $2.0(-4)$ & $<0.20$ & $<0.82(0.54)$ & $<3.10(0.93):$ \\
\hline 330.849 & $15_{1,14,14 / 16 / 15}-14_{1,13,14 / 15 / 13}$ & 170 & $5.2(-4)$ & $\sim 0.32(0.31)$ & $<1.53(0.71)$ & $2.01(0.71)$ \\
\hline 352.898 & $16_{1,15,15 / 17 / 16}-15_{1,14,15 / 16 / 14}$ & 187 & $6.3(-4)$ & $<0.18$ & $\sim 1.84(1.00)$ & $<3.12(1.02):$ \\
\hline \multicolumn{7}{|l|}{$\mathrm{HN}^{13} \mathrm{CO}$} \\
\hline 219.664 & $10_{3,8 / 7,10}-9_{3,7 / 6,10}$ & 47 & $1.4(-4)$ & $<1.32$ & $<0.21$ & $<0.41$ \\
\hline 219.740 & $10_{2911 / 9 / 10}-9_{2810 / 8 / 9}$ & 31 & $1.4(-4)$ & $<0.28$ & $<0.24$ & $<0.26$ \\
\hline 219.744 & $10_{2,8,11 / 9 / 10}-9_{2,7,10 / 8 / 9}$ & 31 & $1.4(-4)$ & $<0.28$ & $<0.24$ & $<0.26$ \\
\hline 219.804 & $10_{0,10,10 / 9 / 8}-9_{0,9,10 / 9 / 8}$ & 58 & $1.5(-4)$ & $<0.28$ & $<0.24$ & $<0.63$ \\
\hline 240.881 & $11_{11,11,12 / 11 / 10}-10_{10,11,11 / 10 / 9}$ & 113 & $2.0(-4)$ & $<0.20$ & $<0.23$ & $<0.98$ \\
\hline 330.860 & $15_{1,14,16 / 14 / 15}-14_{1,13,15 / 13 / 14}$ & 170 & $5.2(-4)$ & $<0.31$ & $<0.32$ & $<0.31$ \\
\hline
\end{tabular}

Notes. The notation $a(-b)$ stands for $a \times 10^{-b}$. $<$ Means upper limit. $\sim$ Means uncertain detection, $S / N \lesssim 2$. - Means frequency not observed. : Means blended line.

Table A.5. Observed line fluxes $\int T_{\mathrm{MB}} \mathrm{d} V\left(\mathrm{~K} \mathrm{~km} \mathrm{~s}^{-1}\right)$ for $\mathrm{NH}_{2} \mathrm{CHO}$.

\begin{tabular}{llrcccc}
\hline \hline $\begin{array}{l}\text { Frequency } \\
\text { [GHz] }\end{array}$ & Transition & $\begin{array}{c}E_{\text {up }} \\
{[\mathrm{K}]}\end{array}$ & $\begin{array}{c}A \\
{\left[\mathrm{~s}^{-1}\right]}\end{array}$ & $\begin{array}{l}\text { Sources } \\
\text { IRAS 20126+4104 }\end{array}$ & IRAS 18089-1732 & G31.41+0.31 \\
\hline $\mathrm{NH}_{2} \mathrm{CHO}$ & & & & & & \\
\hline 218.460 & $10_{10,1,9}-9_{9,1,8}$ & 61 & $7.5(-4)$ & - & $<$ & $<2.45(0.49):$ \\
339.716 & $16_{16,8,8 / 9}-15_{15,8,7 / 8}$ & 329 & $2.2(-3)$ & $<0.15$ & $<0.17$ & $<4.04(0.81):$ \\
339.781 & $16_{16,7,10 / 9}-15_{15,7,9 / 8}$ & 284 & $2.3(-3)$ & $\sim 0.74(0.42)$ & $\sim 0.29(0.29)$ & $<2.66(1.20):$ \\
339.904 & $16_{16,6,11 / 10}-15_{15,6,10 / 9}$ & 246 & $2.5(-3)$ & $<0.89(0.39):$ & $\sim 0.48(0.30)$ & $\sim 1.41(0.76)$ \\
340.135 & $16_{16,5,12}-15_{15,5,11}$ & 213 & $2.6(-3)$ & $<0.78(0.16):$ & $<1.40(0.28):$ & $<1.11(0.22):$ \\
340.139 & $16_{16,5,11}-15_{15,5,10}$ & 213 & $2.6(-3)$ & $<0.78(0.16):$ & $<1.40(0.28):$ & $<1.11(0.22):$ \\
345.183 & $17_{17,0,17}-16_{16,0,16}$ & 151 & $3.0(-3)$ & $<0.20$ & $1.16(0.53)$ & $2.42(0.94)$ \\
345.327 & $16_{16,1,15}-15_{15,1,14}$ & 145 & $3.0(-3)$ & $<0.43$ & $<1.87(0.37):$ & $<5.46(1.09):$ \\
\hline
\end{tabular}

Notes. The notation $a(-b)$ stands for $a \times 10^{-b} .<$ Means upper limit. $\sim$ Means uncertain detection, $S / N \lesssim 2 .-$ Means frequency not observed. : Means blended line. 
K. Isokoski et al.: Chemistry of massive young stellar objects with a disk-like structure

Table A.6. Observed line fluxes $\int T_{\mathrm{MB}} \mathrm{d} V\left(\mathrm{~K} \mathrm{~km} \mathrm{~s}^{-1}\right)$ for $\mathrm{CH}_{3} \mathrm{CN}$ and its isotopic species.

\begin{tabular}{|c|c|c|c|c|c|c|}
\hline $\begin{array}{l}\text { Frequency } \\
\text { [GHz] }\end{array}$ & Transition & $\begin{array}{l}E_{\mathrm{up}} \\
{[\mathrm{K}]}\end{array}$ & $\begin{array}{c}A \\
{\left[\mathrm{~s}^{-1}\right]}\end{array}$ & $\begin{array}{l}\text { Sources } \\
\text { IRAS 20126+4104 }\end{array}$ & IRAS 18089-1732 & $\mathrm{G} 31.41+0.31$ \\
\hline \multicolumn{7}{|l|}{$\mathrm{CH}_{3} \mathrm{CN}$} \\
\hline 238.844 & $13_{8}-12_{8}$ & 537 & $5.0(-4)$ & - & $<0.22$ & $<0.17$ \\
\hline 238.913 & $13_{7}-12_{7}$ & 430 & $5.8(-4)$ & $<0.21$ & $\sim 0.37(0.27)$ & $1.82(0.62)$ \\
\hline 238.972 & $13_{6}-12_{6}$ & 337 & $6.4(-4)$ & $\sim 0.33(0.38)$ & $\sim 0.84(0.37)$ & $3.22(1.11)$ \\
\hline 239.023 & $13_{5}-12_{5}$ & 259 & $6.9(-4)$ & 0.93 (0.49) & $<6.43$ (1.29): & $3.19(0.88)$ \\
\hline 239.064 & $13_{4}-12_{4}$ & 195 & $7.4(-4)$ & $\sim 0.51(0.38)$ & $1.17(0.45)$ & $5.25(1.44)$ \\
\hline 239.096 & $13_{3}-12_{3}$ & 145 & $7.7(-4)$ & $1.04(0.40)$ & $1.64(0.55)$ & $5.21(1.37)$ \\
\hline 239.120 & $13_{2}-12_{2}$ & 109 & $7.9(-4)$ & $\sim 0.63(0.38)$ & $1.80(0.61)$ & $5.71(1.37)$ \\
\hline 239.133 & $13_{1}-12_{1}$ & 87 & $8.1(-4)$ & $0.73(0.26)^{*}$ & $1.72(0.52)^{*}$ & $4.56(1.19)$ \\
\hline 239.138 & $13_{0}-12_{0}$ & 80 & $8.1(-4)$ & $0.73(0.26)^{*}$ & $1.72(0.52)^{*}$ & $4.60(1.15)$ \\
\hline 330.843 & $18_{6}-17_{6}$ & 408 & $1.9(-3)$ & $\sim 0.31(0.26)$ & $4.63(1.28)$ & $7.44(2.20)$ \\
\hline 330.913 & $18_{5}-17_{5}$ & 329 & $2.0(-3)$ & - & $3.59(1.13)$ & $5.91(1.87)$ \\
\hline 330.970 & $18_{4}-17_{4}$ & 265 & $2.1(-3)$ & - & $2.81(0.78)$ & $6.70(2.07)$ \\
\hline 331.014 & $18_{3}-17_{3}$ & 215 & $2.1(-3)$ & - & $4.66(1.30)$ & $8.26(2.38)$ \\
\hline 331.046 & $18_{2}-17_{2}$ & 180 & $2.2(-3)$ & - & $4.51(1.31)$ & $10.24(2.87)$ \\
\hline 331.065 & $18_{1}-17_{1}$ & 158 & $2.2(-3)$ & - & $4.01(1.09)^{*}$ & $6.25(1.96)$ \\
\hline 331.072 & $18_{0}-17_{0}$ & 151 & $2.2(-3)$ & - & $4.01(1.09)^{*}$ & $7.86(2.30)$ \\
\hline \multicolumn{7}{|l|}{$\mathrm{CH}_{3}{ }^{13} \mathrm{CN}$} \\
\hline 238.855 & $13_{6}-12_{6}$ & 337 & $9.2(-4)$ & - & $<0.22$ & $<10.23(2.58):$ \\
\hline 238.905 & $13_{5}-12_{5}$ & 259 & $1.0(-3)$ & $<0.21$ & $<0.22$ & $<1.00(0.48):$ \\
\hline 238.946 & $13_{4}-12_{4}$ & 195 & $1.1(-3)$ & $<0.21$ & $<0.22$ & $2.21(0.70)$ \\
\hline 238.978 & $13_{3}-12_{3}$ & 145 & $1.1(-3)$ & $<0.21$ & $\sim 0.35(0.31)$ & $1.51(0.58)$ \\
\hline 239.001 & $13_{2}-12_{2}$ & 109 & $1.2(-3)$ & $<0.21$ & $<0.22$ & 0.62 (0.35) \\
\hline 239.015 & $13_{1}-12_{1}$ & 87 & $1.2(-3)$ & $<0.21$ & $<0.22$ & $4.61(0.97)^{*}$ \\
\hline 239.020 & $13_{0}-12_{0}$ & 80 & $1.2(-3)$ & $<0.21$ & $<0.22$ & $4.61(0.97)^{*}$ \\
\hline 330.806 & $18_{4}-17_{4}$ & 265 & $3.0(-3)$ & $<0.31$ & $<0.32$ & $<8.08(2.52):$ \\
\hline 330.851 & $18_{3}-17_{3}$ & 215 & $3.1(-3)$ & $<0.31$ & $<2.66(0.53):$ & $<4.12(1.23):$ \\
\hline 330.882 & $18_{2}-17_{2}$ & 179 & $3.1(-3)$ & $<0.31$ & $<0.32$ & 0.69 (0.49) \\
\hline 330.901 & $18_{1}-17_{1}$ & 158 & $3.2(-3)$ & $<0.31$ & $<1.49(0.30):$ & $2.37(0.93)$ \\
\hline 330.908 & $18_{0}-17_{0}$ & 151 & $3.2(-3)$ & $<0.31$ & $<1.49(0.30):$ & $3.48(1.12)$ \\
\hline
\end{tabular}

Notes. The notation $a(-b)$ stands for $a \times 10^{-b}$. $<$ Means upper limit. $\sim$ Means uncertain detection, $S / N \lesssim 2$. - Means frequency not observed. : Means blended line. * Calculated flux (see Eq. (4)).

Table A.7. Observed line fluxes $\int T_{\mathrm{MB}} \mathrm{d} V\left(\mathrm{~K} \mathrm{~km} \mathrm{~s}^{-1}\right)$ for $\mathrm{C}_{2} \mathrm{H}_{5} \mathrm{CN}$.

\begin{tabular}{llrcccc}
\hline \hline $\begin{array}{l}\text { Frequency } \\
\text { [GHz] }\end{array}$ & Transition & $\begin{array}{r}E_{\text {up }} \\
{[\mathrm{K}]}\end{array}$ & $\begin{array}{c}A \\
{\left[\mathrm{~s}^{-1}\right]}\end{array}$ & $\begin{array}{l}\text { Sources } \\
\text { IRAS 20126+4104 }\end{array}$ & IRAS 18089-1732 & G31.41+0.31 \\
\hline $\mathrm{C}_{2} \mathrm{H}_{5} \mathrm{CN}$ & & & \multicolumn{7}{c}{} & \\
\hline 218.390 & $24_{3,21}-23_{3,20}$ & 140 & $8.7(-4)$ & $<0.18$ & - & $\sim 1.03(0.45)$ \\
219.903 & $12_{3,10}-11_{2,9}$ & 44 & $3.0(-5)$ & $<0.28$ & $<0.24$ & $\sim 0.18(0.13)$ \\
225.236 & $25_{4,21}-24_{4,20}$ & 158 & $9.4(-4)$ & $<0.00$ & $\sim 0.53(0.36)$ & $2.53(0.85)$ \\
225.307 & $12_{3,9}-11_{2,10}$ & 44 & $3.2(-5)$ & $<0.19$ & $<0.25$ & $<1.46(0.57):$ \\
225.317 & $23_{2,22}-22_{1,21}$ & 122 & $4.8(-5)$ & $<0.19$ & $<0.25$ & $<1.79(0.65):$ \\
240.699 & $16_{9,7 / 8}-17_{8,10 / 9}$ & 148 & $7.9(-6)$ & $<0.20$ & $<0.48(0.10):$ & $<0.89(0.46):$ \\
240.861 & $28_{1,28}-27_{0,27}$ & 169 & $1.0(-4)$ & $<0.20$ & $<0.27(0.05):$ & $\sim 0.78(0.37)$ \\
338.143 & $37_{3,34}-36_{3,33}$ & 317 & $3.3(-3)$ & - & - & $5.74(2.44)$ \\
339.895 & $39_{2,38}-38_{2,37}$ & 334 & $3.3(-3)$ & $<0.15$ & $\sim 0.38(0.68)$ & $3.45(1.05)$ \\
339.968 & $38_{2,36}-37_{2,35}$ & 327 & $3.3(-3)$ & $<0.15$ & $\sim 0.50(0.32)$ & $2.20(0.69)$ \\
340.149 & $39_{1,38}-38_{1,37}$ & 334 & $3.3(-3)$ & $<0.15$ & $\sim 0.26(0.17)$ & $2.20(0.82)$ \\
352.992 & $21_{2,19}-20_{1,20}$ & 105 & $1.4(-5)$ & $<0.13$ & $<0.24$ & $<0.19$ \\
353.089 & $23_{3,20}-22_{2,21}$ & 129 & $5.8(-5)$ & $<0.16$ & $<0.24$ & $\sim 0.58(0.29)$ \\
354.477 & $40_{3,38}-39_{3,37}$ & 361 & $3.8(-3)$ & $<0.18$ & $<3.38(0.68):$ & $1.33(0.65)$ \\
\hline
\end{tabular}

Notes. The notation $a(-b)$ stands for $a \times 10^{-b}$. $<$ Means upper limit. $\sim$ Means uncertain detection, $S / N \lesssim 2$. - Means frequency not observed. : Means blended line. 
Table A.8. Observed line fluxes $\int T_{\mathrm{MB}} \mathrm{d} V\left(\mathrm{~K} \mathrm{~km} \mathrm{~s}^{-1}\right)$ for $\mathrm{HCOOCH}_{3}$.

\begin{tabular}{|c|c|c|c|c|c|c|}
\hline $\begin{array}{l}\text { Frequency } \\
{[\mathrm{GHz}]}\end{array}$ & Transition & $\begin{array}{l}E_{\text {up }} \\
{[\mathrm{K}]}\end{array}$ & $\begin{array}{c}A \\
{\left[\mathrm{~s}^{-1}\right]}\end{array}$ & $\begin{array}{l}\text { Sources } \\
\text { IRAS 20126+4104 }\end{array}$ & IRAS 18089-1732 & $\mathrm{G} 31.41+0.31$ \\
\hline \multicolumn{7}{|l|}{$\mathrm{HCOOCH}_{3}$} \\
\hline 218.281 & $17_{3,14,2}-16_{3,13,2}$ & 100 & $1.5(-4)$ & $<0.18$ & - & $1.38(0.42)$ \\
\hline 218.298 & $17_{3,14,0}-16_{3,13,0}$ & 100 & $1.5(-4)$ & $<0.18$ & - & $1.00(0.430)$ \\
\hline 219.584 & $18_{13,5 / 6,3}-17_{13,4 / 5,3}$ & 401 & $7.7(-5)$ & $<1.33$ & - & $\sim 0.17(0.15)$ \\
\hline 219.592 & $28_{9,19,2}-28_{8,20,2}$ & 295 & $1.6(-5)$ & $<1.33$ & - & $\sim 0.30(0.22)$ \\
\hline 219.623 & $18_{12,6 / 7,3}-17_{12,5 / 6,3}$ & 384 & $8.9(-5)$ & $<1.33$ & - & $\sim 0.66(0.32)$ \\
\hline 219.642 & $18_{13,6,4}-17_{13,5,4}$ & 401 & $7.7(-5)$ & $<1.33$ & $<0.21$ & $\sim 0.55(0.43)$ \\
\hline 219.696 & $18_{11,8 / 7,3}-17_{11,7 / 6,3}$ & 369 & $1.0(-4)$ & $<0.28$ & $<0.21$ & $0.69(0.25)$ \\
\hline 219.705 & $18_{4,15,3}-17_{4,14,3}$ & 300 & $1.5(-4)$ & $<0.28$ & $<0.21$ & $0.77(0.27)$ \\
\hline 219.764 & $18_{9,9,5}-17_{9,8,5}$ & 342 & $1.2(-4)$ & $<0.28$ & $<0.21$ & $0.61(0.24)$ \\
\hline 219.822 & $18_{10,9 / 8,3}-17_{10,8 / 7,3}$ & 355 & $1.1(-4)$ & $<0.28$ & $<0.21$ & $<1.10(0.55):$ \\
\hline 222.149 & $18_{6,12,3}-17_{6,11,3}$ & 312 & $1.5(-4)$ & $<0.22$ & $1.25(0.25):$ & $<3.05(0.83)$ \\
\hline 222.177 & $18_{6,12,5}-17_{6,11,5}$ & 312 & $1.5(-4)$ & $<0.18$ & $<0.20$ & $\sim 1.14(0.67)$ \\
\hline 222.421 & $18_{8,10,2}-17_{8,9,2}$ & 144 & $1.3(-4)$ & $<0.22$ & $<1.32(0.26):$ & $1.62(0.45)$ \\
\hline 222.438 & $18_{8,11,0}-17_{8,10,0}$ & 144 & $1.3(-4)$ & $<0.22$ & $0.35(0.16)^{*}$ & $1.07(0.39)^{*}$ \\
\hline 222.440 & $18_{8,10,0}-17_{8,9,0}$ & 144 & $1.3(-4)$ & $<0.22$ & $0.35(0.16)^{*}$ & $1.07(0.39)^{*}$ \\
\hline 222.442 & $18_{8,11,1}-17_{8,10,1}$ & 144 & $1.3(-4)$ & $<0.22$ & $0.35(0.16)^{*}$ & $1.07(0.39)^{*}$ \\
\hline 225.372 & $20_{21,9,3}-19_{21,8,3}$ & 307 & $1.7(-4)$ & $<0.19$ & $<0.31$ & $1.38(0.56)$ \\
\hline 225.449 & $20_{11,9,3}-19_{11,8,3}$ & 307 & $1.7(-4)$ & $<0.19$ & $<0.18$ & $<1.30(0.55)$ \\
\hline 238.927 & $20_{3,18,1}-19_{2,17,2}$ & 128 & $2.1(-5)$ & $<0.21$ & $<0.22$ & $\sim 0.40(0.23)$ \\
\hline 238.933 & $20_{3,18,0}-19_{2,17,0}$ & 128 & $2.1(-5)$ & $<0.21$ & $<0.22$ & $\sim 0.47(0.20)$ \\
\hline 238.947 & $19_{3,16,5}-18_{3,15,5}$ & 309 & $2.0(-4)$ & $<0.21$ & $\sim 0.29(0.26)$ & $<0.88(0.38)$ : \\
\hline 239.111 & $7_{6,2,4}-6_{5,2,4}$ & 227 & $2.7(-5)$ & $<0.21$ & $<0.22$ & $<0.15(0.17)$ \\
\hline 241.059 & $30_{3,27,0}-30_{3,28,0}$ & 281 & $5.8(-6)$ & - & $<0.23$ & $\sim 0.33(0.31)$ \\
\hline 241.068 & $30_{3,27,0}-30_{2,28,0}$ & 281 & $1.1(-5)$ & - & $<0.23$ & $\sim 0.76(0.53)$ \\
\hline 330.941 & $30_{2 / 1,29,4 / 5}-29_{2 / 1,28,4 / 5}$ & 443 & $5.5(-4)$ & $<0.31$ & $\sim 0.73(0.38)$ & $\sim 0.75(0.83)$ \\
\hline 331.021 & $25_{5,21,0}-24_{4,20,0}$ & 210 & $3.5(-5)$ & $<0.34$ & $<0.40$ & $<8.29(1.66)$ : \\
\hline 331.036 & $25_{5,21,1}-24_{4,20,2}$ & 210 & $3.5(-5)$ & $<0.32$ & $<0.34$ & $<10.01(3.05):$ \\
\hline 331.121 & $27_{12,16,4}-26_{12,15,4}$ & 505 & $4.5(-4)$ & $<0.29$ & - & $<0.74(0.69)$ \\
\hline 331.149 & $28_{4,25,1}-27_{4,24,1}$ & 248 & $5.3(-4)$ & $<0.29$ & $0.69(0.31)$ & $2.60(1.39)$ \\
\hline 331.160 & $28_{4,25,0}-27_{4,24,0}$ & 248 & $5.3(-4)$ & $<0.29$ & $<0.99(0.42)$ & $<2.24(1.15)$ \\
\hline 331.161 & $27_{11,17 / 16,3}-26_{11,16 / 15,3}$ & 490 & $4.6(-4)$ & $<0.29$ & $<0.99(0.42)$ : & $<2.24(1.15)$ \\
\hline 338.338 & $27_{8,19,2}-26_{8,18,2}$ & 267 & $5.4(-4)$ & $<0.26$ & $<0.39$ & $6.26(2.37)$ \\
\hline 338.356 & $27_{8,19,0}-26_{8,18,0}$ & 267 & $5.4(-4)$ & $<0.23$ & $<0.44$ & $5.09(2.08)$ \\
\hline 338.393 & $28_{5,24,3}-27_{5,23,3}$ & 443 & $5.7(-4)$ & $<0.23$ & $<0.43$ & $<3.80(2.05)$ : \\
\hline 338.396 & $27_{7,21,1}-26_{7,20,1}$ & 258 & $5.5(-4)$ & $<0.23$ & $<0.45$ & $<3.80$ (2.05): \\
\hline 338.414 & $27_{7,21,0}-26_{7,20,0}$ & 258 & $5.5(-4)$ & $<8.06(2.04):$ & $<0.45$ & $<43.32$ (9.59): \\
\hline 339.882 & $29_{3,26,3}-28_{3,25,3}$ & 450 & $5.8(-4)$ & $<0.22$ & $<0.79(0.16)$ & $\sim 0.73(0.33)$ \\
\hline 340.044 & $29_{4,26,4}-28_{4,25,4}$ & 450 & $5.8(-4)$ & $<0.15$ & $<0.12$ & $<3.75(0.75)$ \\
\hline 340.115 & $27_{7,20,5}-26_{7,19,5}$ & 444 & $5.5(-4)$ & $<0.15$ & $\sim 0.30(0.31):$ & $0.77(0.32)$ \\
\hline 345.068 & $28_{14,14,2}-27_{14,13,2}$ & 370 & $4.7(-4)$ & $<0.26$ & $0.28(0.11)$ & $<3.93$ (1.62): \\
\hline 345.069 & $28_{14,15 / 14,0}-27_{14,14 / 13,0}$ & 370 & $4.7(-4)$ & $<0.26$ & $0.56(0.22)$ & $<3.93$ (1.62): \\
\hline 345.073 & $16_{6,11,0}-15_{5,10,0}$ & 104 & $3.9(-5)$ & $<0.26$ & $<0.19$ & $<5.62(1.29)$ : \\
\hline 345.085 & $19_{13,6,2}-19_{12,7,2}$ & 224 & $3.5(-5)$ & - & $\sim 0.37(0.20)$ & $<1.73(0.35)$ \\
\hline 345.091 & $28_{14,15,1}-27_{14,14,1}$ & 370 & $4.7(-4)$ & $<0.26$ & $<0.50(0.32)$ & $<4.14(1.70)$ \\
\hline 345.148 & $28_{6,23,3}-27_{6,22,3}$ & 452 & $6.0(-4)$ & $<0.26$ & $\sim 0.55(0.34)$ & $\sim 0.59(0.54)$ \\
\hline 345.163 & $11_{8,3,5}-10_{7,3,5}$ & 269 & 7.1(-5) & $<0.26$ & $<0.19$ & $\sim 0.50(0.47)$ \\
\hline 345.230 & $18_{13,5,2}-18_{12,6,2}$ & 213 & $3.2(-5)$ & $<0.25$ & $\sim 0.59(0.40)$ & $<8.18$ (3.04): \\
\hline 345.242 & $18_{13,6,1}-18_{12,7,1}$ & 213 & $3.2(-5)$ & $<0.25$ & $<0.85(0.83)$ & $<8.18$ (3.04): \\
\hline 345.248 & $28_{10,19,4}-27_{10,18,4}$ & 493 & $5.5(-4)$ & $<0.26$ & $<0.19$ & $<0.34$ \\
\hline 352.817 & $33_{0 / 1 / 0 / 1,33,3}-32_{1 / 1 / 0 / 0,32,3}$ & 479 & $1.1(-4)$ & $<0.18$ & $\sim 0.38(0.28)$ & $<2.68$ (0.76): \\
\hline 352.841 & $33_{1 / 0,33,4 / 5}-32_{1 / 0,32,4 / 5}$ & 479 & $7.7(-4)$ & $<0.18$ & $<0.50(0.42)$ & $1.72(0.47)$ \\
\hline 352.912 & $31_{2,29,2}-30_{3,28,1}$ & 286 & $8.5(-5)$ & $<0.18$ & $<0.26$ & $0.30(0.08)$ \\
\hline 352.918 & $31_{3,29,1}-30_{3,28,1}$ & 286 & $6.6(-4)$ & $<0.18$ & $<1.10(0.36)$ & $2.32(0.62)^{*}$ \\
\hline 352.922 & $31_{2,29,2}-30_{2,28,2}$ & 286 & $6.6(-4)$ & $<0.18$ & $<1.10(0.36)$ & $2.32(0.62)^{*}$ \\
\hline 352.926 & $31_{3,29,0}-30_{3,28,0}$ & 286 & $6.6(-4)$ & $<0.18$ & $<1.10(0.36)$ & $2.32(0.62)^{*}$ \\
\hline 352.930 & $31_{2,29,0}-30_{2,28,0}$ & 286 & $6.6(-4)$ & $<0.18$ & $<1.10(0.36):$ & $2.32(0.62)^{*}$ \\
\hline
\end{tabular}

Notes. The notation $a(-b)$ stands for $a \times 10^{-b}$. $<$ Means upper limit. $\sim$ Means uncertain detection, $S / N \lesssim 2 .-$ Means frequency not observed. : Means blended line. * Calculated flux (see Eq. (4)). 
K. Isokoski et al.: Chemistry of massive young stellar objects with a disk-like structure

Table A.9. Observed line fluxes $\int T_{\mathrm{MB}} \mathrm{d} V\left(\mathrm{~K} \mathrm{~km} \mathrm{~s}^{-1}\right)$ for $\mathrm{HCOOCH}_{3}$ continued.

\begin{tabular}{llrcccc}
\hline \hline $\begin{array}{l}\text { Frequency } \\
\text { [GHz] }\end{array}$ & Transition & $\begin{array}{r}E_{\text {up }} \\
{[\mathrm{K}]}\end{array}$ & $\begin{array}{c}A \\
{\left[\mathrm{~s}^{-1}\right]}\end{array}$ & $\begin{array}{l}\text { Sources } \\
\text { IRAS 20126+4104 }\end{array}$ & IRAS 18089-1732 & G31.41+0.31 \\
\hline HCOOCH & & & & & & \\
\hline 354.427 & $29_{16,13 / 14,3}-28_{16,12 / 13,3}$ & 614 & $4.7(-4)$ & $<0.18$ & $<0.23$ & $\sim 1.04(0.64)$ \\
354.477 & $29_{15,15,4}-28_{15,14,4}$ & 593 & $5.0(-4)$ & $<0.13$ & $<0.23$ & $<0.40(0.58):$ \\
354.574 & $12_{8,5 / 4,3}-11_{7,4 / 5,3}$ & 276 & $7.4(-5)$ & $<0.18$ & $<0.23$ & $<1.44(0.78):$ \\
354.605 & $29_{15,15 / 14,3}-28_{15,14 / 13,3}$ & 593 & $5.0(-4)$ & $<0.18$ & $<0.23$ & $1.96(0.46)$ \\
354.608 & $33_{1 / 0,33,1 / 2}-32_{1 / 1,32,1 / 2}$ & 293 & $7.2(-4)$ & $<0.18$ & $1.11(0.42)^{*}$ & $3.14(0.49)^{*}$ \\
354.608 & $33_{0 / 1,33,2 / 1}-32_{1 / 0,32,1 / 2}$ & 293 & $6.8(-4)$ & $<0.18$ & $1.05(0.40)^{*}$ & $2.75(0.47)^{*}$ \\
354.629 & $28_{7,21,5}-27_{7,20,5}$ & 461 & $6.4(-4)$ & $<0.18$ & $<0.23$ & $\sim 1.20(0.68)$ \\
354.742 & $12_{8,5,1}-11_{7,5,1}$ & 88 & $7.3(-5)$ & $<0.18$ & $<0.23$ & $1.19(0.44)$ \\
354.759 & $12_{8,4,2}-11_{7,4,2}$ & 88 & $7.3(-5)$ & $<0.16$ & $<0.17$ & $<3.23(0.65):$ \\
354.806 & $12_{8,5 / 4,0}-11_{7,4 / 5,0}$ & 88 & $7.3(-5)$ & $<0.18$ & $<0.23$ & $3.90(1.18)$ \\
354.839 & $29_{14,15 / 16,3}-28_{14,14 / 15,3}$ & 574 & $5.2(-4)$ & $<0.15$ & $<0.36(0.46):$ & $<4.91(1.40):$ \\
364.297 & $33_{1 / 2,32,2 / 1}-32_{1,31,2}$ & 308 & $7.3(-4)$ & $<0.24$ & $<6.81(1.36):$ & $<3.67(1.16):$ \\
364.302 & $33_{2 / 1,32,0}-32_{2 / 1,31,0}$ & 308 & $7.3(-4)$ & $0.80(0.91)$ & $<6.81(1.36):$ & $<5.00(1.42):$ \\
\hline
\end{tabular}

Notes. The notation $a(-b)$ stands for $a \times 10^{-b}$. $<$ Means upper limit. $\sim$ Means uncertain detection, $S / N \lesssim 2 .-$ Means frequency not observed. : Means blended line. ${ }^{*}$ Calculated flux (see Eq. (4)).

Table A.10. Observed line fluxes $\int T_{\mathrm{MB}} \mathrm{d} V\left(\mathrm{~K} \mathrm{~km} \mathrm{~s}^{-1}\right)$ for $\mathrm{CH}_{3} \mathrm{OCH}_{3}$.

\begin{tabular}{|c|c|c|c|c|c|c|}
\hline $\begin{array}{l}\text { Frequency } \\
{[\mathrm{GHz}]}\end{array}$ & Transition & $\begin{array}{l}E_{\text {up }} \\
{[\mathrm{K}]} \\
\end{array}$ & $\begin{array}{c}A \\
{\left[\mathrm{~s}^{-1}\right]}\end{array}$ & $\begin{array}{l}\text { Sources } \\
\text { IRAS 20126+4104 }\end{array}$ & IRAS 18089-1732 & $\mathrm{G} 31.41+0.31$ \\
\hline \multicolumn{7}{|l|}{$\mathrm{CH}_{3} \mathrm{OCH}_{3}$} \\
\hline 218.490 & $23_{3,21,2 / 3}-23_{2,22,2 / 3}$ & 264 & $3.4(-5)$ & $<0.18$ & - & $<1.19(0.75):$ \\
\hline 218.492 & $23_{3,21,1}-23_{2,22,1}$ & 264 & $3.4(-5)$ & $<0.18$ & - & $<1.19(0.75):$ \\
\hline 218.495 & $23_{3,21,0}-23_{2,22,0}$ & 264 & $3.4(-5)$ & $<0.18$ & - & $<1.19(0.75)$ \\
\hline 222.239 & $4_{3,2,2}-3_{2,1,2}$ & 22 & $2.8(-5)$ & $<0.22$ & $0.82(0.56)$ & $\sim 0.93(0.43)$ \\
\hline 222.248 & $4_{3,2,3 / 1}-3_{2,1,3 / 1}$ & 22 & $4.2(-5)$ & $<0.22$ & $\sim 0.43(0.20)$ & $<1.15(0.35):$ \\
\hline 222.255 & $4_{3,2,0}-3_{2,1,0}$ & 22 & $4.9(-5)$ & $<0.22$ & $\sim 0.62(0.21)$ & $1.11(0.98)$ \\
\hline 222.259 & $4_{3,1,1}-3_{2,1,1}$ & 22 & $1.6(-5)$ & $<0.22$ & $\sim 0.30(0.21)^{*}$ & $2.37(0.74)^{*}$ \\
\hline 222.260 & $4_{3,1,2}-3_{2,1,2}$ & 22 & $2.1(-5)$ & $<0.22$ & $\sim 0.11(0.21)^{*}$ & $0.83(0.26)^{*}$ \\
\hline 222.326 & $25_{3,23,0}-24_{4,20,0}$ & 308 & $7.9(-6)$ & $<0.22$ & $<0.27$ & $\sim 0.42(0.19)^{*}$ \\
\hline 222.327 & $25_{3,22,1}-24_{4,20,1}$ & 308 & $7.9(-6)$ & $<0.22$ & $<0.27$ & $\sim 1.12(0.52)^{*}$ \\
\hline 222.329 & $25_{3,22 / 23,2 / 3}-24_{4,20 / 20,2 / 3}$ & 308 & $7.9(-6)$ & $<0.22$ & $<0.27$ & $\sim 0.42(0.21)^{*}$ \\
\hline 222.414 & $4_{3,2,2}-3_{2,2,2}$ & 22 & $2.1(-5)$ & $<0.22$ & $\sim 0.20(0.10)$ & $<0.73(0.15)$ \\
\hline 222.423 & $4_{3,2,1}-3_{2,2,1}$ & 22 & $1.6(-5)$ & $<0.22$ & $\sim 0.56(0.30)$ & $<2.09(0.42):$ \\
\hline 222.427 & $4_{3,1,3}-3_{2,2,3}$ & 22 & $4.9(-5)$ & $<0.22$ & $\sim 0.23(0.12)$ & $<0.85(0.11)$ \\
\hline 222.434 & $4_{3,1,1 / 0}-3_{2,2,1 / 0}$ & 22 & $4.2(-5)$ & $<0.22$ & $1.68(0.63)$ & $<1.86(0.52)$ \\
\hline 222.435 & $4_{3,1,2}-3_{2,2,2}$ & 22 & $2.8(-5)$ & $<0.22$ & $\sim 0.22(0.08)$ & $<0.34(0.10)$ \\
\hline 225.202 & $24_{4,21,2 / 3}-24_{3,22,2 / 3}$ & 296 & $4.7(-5)$ & $<0.19$ & $<0.30$ & $0.55(0.18)^{*}$ \\
\hline 225.204 & $24_{4,21,1}-24_{3,22,1}$ & 296 & $4.7(-5)$ & $<0.19$ & $\sim 0.15(0.14)^{*}$ & $0.87(0.28)^{*}$ \\
\hline 225.205 & $24_{4,21,0}-24_{3,22,0}$ & 296 & $4.7(-5)$ & $<0.19$ & $\sim 0.09(0.08)^{*}$ & $0.55(0.18)^{*}$ \\
\hline 238.975 & $29_{5,25,2 / 3 / 1 / 0}-28_{6,22,2 / 3 / 1 / 0}$ & 432 & $1.6(-5)$ & $<0.21$ & $<0.22$ & $<1.64(0.64):$ \\
\hline 239.020 & $24_{5,19,5 / 3}-24_{4,20,5 / 3}$ & 309 & $6.1(-5)$ & $<0.21$ & $<0.63(0.12):$ & $<0.68(0.14):$ \\
\hline 239.021 & $24_{5,19,1}-24_{4,20,1}$ & 309 & $6.1(-5)$ & $<0.21$ & <1.67 (0.33): & $<1.82(0.36):$ \\
\hline 239.021 & $24_{5,19,0}-24_{4,20,0}$ & 309 & $6.1(-5)$ & $<0.21$ & $<0.63(0.13)$ & $<0.68(0.14)$ \\
\hline 240.978 & $5_{3,3,2}-4_{2,2,2}$ & 26 & $4.5(-5)$ & $<0.20$ & $\sim 0.11(0.07)^{*}$ & $2.16(0.66)^{*}$ \\
\hline 240.983 & $5_{3,3,3}-4_{2,2,3}$ & 26 & $5.4(-5)$ & $<0.20$ & $\sim 0.06(0.04)^{*}$ & $0.19(0.06)^{*}$ \\
\hline 240.985 & $5_{3,3,1}-4_{2,2,1}$ & 26 & $5.1(-5)$ & $<0.20$ & $\sim 0.49(0.30)^{*}$ & $1.49(0.46)^{*}$ \\
\hline 240.990 & $5_{3,3,0}-4_{2,2,0}$ & 26 & $5.4(-5)$ & $<0.20$ & $\sim 0.19(0.12)$ & $<0.64(0.28)$ \\
\hline
\end{tabular}

Notes. The notation $a(-b)$ stands for $a \times 10^{-b}$. $<$ Means upper limit. $\sim$ Means uncertain detection, $S / N \lesssim 2$. - Means frequency not observed. : Means blended line. * Calculated flux (see Eq. (4)). 
Table A.11. Observed line fluxes $\int T_{\mathrm{MB}} \mathrm{d} V\left(\mathrm{~K} \mathrm{~km} \mathrm{~s}^{-1}\right)$ for $\mathrm{CH}_{2} \mathrm{CO}$.

\begin{tabular}{llrcccc}
\hline \hline $\begin{array}{l}\text { Frequency } \\
{[\mathrm{GHz}]}\end{array}$ & Transition & $\begin{array}{r}E_{\text {up }} \\
{[\mathrm{K}]}\end{array}$ & $\begin{array}{c}A \\
{\left[\mathrm{~s}^{-1}\right]}\end{array}$ & $\begin{array}{l}\text { Sources } \\
\text { IRAS 20126+4104 }\end{array}$ & IRAS 18089-1732 & $\mathrm{G} 31.41+0.31$ \\
\hline $\mathrm{CH}_{2} \mathrm{CO}$ & & & & & & \\
\hline 222.120 & $11_{4,8 / 7}-10_{4,7 / 6}$ & 273 & $1.1(-4)$ & $<0.22$ & $<0.27$ & $<0.54(0.10):$ \\
222.198 & $11_{0,11}-10_{0,10}$ & 65 & $1.2(-4)$ & $<0.22$ & $<0.81(0.26):$ & $<2.34(0.75):$ \\
222.201 & $11_{3,9 / 8}-10_{3,8 / 7}$ & 181 & $1.1(-4)$ & $<0.22$ & $<0.81(0.26):$ & $<2.34(0.75):$ \\
222.229 & $11_{2,10}-10_{2,9}$ & 116 & $1.2(-4)$ & $<0.22$ & $<0.28(0.06):$ & $<2.22(0.32):$ \\
222.315 & $11_{2,9}-10_{2,8}$ & 116 & $1.2(-4)$ & $<0.22$ & $\sim 0.24(0.22)$ & $\sim 0.91(0.57)$ \\
$363.937 !$ & $18_{2,16}-17_{2,15}$ & 218 & $5.5(-4)$ & $<4.65(1.08):$ & $<0.22$ & $<20.29(3.31):$ \\
\hline
\end{tabular}

Notes. The notation $a(-b)$ stands for $a \times 10^{-b}$. $<$ Means upper limit. $\sim$ Means uncertain detection, $S / N \lesssim 2$. - Means frequency not observed. : Means blended line. ! Frequency from CDMS.

Table A.12. Observed line fluxes $\int T_{\mathrm{MB}} \mathrm{d} V\left(\mathrm{~K} \mathrm{~km} \mathrm{~s}^{-1}\right)$ for $\mathrm{CH}_{3} \mathrm{CHO}$.

\begin{tabular}{llrcccc}
\hline \hline $\begin{array}{l}\text { Frequency } \\
{[\mathrm{GHz}]}\end{array}$ & Transition & $\begin{array}{c}E_{\text {up }} \\
{[\mathrm{K}]}\end{array}$ & $\begin{array}{c}A \\
{\left[\mathrm{~s}^{-1}\right]}\end{array}$ & $\begin{array}{l}\text { Sources } \\
\text { IRAS 20126+4104 }\end{array}$ & IRAS 18089-1732 & $\mathrm{G} 31.41+0.31$ \\
\hline $\mathrm{CH}_{3} \mathrm{CHO}$ & & & & & & \\
\hline 330.822 & $5_{3,3,1}-4_{2,3,1}$ & 34 & $1.2(-4)$ & $<0.31$ & $\sim 0.71(0.80)$ & $\sim 0.97(0.52)$ \\
331.039 & $17_{3,14,3}-16_{3,13,3}$ & 367 & $1.2(-3)$ & $<1.18(0.88):$ & $<0.42(0.29):$ & $<2.50(1.47):$ \\
354.458 & $18_{2,16,3}-17_{2,15,3}$ & 375 & $1.5(-3)$ & $<0.18$ & $<3.11(1.11):$ & $<3.25(1.26):$ \\
354.525 & $19_{0,19,5}-18_{0,18,5}$ & 377 & $1.5(-3)$ & $<0.17$ & $<0.19$ & $<0.34$ \\
354.813 & $18_{2,16,2}-17_{2,15,2}$ & 170 & $1.5(-3)$ & $<0.18$ & $<0.23$ & $\sim 1.54(0.92)$ \\
354.844 & $18_{2,16,0}-17_{2,15,0}$ & 170 & $1.5(-3)$ & $<0.18:$ & $<1.13(0.55):$ & $<4.92(1.34):$ \\
\hline
\end{tabular}

Notes. The notation $a(-b)$ stands for $a \times 10^{-b}$. $<$ Means upper limit. $\sim$ Means uncertain detection, $S / N \lesssim 2 .-$ Means frequency not observed. : Means blended line.

Table A.13. Observed line fluxes $\int T_{\mathrm{MB}} \mathrm{d} V\left(\mathrm{~K} \mathrm{~km} \mathrm{~s}^{-1}\right)$ for $\mathrm{HCOOH}$ and its isotopic species.

\begin{tabular}{|c|c|c|c|c|c|c|}
\hline $\begin{array}{l}\text { Frequency } \\
{[\mathrm{GHz}]}\end{array}$ & Transition & $\begin{array}{l}E_{\text {up }} \\
{[\mathrm{K}]}\end{array}$ & $\begin{array}{c}A \\
{\left[\mathrm{~s}^{-1}\right]}\end{array}$ & $\begin{array}{l}\text { Sources } \\
\text { IRAS 20126+4104 }\end{array}$ & IRAS 18089-1732 & $\mathrm{G} 31.41+0.31$ \\
\hline \multicolumn{7}{|l|}{$\mathrm{HCOOH}$} \\
\hline 222.110 & $7_{2,6}-7_{1,7}$ & 43 & $1.9(-6)$ & $<0.22$ & $<0.27$ & $<0.24$ \\
\hline 225.086 & $10_{4,7}-9_{4,6}$ & 110 & $1.0(-4)$ & $<0.18$ & $<0.18$ & $<1.97$ (1.70): \\
\hline 225.091 & $10_{4,6}-9,5$ & 110 & $1.0(-4)$ & $<0.18$ & $<0.18$ & $<1.97$ (1.70): \\
\hline 225.238 & $10_{3,8}-9_{3,7}$ & 88 & $1.1(-4)$ & $<0.19$ & $<0.39(0.24)$ & $<2.59$ (0.78): \\
\hline 330.931 & $4_{3,1}-4_{2,2}$ & 39 & $5.1(-6)$ & $<0.31$ & $<0.32$ & $\sim 0.47(0.63)$ \\
\hline 331.145 & $3_{3,0}-3_{2,1}$ & 35 & $3.6(-6)$ & $<0.29$ & $<0.29$ : & $<2.77$ (1.80): \\
\hline 338.109 & $15_{1,15}-14_{0,14}$ & 127 & $1.1(-5)$ & -- & - & $<5.11$ (3.10): \\
\hline 338.202 & $15_{3,13}-14_{3,12}$ & 158 & $4.1(-4)$ & - & - & $<13.55(6.28)$ \\
\hline 345.031 & $16_{0,16}-15_{0,15}$ & 143 & $4.5(-4)$ & $<0.26$ & $\sim 0.30(0.30)$ & $\sim 1.18(0.70)$ \\
\hline 345.253 & $14_{3,12}-14_{2,13}$ & 142 & $8.3(-6)$ & $<0.29$ & $<0.19$ : & $<1.59$ (1.01): \\
\hline 354.448 & $17_{0,17}-16_{1,16}$ & 161 & $1.3(-5)$ & $<0.18$ & $<1.70(0.57):$ & $<6.42$ (1.60): \\
\hline
\end{tabular}

Notes. The notation $a(-b)$ stands for $a \times 10^{-b}$. $<$ Means upper limit. $\sim$ Means uncertain detection, $S / N \lesssim 2$. - Means frequency not observed. : Means blended line. 
K. Isokoski et al.: Chemistry of massive young stellar objects with a disk-like structure

Table A.14. Observed line fluxes $\int T_{\mathrm{MB}} \mathrm{d} V\left(\mathrm{~K} \mathrm{~km} \mathrm{~s}^{-1}\right)$ for $\mathrm{CH}_{3} \mathrm{CCH}$.

\begin{tabular}{lcrcccc}
\hline \hline $\begin{array}{l}\text { Frequency } \\
{[\mathrm{GHz}]}\end{array}$ & Transition & $\begin{array}{r}E_{\text {up }} \\
{[\mathrm{K}]}\end{array}$ & $\begin{array}{c}A \\
{\left[\mathrm{~s}^{-1}\right]}\end{array}$ & $\begin{array}{l}\text { Sources } \\
\text { IRAS 20126+4104 }\end{array}$ & IRAS 18089-1732 & G31.41+0.31 \\
\hline $\mathrm{CH}_{3} \mathrm{CCH}$ & & & & & & \\
\hline 222.099 & $13_{4}-12_{4}$ & 190 & $3.4(-5)$ & $<0.22$ & $<0.65(0.35):$ & $<2.79(0.56):$ \\
222.129 & $13_{3}-12_{3}$ & 140 & $3.6(-5)$ & $\sim 0.29(0.17)$ & $1.14(0.43)$ & $3.15(0.94)$ \\
222.150 & $13_{2}-12_{2}$ & 104 & $3.7(-5)$ & $\sim 0.41(0.19)$ & $1.25(0.46)$ & $<4.25(0.85):$ \\
222.163 & $13_{1}-12_{1}$ & 82 & $3.8(-5)$ & $0.74(0.29)$ & $2.20(0.68)$ & $3.14(1.01)$ \\
222.167 & $13_{0}-12_{0}$ & 75 & $3.8(-5)$ & $0.93(0.35)$ & $2.13(0.70)$ & $3.27(0.97)$ \\
239.088 & $14_{6}-13_{6}$ & 346 & $3.9(-5)$ & $<0.21$ & $<0.22(0.05):$ & $<2.40(0.48):$ \\
239.138 & $14_{5}-13_{5}$ & 267 & $4.1(-5)$ & $<0.21$ & $<2.38(0.48):$ & $<6.39(1.28):$ \\
239.179 & $14_{4}-13_{4}$ & 202 & $4.3(-5)$ & $0.71(0.14)$ & $<0.68(0.14):$ & $\sim 0.39(0.21)$ \\
239.211 & $14_{3}-13_{3}$ & 151 & $4.5(-5)$ & $\sim 0.40(0.24)$ & $\sim 0.75(0.41)$ & $2.47(0.64)$ \\
239.234 & $14_{2}-13_{2}$ & 115 & $4.6(-5)$ & $0.36(0.16)$ & $\sim 0.89(0.89)$ & $2.06(0.63)$ \\
239.248 & $14_{1}-13_{1}$ & 93 & $4.7(-5)$ & $0.79(0.23)$ & $1.62(0.52)$ & $2.91(0.74)$ \\
239.252 & $14_{0}-13_{0}$ & 86 & $4.7(-5)$ & $0.87(0.24)$ & $1.68(0.43)$ & $3.46(1.07)$ \\
\hline
\end{tabular}

Notes. The notation $a(-b)$ stands for $a \times 10^{-b}$. $<$ Means upper limit. $\sim$ Means uncertain detection, $S / N \lesssim 2 .-$ Means frequency not observed. : Means blended line. 


\section{Appendix B: Rotation diagrams}

RTD diagrams for $\mathrm{H}_{2} \mathrm{CO}, \mathrm{CH}_{3} \mathrm{OH}, \mathrm{C}_{2} \mathrm{H}_{5} \mathrm{OH}, \mathrm{HNCO}, \mathrm{NH}_{2} \mathrm{CHO}$, $\mathrm{CH}_{3} \mathrm{CN}, \mathrm{C}_{2} \mathrm{H}_{5} \mathrm{CN}, \quad \mathrm{HCOOCH}_{3}, \mathrm{CH}_{3} \mathrm{OCH}_{3}, \mathrm{CH}_{2} \mathrm{CO}$ and $\mathrm{CH}_{3} \mathrm{CCH}$. Lines from different frequency bands are corrected for differential beam dilution assuming a $R_{T=100 \mathrm{~K}}$ source size for the warm species and 14" source size for the cold species, as indicated in the plots. Optically thin, unblended lines with $S / N \gtrsim 2$ are marked with filled circles. Lines with high $\mathrm{S} / \mathrm{N}(\lesssim 2)$ are marked with diamonds, those included in the fit with filled diamonds. Optically thick lines and blended lines are marked with open squares and triangles, respectively. Upper limits are marked with arrows. Upper limits used to constrain the fit are marked with filled stars. The error bars are calculated using Eq. (A.2).
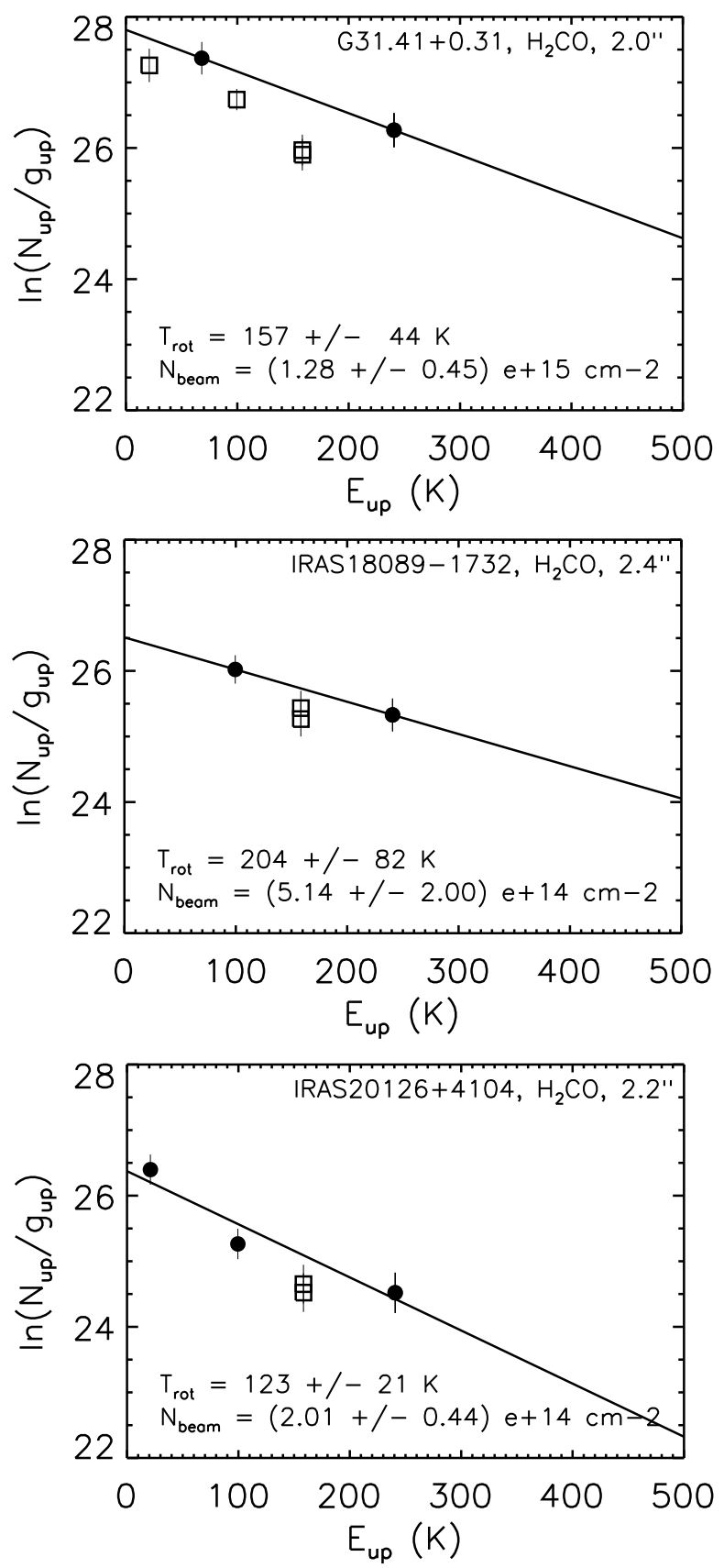

Fig. B.1. RTD fits for $\mathrm{H}_{2}$ CO. All lines included into the fit belong to para- $\mathrm{H}_{2} \mathrm{CO}$.
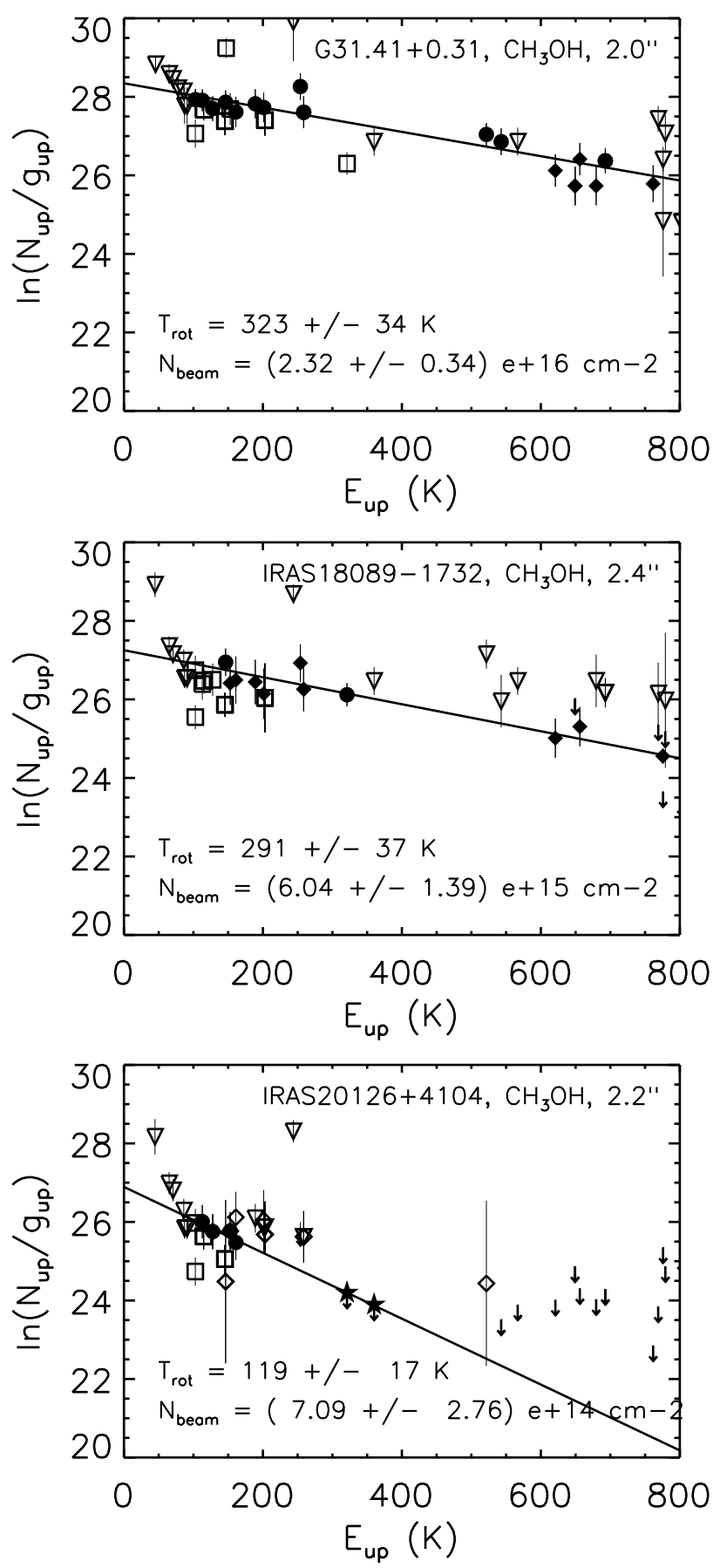

Fig. B.2. RTD fits for $\mathrm{CH}_{3} \mathrm{OH}$. Lines with $E_{\text {up }}<100 \mathrm{~K}$ are considered contaminated with the cold $\mathrm{CH}_{3} \mathrm{OH}$. Lines with $S / N \gtrsim 1$ are included in the fit. 
K. Isokoski et al.: Chemistry of massive young stellar objects with a disk-like structure
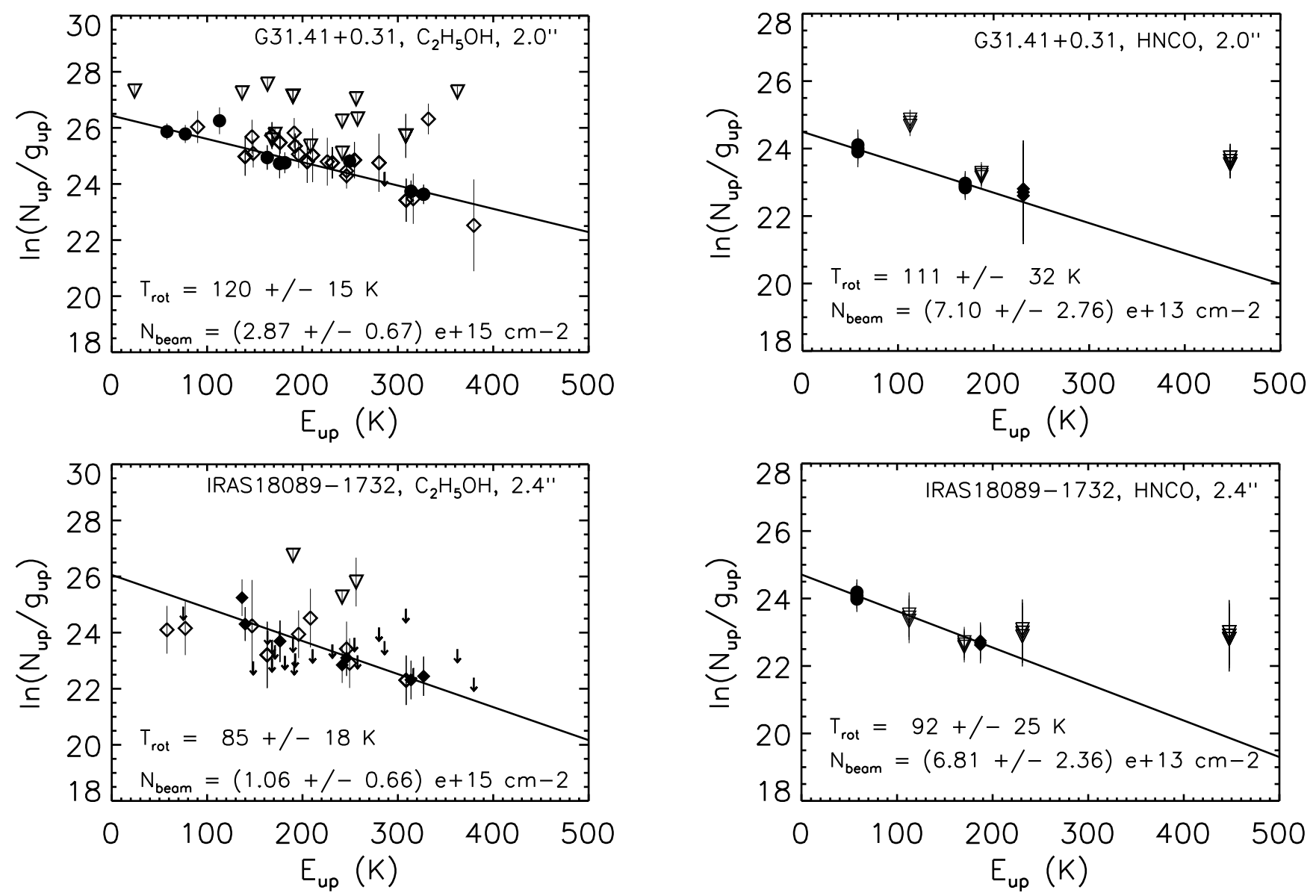

Fig. B.3. RTD fits for $\mathrm{C}_{2} \mathrm{H}_{5} \mathrm{OH}$. No $\mathrm{C}_{2} \mathrm{H}_{5} \mathrm{OH}$ was detected in IRAS 20126+4104. For IRAS 18089 lines with $S / N \gtrsim 1$ have been used.

Fig. B.4. RTD fits for HNCO. No HNCO was detected in IRAS $20126+4104$. 

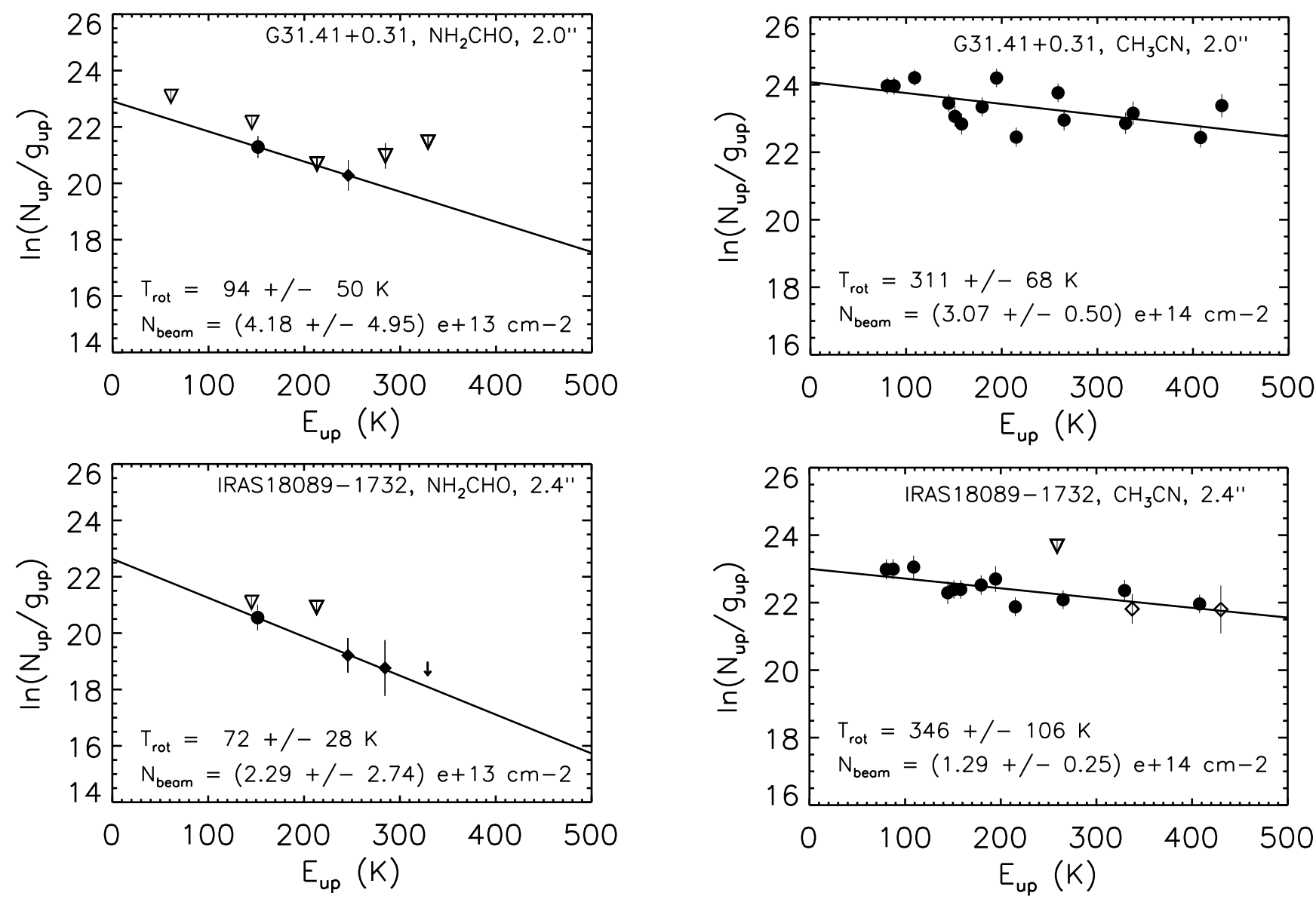

Fig. B.5. RTD fits for $\mathrm{NH}_{2} \mathrm{CHO}$. No $\mathrm{NH}_{2} \mathrm{CHO}$ was detected in

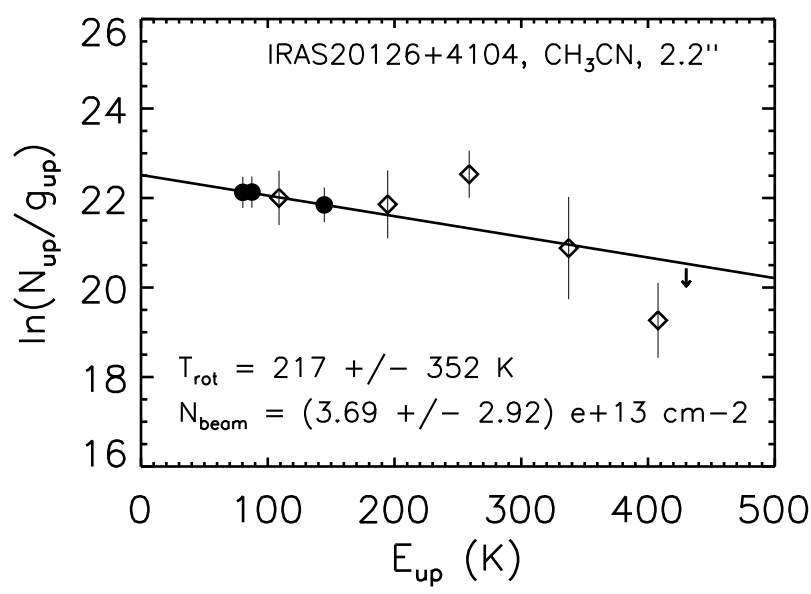

Fig. B.6. RTD fits for $\mathrm{CH}_{3} \mathrm{CN}$. 
K. Isokoski et al.: Chemistry of massive young stellar objects with a disk-like structure
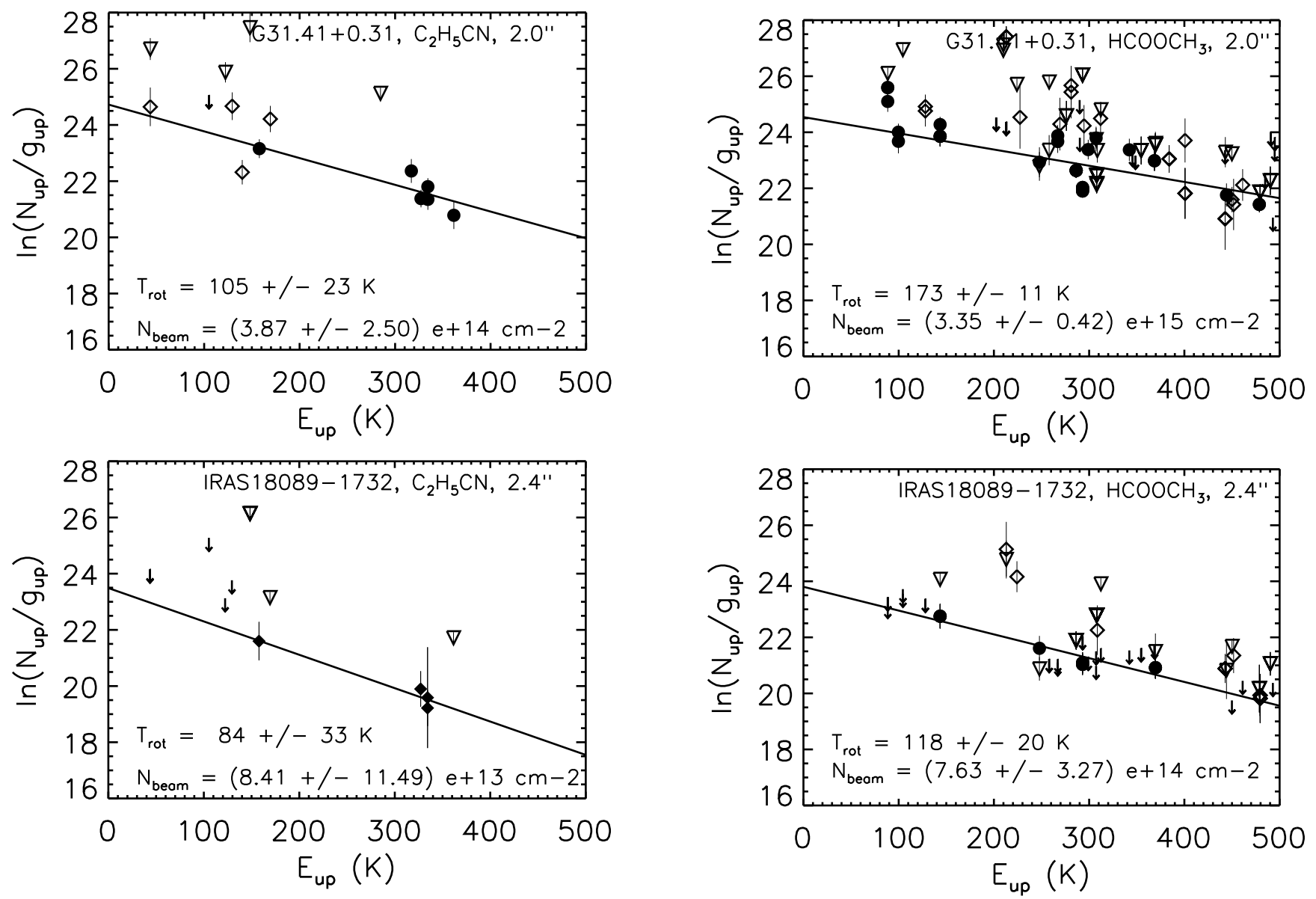

Fig. B.7. RTD fits for $\mathrm{C}_{2} \mathrm{H}_{5} \mathrm{CN}$. No $\mathrm{C}_{2} \mathrm{H}_{5} \mathrm{CN}$ was detected in IRAS 20126+4104. For IRAS 18089 lines with $S / N \lesssim 2$ have been included in the fit.

Fig. B.8. RTD fits for $\mathrm{HCOOCH}_{3}$. No $\mathrm{HCOOCH}_{3}$ was detected in IRAS $20126+4104$. 

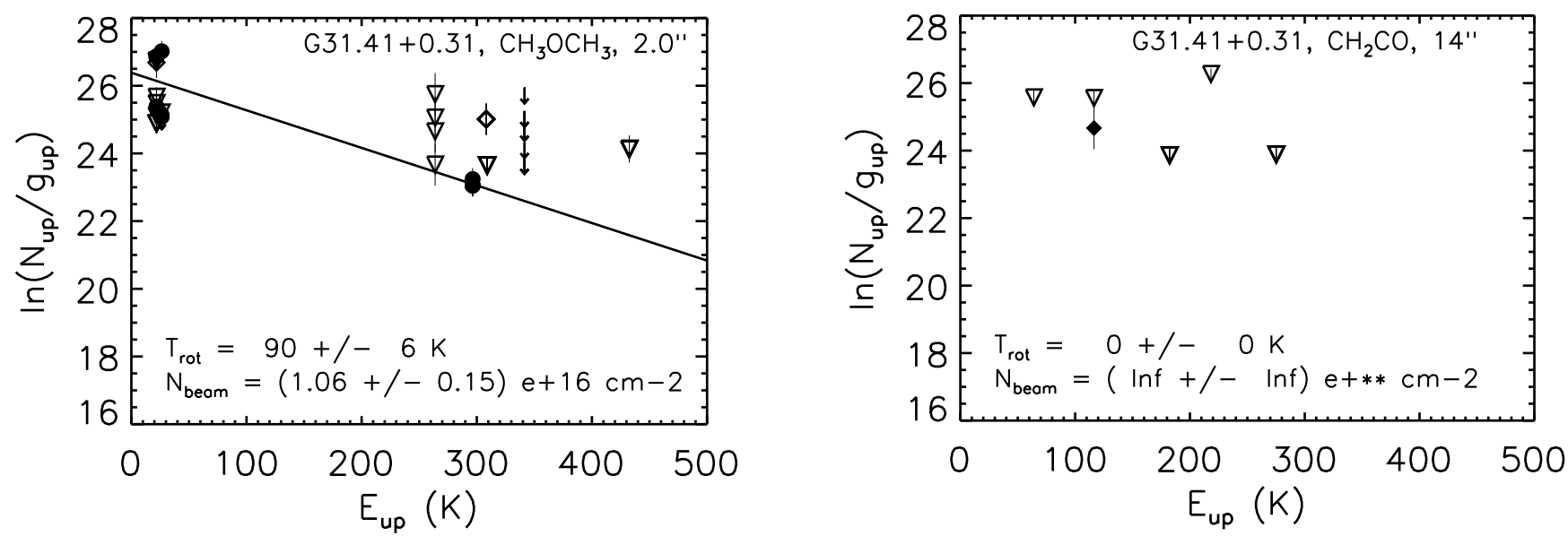

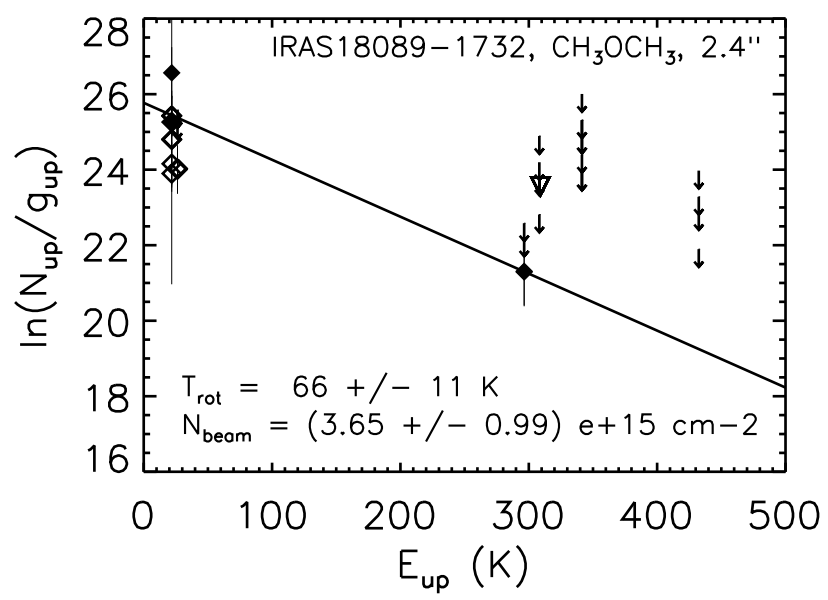

Fig. B.9. RTD fits for $\mathrm{CH}_{3} \mathrm{OCH}_{3}$. No $\mathrm{CH}_{3} \mathrm{OCH}_{3}$ was detected in IRAS $20126+4104$.

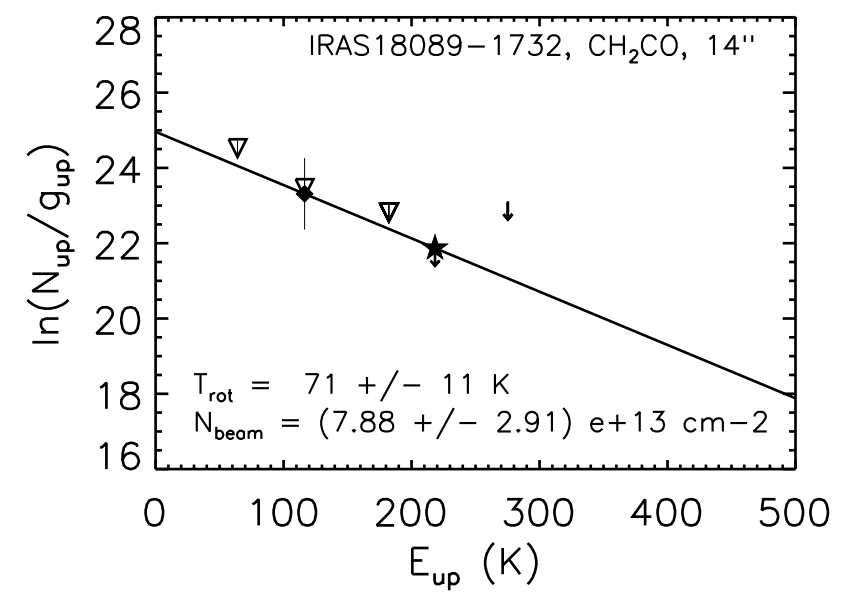

Fig. B.10. RTD fits for $\mathrm{CH}_{2} \mathrm{CO}$. No $\mathrm{CH}_{2} \mathrm{CO}$ was detected in IRAS 20126+4104. 
K. Isokoski et al.: Chemistry of massive young stellar objects with a disk-like structure

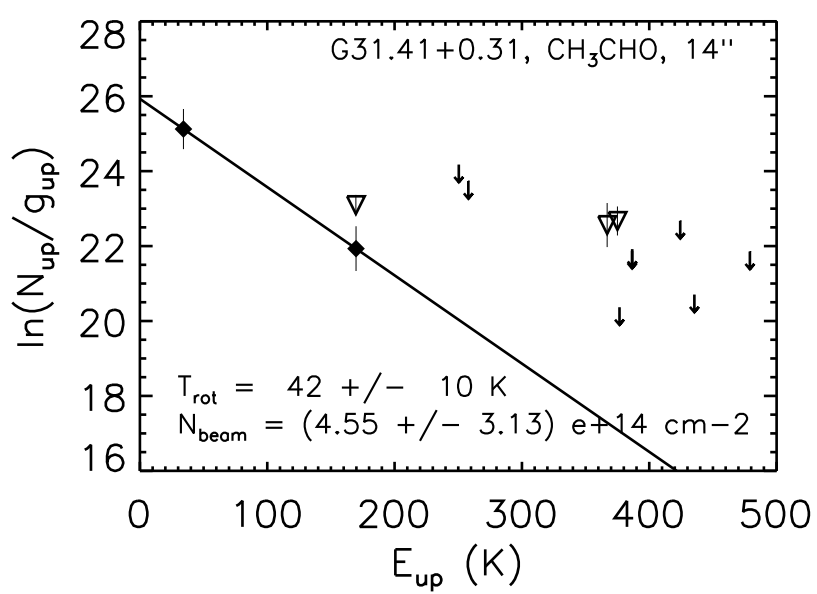

Fig. B.11. RTD fits for $\mathrm{CH}_{3} \mathrm{CHO}$.

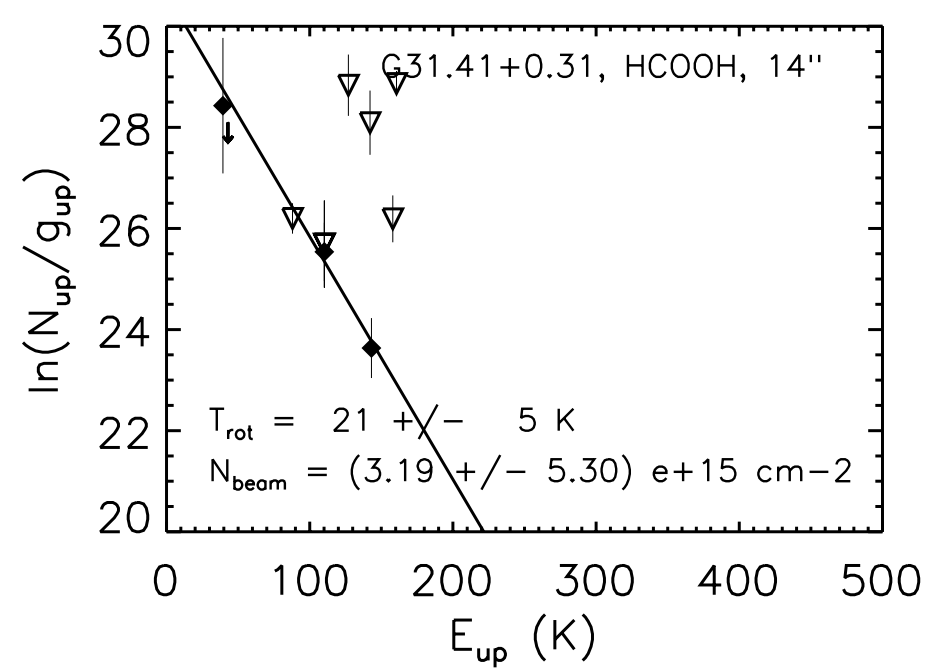

Fig. B.12. RTD fits for $\mathrm{HCOOH}$.
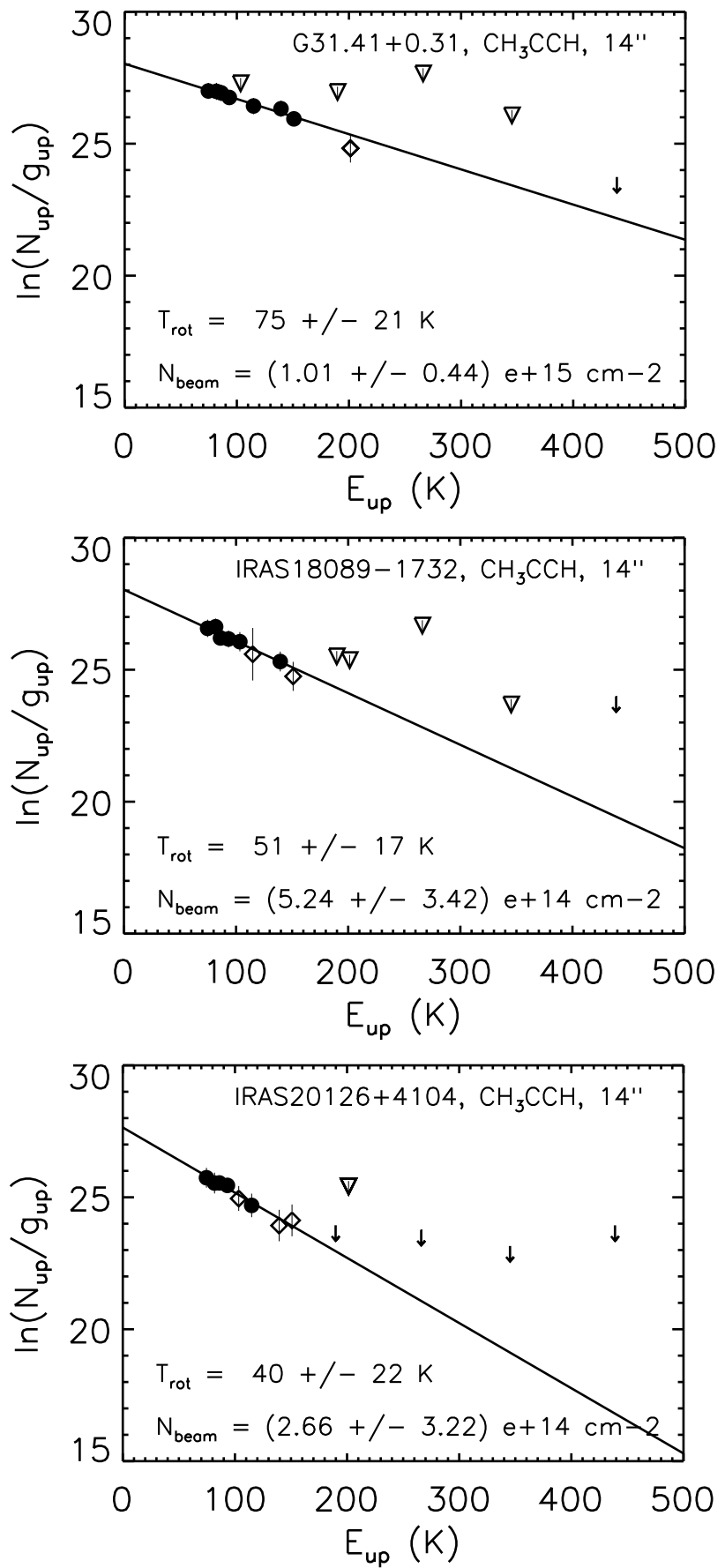

Fig. B.13. RTD fits for $\mathrm{CH}_{3} \mathrm{CCH}$. 


\section{Appendix C: Weeds model parameters}

Table C.1. Weeds model parameters for IRAS 20126+4104.

\begin{tabular}{|c|c|c|c|c|}
\hline Species & $\begin{array}{c}N_{\mathrm{S}} \\
{\left[\mathrm{cm}^{-2}\right]}\end{array}$ & $\begin{array}{l}T_{\mathrm{ex}} \\
{[\mathrm{K}]}\end{array}$ & $\begin{array}{c}\theta_{\mathrm{S}} \\
{\left[{ }^{\prime \prime}\right]}\end{array}$ & $\begin{array}{c}\Delta v \\
{\left[\mathrm{~km} \mathrm{~s}^{-1}\right]}\end{array}$ \\
\hline $\mathrm{CH}_{3} \mathrm{OH}$ & $1.5 \mathrm{E}+17$ & 300 & 2.2 & 6 \\
\hline $\mathrm{CH}_{3} \mathrm{OH}$ & $4.8 \mathrm{E}+16$ & 20 & 3.0 & 5 \\
\hline${ }^{13} \mathrm{CH}_{3} \mathrm{OH}$ & - & - & - & - \\
\hline $\mathrm{H}_{2} \mathrm{CO}$ & $6.0 \mathrm{E}+15$ & 150 & 2.2 & 6 \\
\hline $\mathrm{H}_{2}{ }^{13} \mathrm{CO}$ & $<2.0 \mathrm{E}+15$ & 150 & 2.2 & 6 \\
\hline $\mathrm{CH}_{3} \mathrm{CN}^{1}$ & $1.3 \mathrm{E}+15$ & 200 & 2.2 & 6 \\
\hline $\mathrm{CH}_{3}{ }^{13} \mathrm{CN}$ & $<2.0 \mathrm{E}+13$ & 200 & 2.2 & 6 \\
\hline HNCO & $1.0 \mathrm{E}+15$ & 200 & 2.2 & 6 \\
\hline $\mathrm{HN}^{13} \mathrm{CO}$ & $<1.0 \mathrm{E}+14$ & 200 & 2.2 & 6 \\
\hline $\mathrm{C}_{2} \mathrm{H}_{5} \mathrm{OH}$ & $<3.0 \mathrm{E}+15$ & 100 & 2.2 & 6 \\
\hline $\mathrm{C}_{2} \mathrm{H}_{5} \mathrm{CN}$ & $<5.0 \mathrm{E}+14$ & 80 & 2.2 & 5 \\
\hline $\mathrm{CH}_{3} \mathrm{OCH}_{3}$ & $<1.0 \mathrm{E}+16$ & 100 & 2.2 & 6 \\
\hline $\mathrm{HCOOCH}_{3}$ & $<2.0 \mathrm{E}+15$ & 200 & 2.2 & 6 \\
\hline $\mathrm{NH}_{2} \mathrm{CHO}$ & $3.0 \mathrm{E}+14$ & 300 & 2.2 & 6 \\
\hline $\mathrm{CH}_{2} \mathrm{CO}$ & $<5.0 \mathrm{E}+13$ & 50 & 14.0 & 6 \\
\hline $\mathrm{CH}_{3} \mathrm{CHO}$ & $<1.0 \mathrm{E}+14$ & 50 & 8.0 & 6 \\
\hline $\mathrm{HCOOH}$ & $<5.0 \mathrm{E}+13$ & 40 & 8.0 & 6 \\
\hline $\mathrm{CH}_{3} \mathrm{CCH}$ & $7.0 \mathrm{E}+14$ & 35 & 14.0 & 2 \\
\hline \multicolumn{5}{|c|}{ Additional species } \\
\hline $\mathrm{CH}_{3} \mathrm{COCH}_{3}$ & $<0.1 \mathrm{E}+17$ & 300 & 2.2 & 5 \\
\hline HCCCN & $1 E+13$ & 100 & 14 & 7 \\
\hline SO & $0.3 E+15$ & 50 & 14 & 6 \\
\hline${ }^{34} \mathrm{SO}$ & $0.2 \mathrm{E}+14$ & 50 & 14.0 & 6 \\
\hline $\mathrm{SO}_{2}$ & $0.3 \mathrm{E}+15$ & 50 & 14.0 & 6 \\
\hline${ }^{33} \mathrm{SO} 2$ & $0.05 E+15$ & 50 & 14.0 & 5 \\
\hline $\mathrm{HCN}$ & $0.4 \mathrm{E}+14$ & 50 & 14.0 & 20 \\
\hline $\mathrm{HCN}$ & $4 \mathrm{E}+13$ & 50 & 14.0 & 5 \\
\hline $\mathrm{H}^{13} \mathrm{CN}$ & $0.1 \mathrm{E}+13$ & 50 & 14.0 & 6 \\
\hline $\mathrm{CN}, v=0,1$ & $0.2 \mathrm{E}+15$ & 50 & 14 & 2 \\
\hline
\end{tabular}

Notes. ${ }^{13} \mathrm{CH}_{3} \mathrm{OH}$ is not available in the JPL database used for Weeds modeling. ${ }^{(1)}$ Based on $21^{\prime \prime}$ beam spectra.
Table C.2. Weeds model parameters for IRAS 18089-1732.

\begin{tabular}{|c|c|c|c|c|}
\hline Species & $\begin{array}{c}N_{\mathrm{S}} \\
{\left[\mathrm{cm}^{-2}\right]}\end{array}$ & $\begin{array}{l}T_{\mathrm{ex}} \\
{[\mathrm{K}]}\end{array}$ & $\begin{array}{c}\theta_{\mathrm{S}} \\
{\left[{ }^{\prime \prime}\right]}\end{array}$ & $\begin{array}{c}\Delta v \\
{\left[\mathrm{~km} \mathrm{~s}^{-1}\right]}\end{array}$ \\
\hline $\mathrm{CH}_{3} \mathrm{OH}$ & $3.5 \mathrm{E}+17$ & 300 & 2.4 & 5 \\
\hline $\mathrm{CH}_{3} \mathrm{OH}$ & $2.6 \mathrm{E}+17$ & 20 & 3.0 & 5 \\
\hline${ }^{13} \mathrm{CH}_{3} \mathrm{OH}$ & - & - & - & - \\
\hline $\mathrm{H}_{2} \mathrm{CO}$ & $1.5 \mathrm{E}+16$ & 150 & 2.4 & 6 \\
\hline $\mathrm{H}_{2}{ }^{13} \mathrm{CO}$ & $3.5 \mathrm{E}+15$ & 150 & 2.4 & 6 \\
\hline $\mathrm{CH}_{3} \mathrm{CN}$ & $3.5 \mathrm{E}+15$ & 200 & 2.4 & 6 \\
\hline $\mathrm{CH}_{3}{ }^{13} \mathrm{CN}$ & $4.0 \mathrm{E}+14$ & 200 & 2.4 & 6 \\
\hline $\mathrm{HNCO}$ & $4.0 \mathrm{E}+15$ & 200 & 2.4 & 6 \\
\hline $\mathrm{HN}^{13} \mathrm{CO}$ & $7.0 \mathrm{E}+14$ & 200 & 2.4 & 6 \\
\hline $\mathrm{C}_{2} \mathrm{H}_{5} \mathrm{OH}$ & $2.5 \mathrm{E}+16$ & 150 & 2.4 & 6 \\
\hline $\mathrm{C}_{2} \mathrm{H}_{5} \mathrm{CN}$ & $4.0 \mathrm{E}+15$ & 80 & 2.4 & 5 \\
\hline $\mathrm{CH}_{3} \mathrm{OCH}_{3}$ & $1.0 \mathrm{E}+17$ & 100 & 2.4 & 6 \\
\hline $\mathrm{HCOOCH}_{3}$ & $3.0 \mathrm{E}+16$ & 200 & 2.4 & 6 \\
\hline $\mathrm{NH}_{2} \mathrm{CHO}$ & $5.0 \mathrm{E}+14$ & 100 & 2.4 & 6 \\
\hline $\mathrm{CH}_{2} \mathrm{CO}$ & $1.5 \mathrm{E}+14$ & 50 & 14.0 & 5 \\
\hline $\mathrm{CH}_{3} \mathrm{CHO}$ & $<1.0 \mathrm{E}+14$ & 50 & 8.0 & 6 \\
\hline $\mathrm{HCOOH}$ & $<5.0 \mathrm{E}+13$ & 40 & 8.0 & 6 \\
\hline $\mathrm{CH}_{3} \mathrm{CCH}$ & $1.8 \mathrm{E}+15$ & 40 & 14.0 & 3.5 \\
\hline \multicolumn{5}{|c|}{ Additional species } \\
\hline $\mathrm{CH}_{3} \mathrm{COCH}_{3}$ & $0.5 \mathrm{E}+17$ & 300 & 2.4 & 5 \\
\hline $\mathrm{HCCCN}$ & $3 E+13$ & 150 & 14 & 6 \\
\hline SO & $1 E+15$ & 50 & 14 & 6 \\
\hline${ }^{34} \mathrm{SO}$ & $0.5 E+14$ & 50 & 14.0 & 6 \\
\hline $\mathrm{SO}_{2}$ & $0.5 E+15$ & 50 & 14.0 & 6 \\
\hline${ }^{33} \mathrm{SO}_{2}$ & $0.5 \mathrm{E}+15$ & 50 & 14.0 & 5 \\
\hline $\mathrm{HCN}$ & $2 \mathrm{E}+14$ & 50 & 14.0 & 7 \\
\hline $\mathrm{HCN}$ & $-5 E+13$ & 50 & 14.0 & 4 \\
\hline $\mathrm{H}^{13} \mathrm{CN}$ & $1.5 \mathrm{E}+13$ & 50 & 14.0 & 6 \\
\hline $\mathrm{CN}, v=0,1$ & $0.4 \mathrm{E}+15$ & 50 & 14 & 5 \\
\hline $\mathrm{NH}_{2} \mathrm{CN}$ & $0.1 \mathrm{E}+14$ & 50 & 14 & 7 \\
\hline $\mathrm{OC}^{34} \mathrm{~S}$ & $0.5 \mathrm{E}+15$ & 50 & 14.0 & 7 \\
\hline $\mathrm{CP}$ & $0.5 \mathrm{E}+15$ & 50 & 14.0 & 4 \\
\hline $\mathrm{C}^{34} \mathrm{~S}$ & $1.4 \mathrm{E}+14$ & 50 & 14.0 & 5 \\
\hline $\mathrm{HCOCH}_{2} \mathrm{OH}$ & $0.05 E+17$ & 300 & 2.0 & 6 \\
\hline
\end{tabular}

Notes. ${ }^{13} \mathrm{CH}_{3} \mathrm{OH}$ is not available in the JPL database used for Weeds modeling. 
Table C.3. Weeds model parameters for G31.41+0.31.

\begin{tabular}{|c|c|c|c|c|}
\hline Species & $\begin{array}{c}N_{\mathrm{S}} \\
{\left[\mathrm{cm}^{-2}\right]}\end{array}$ & $\begin{array}{l}T_{\mathrm{ex}} \\
{[\mathrm{K}]}\end{array}$ & $\begin{array}{c}\theta_{\mathrm{S}} \\
{\left[{ }^{\prime \prime}\right]}\end{array}$ & $\begin{array}{c}\Delta v \\
{\left[\mathrm{~km} \mathrm{~s}^{-1}\right]}\end{array}$ \\
\hline $\mathrm{CH}_{3} \mathrm{OH}$ & $2.0 \mathrm{E}+18$ & 300 & 2.0 & 7 \\
\hline $\mathrm{CH}_{3} \mathrm{OH}$ & $2.7 \mathrm{E}+17$ & 20 & 5.0 & 7 \\
\hline${ }^{13} \mathrm{CH}_{3} \mathrm{OH}$ & - & - & - & - \\
\hline $\mathrm{H}_{2} \mathrm{CO}$ & $6.0 \mathrm{E}+16$ & 150 & 2.0 & 6 \\
\hline $\mathrm{H}_{2}{ }^{13} \mathrm{CO}$ & $7.0 \mathrm{E}+15$ & 150 & 2.0 & 6 \\
\hline $\mathrm{CH}_{3} \mathrm{CN}^{1}$ & $2.0 \mathrm{E}+16$ & 300 & 2.0 & 7 \\
\hline $\mathrm{CH}_{3}{ }^{13} \mathrm{CN}$ & $2.0 \mathrm{E}+15$ & 300 & 2.0 & 7 \\
\hline $\mathrm{HNCO}$ & $6.0 \mathrm{E}+16$ & 200 & 2.0 & 7 \\
\hline $\mathrm{HN}^{13} \mathrm{CO}$ & $2.0 \mathrm{E}+15$ & 200 & 2.0 & 7 \\
\hline $\mathrm{C}_{2} \mathrm{H}_{5} \mathrm{OH}$ & $2.0 \mathrm{E}+17$ & 100 & 2.0 & 7 \\
\hline $\mathrm{C}_{2} \mathrm{H}_{5} \mathrm{CN}$ & $2.0 \mathrm{E}+16$ & 80 & 2.0 & 5 \\
\hline $\mathrm{CH}_{3} \mathrm{OCH}_{3}$ & $1.0 \mathrm{E}+18$ & 100 & 2.0 & 5 \\
\hline $\mathrm{HCOOCH}_{3}{ }^{2}$ & $1.0 \mathrm{E}+18$ & 300 & 2.0 & 7 \\
\hline $\mathrm{NH}_{2} \mathrm{CHO}$ & $4.0 \mathrm{E}+15$ & 300 & 2.0 & 7 \\
\hline $\mathrm{CH}_{2} \mathrm{CO}$ & $6.5 \mathrm{E}+14$ & 50 & 14.0 & 6 \\
\hline $\mathrm{CH}_{3} \mathrm{CHO}$ & $1.0 \mathrm{E}+15$ & 50 & 8.0 & 6 \\
\hline $\mathrm{HCOOH}$ & $0.2 \mathrm{E}+16$ & 40 & 8.0 & 6 \\
\hline $\mathrm{CH}_{3} \mathrm{CCH}$ & $2.8 \mathrm{E}+15$ & 60 & 14.0 & 4 \\
\hline \multicolumn{5}{|c|}{ Additional species } \\
\hline $\mathrm{CH}_{3} \mathrm{COCH}_{3}$ & $1 \mathrm{E}+17$ & 100 & 2.0 & 7 \\
\hline HCCCN & $7 \mathrm{E}+13$ & 150 & 14 & 7 \\
\hline SO & $7 E+14$ & 50 & 14 & 8 \\
\hline${ }^{34} \mathrm{SO}$ & $1 \mathrm{E}+14$ & 50 & 14.0 & 6 \\
\hline $\mathrm{SO}_{2}$ & $0.1 E+16$ & 50 & 14.0 & 7 \\
\hline${ }^{33} \mathrm{SO}_{2}$ & $1 \mathrm{E}+15$ & 50 & 14.0 & 6 \\
\hline $\mathrm{HCN}$ & $2 \mathrm{E}+14$ & 50 & 14.0 & 12 \\
\hline $\mathrm{HCN}$ & $-6 \mathrm{E}+13$ & 50 & 14.0 & 6 \\
\hline $\mathrm{H}^{13} \mathrm{CN}$ & $2 E+13$ & 50 & 14.0 & 6 \\
\hline $\mathrm{CN}, \mathrm{v}=0,1$ & $0.8 \mathrm{E}+15$ & 50 & 14 & 6 \\
\hline $\mathrm{NH}_{2} \mathrm{CN}$ & $0.3 \mathrm{E}+14$ & 50 & 14 & 7 \\
\hline $\mathrm{O}^{13} \mathrm{CS}$ & $5 E+14$ & 50 & 14 & 5 \\
\hline $\mathrm{OC}^{34} \mathrm{~S}$ & $1 \mathrm{E}+15$ & 50 & 14.0 & 7 \\
\hline $\mathrm{CP}$ & $1 E+15$ & 50 & 14.0 & 6 \\
\hline$C^{34} S$ & $2 E+14$ & 50 & 14.0 & 7 \\
\hline $\mathrm{HCOCH}_{2} \mathrm{OH}$ & $0.2 \mathrm{E}+17$ & 300 & 2.0 & 7 \\
\hline $\mathrm{S}_{3}$ & $1.5 \mathrm{E}+16$ & 15 & 14 & 6 \\
\hline $\mathrm{CH}_{3} \mathrm{NH}_{2}$ & $1 E+17$ & 150 & 2.0 & 7 \\
\hline
\end{tabular}

Notes. ${ }^{13} \mathrm{CH}_{3} \mathrm{OH}$ is not available in the JPL database used for Weeds modeling. ${ }^{(1)}$ Based on $21^{\prime \prime}$ beam spectra. ${ }^{(2)}$ Based on $21^{\prime \prime}$ beam spectra, $1.5 \mathrm{E}+17$ in the $14^{\prime \prime}$ beam spectra.

\section{Appendix D: Additional detections}

Several lines of other species were found in the observed frequency ranges, particularly in the line-rich $\mathrm{G} 31.41+0.31$. Table D.1 lists additional detections with column densities obtained from the Weeds analysis with the best $T_{\mathrm{ex}}$ when this could be derived. Several transitions of acetone, $\mathrm{CH}_{3} \mathrm{COCH}_{3}$, are detected. In G31, the best agreement is obtained at $100 \mathrm{~K}$, whereas for IRAS 18089 , this is $T_{\text {ex }}=300 \mathrm{~K}$. No $\mathrm{CH}_{3} \mathrm{COCH}_{3}$ was detected in IRAS 20126, and the tabulated value is an upper limit at $300 \mathrm{~K}$. Figure D.1 shows the strongest acetone lines in G31 together with the Weeds model.

Glycoaldehyde, $\mathrm{HCOCH}_{2} \mathrm{OH}$, has previously been detected in G31 (Beltrán et al. 2009), has several lines in the covered ranges. All lines are however blended with other transitions, and only upper limit could therefore be derived reliably. The tabulated column density is for a temperature of $300 \mathrm{~K}$, constrained by non-detection of lines with low $E_{\text {up }}$.

Two transitions of $\mathrm{HC}_{3} \mathrm{~N}$ are detected at $218.325 \mathrm{GHz}$ $\left(E_{\text {up }} 131.0 \mathrm{~K}\right)(J=24 \rightarrow 23)$ and $354.697 \mathrm{GHz}\left(E_{\text {up }} 340.5 \mathrm{~K}\right)$ $(J=39 \rightarrow 38)$. The Weeds model on the two lines, well separated in $E_{\text {up }}$, gives a beam averaged column density of
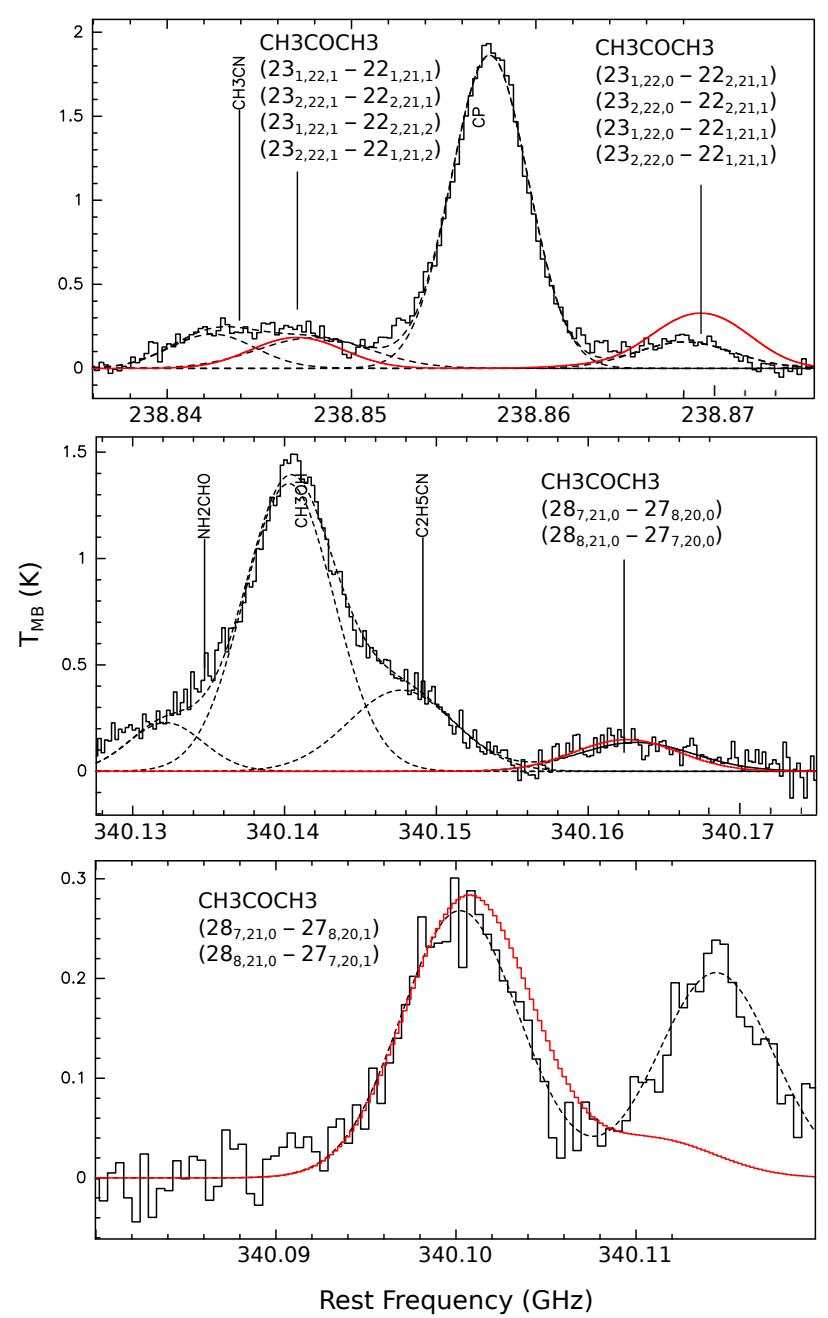

Fig. D.1. Beam-averaged spectra of $\mathrm{CH}_{3} \mathrm{COCH}_{3}\left(23_{1 / 2,22,1}-22_{1 / 2,21,1}\right)$, $\left(23_{1 / 2,22,0}-22_{1 / 2,21,1}\right),\left(28_{7 / 8,21,0}-27_{8 / 7,20,0}\right)$ and $\left(28_{7 / 8,21,0}-27_{8 / 7,20,1}\right)$ towards G31.41+0.31 hot core. Dashed lines indicate Gaussian fits to the lines and red solid line show the Weeds model on the $\mathrm{CH}_{3} \mathrm{COCH}_{3}$ lines at $100 \mathrm{~K}$. 
$7 \times 10^{13} \mathrm{~cm}^{-2}$ and a temperature of $150 \mathrm{~K}$ for $\mathrm{G} 31$. The $\mathrm{HC}_{3} \mathrm{~N}$ emission cannot be matched with emission contained within a $2.0^{\prime \prime}$ volume as the low- $E_{\text {up }}$ transition becomes optically thick. For IRAS 20126, the tabulated column density is at $100 \mathrm{~K}$, constrained by the two transitions. Only the high $E_{\text {up }}$ transition was covered for IRAS 18089 giving a column density of $3 \times 10^{13} \mathrm{~cm}^{-2}$ at $150 \mathrm{~K}$ and $6 \times 10^{13} \mathrm{~cm}^{-2}$ at $100 \mathrm{~K}$.

Several $\mathrm{CH}_{3} \mathrm{NH}_{2}$ transitions are observed with a $T_{\mathrm{ex}}$ of $150 \mathrm{~K}$. Blends with other species make the rotation temperature and column density inaccurate, however. Several unidentified lines coincide with $\mathrm{NH}_{2} \mathrm{CH}_{2} \mathrm{CH}_{2} \mathrm{OH}$, but only upper limits of $1.0 \times 10^{16} \mathrm{~cm}^{-2}$ at $100-300 \mathrm{~K}$ could be derived reliably using Weeds.

Several weak lines of $\mathrm{NH}_{2} \mathrm{CN}$ are detected, with a $T_{\text {ex }}$ of $50 \mathrm{~K}$ derived from the Weeds model, but line blends make the rotation temperature and column density inaccurate. For $\mathrm{CN}$, $\mathrm{SO},{ }^{34} \mathrm{SO}, \mathrm{O}^{13} \mathrm{CS}, \mathrm{OC}^{34} \mathrm{~S}, \mathrm{SO}_{2},{ }^{33} \mathrm{SO}_{2}, \mathrm{C}^{34} \mathrm{~S}$, and $\mathrm{CP}$ not enough lines were observed to derive $T_{\mathrm{ex}}$ values, and tabulated column densities are assuming a temperature of $50 \mathrm{~K}$.

One line of HCN, $J=4-3$, was observed. HCN emission in $\mathrm{G} 31$ is composed of a broad $\left(12 \mathrm{~km} \mathrm{~s}^{-1}\right)$ and a narrow $\left(6 \mathrm{~km} \mathrm{~s}^{-1}\right)$ component (redshifted by $\left.2.5 \mathrm{~km} \mathrm{~s}^{-1}\right)$ causing selfabsorption. For IRAS 18089 , the broad component has a width of $7 \mathrm{~km} \mathrm{~s}^{-1}$ and narrow $4 \mathrm{~km} \mathrm{~s}^{-1}$ (redshifted by $1 \mathrm{~km} \mathrm{~s}^{-1}$ ). For IRAS 20126 the HCN emission has a very broad $20 \mathrm{~km} \mathrm{~s}^{-1}$ component blueshifted by $2 \mathrm{~km} \mathrm{~s}^{-1}$ and a narrow $\left(5 \mathrm{~km} \mathrm{~s}^{-1}\right)$ component redshifted by $1 \mathrm{~km} \mathrm{~s}^{-1}$. The tabulated column densities are those derived from the $\mathrm{H}^{13} \mathrm{CN}$ column density.
Table D.1. Additional detections. Column densities given are source averaged for species with $T_{\mathrm{ex}}>100 \mathrm{~K}$ and beam averaged for species with $T_{\mathrm{ex}}<100 \mathrm{~K}$ (except for HCCCN, the emission of which is warm and arises from extended volume). The tabulated values are those obtained from Weeds analysis with the best $T_{\mathrm{ex}}$.

\begin{tabular}{lccc}
\hline \hline Species & IRAS 20126+4104 & IRAS 18089-1732 & $\mathrm{G} 31.41+0.31$ \\
\hline Source-averaged column densities & & \\
\hline $\mathrm{CH} 3 \mathrm{COCH} 3$ & $<0.1 \mathrm{E}+17$ & $0.5 \mathrm{E}+17$ & $1.0 \mathrm{E}+17$ \\
$\mathrm{HCOCH} 2 \mathrm{OH}$ & - & $<0.5 \mathrm{E}+16$ & $<0.2 \mathrm{E}+17$ \\
$\mathrm{CH}_{3} \mathrm{NH}_{2}$ & - & - & $2.4 \mathrm{E}+14$ \\
$\mathrm{NH}_{2} \mathrm{CH}_{2} \mathrm{CH}_{2} \mathrm{OH}$ & - & - & $<1.0 \mathrm{E}+16$ \\
\hline $\mathrm{Beam}^{-a v e r a g e d ~ c o l u m n ~ d e n s i t i e s ~}$ & & \\
\hline $\mathrm{NH}_{2} \mathrm{CN}$ & - & $<0.1 \mathrm{E}+14$ & $7.0 \mathrm{E}+14$ \\
$\mathrm{OC}-13-\mathrm{S}$ & - & - & $5.0 \mathrm{E}+14$ \\
$\mathrm{OC}-34-\mathrm{S}$ & - & $0.5 \mathrm{E}+15$ & $1.0 \mathrm{E}+15$ \\
$\mathrm{HCCCN}$ & $1.0 \mathrm{E}+13$ & $3.0 \mathrm{E}+13$ & $7.0 \mathrm{E}+13$ \\
$\mathrm{~S}$ & - & - & $1.5 \mathrm{E}+16$ \\
$\mathrm{CN}, v=0,1$ & $0.2 \mathrm{E}+15$ & $0.4 \mathrm{E}+15$ & $0.8 \mathrm{E}+15$ \\
$\mathrm{SO}$ & & $0.5 \mathrm{E}+15$ & $0.1 \mathrm{E}+16$ \\
$\mathrm{SO}$ & $0.3 \mathrm{E}+15$ & $1.0 \mathrm{E}+15$ & $7.0 \mathrm{E}+14$ \\
$\mathrm{CS}-34$ & $0.3 \mathrm{E}+15$ & $1.4 \mathrm{E}+14$ & $2.4 \mathrm{E}+14$ \\
$\mathrm{CP}$ & - & - & $1.0 \mathrm{E}+15$ \\
$\mathrm{~S}-33-\mathrm{O}{ }_{2}$ & - & $0.5 \mathrm{E}+15$ & $1.0 \mathrm{E}+15$ \\
$\mathrm{~S}-34-\mathrm{O}$ & $<0.5 \mathrm{E}+14$ & $0.5 \mathrm{E}+14$ & $1.0 \mathrm{E}+14$ \\
$\mathrm{HCN}$ & $0.2 \mathrm{E}+14$ & $2.0 \mathrm{E}+14$ & $2.0 \mathrm{E}+14$ \\
$\mathrm{HC}-13-\mathrm{N}$ & $8 \mathrm{E}+13$ & $1.5 \mathrm{E}+13$ & $2.0 \mathrm{E}+13$ \\
\hline & $0.1 \mathrm{E}+13$ & &
\end{tabular}

